\title{
ANL FOUR-METER CALOAMETEA DESIGN AND OPERATION MANUAL
}

by

R. B. Porry, R. N. Lowis, G. A. Youngdahl,

E. A. Jung, and C. T. Roche

\section{MASTER}

\section{MATONAL LABORATORY, ARGONNE, ILLINOIS}

\section{or the U. S. DEPARTMENT OF ENERGY}


TABLE OF CONTENTS

Page

I. INTRODUCTION . . . . . . . . . . . . . . . . 1

II. IAEA FOUR-METER CALORIMETRIC SYSTEM . . . . . . . 3

A. Envi ronmental Operation Conditions . . . . . . . 3

B. Systen Setup ................. 3

III. PHYSICAL DESCRIPTION . . . . . . . . . . . 4

IV. DATA ACQUISITION SYSTEM (DAS) . . . . . . . . . 4

A. Physical Description............. 4

B. Keyboard Action-Response . . . . . . . . 5

V. RECOMMENDED PROCEDURES . . . . . . . . . . 10

A. Assay Procedure ................ 10

B. Electrical Calibration Procedure . . . . . 12

IV. DATA ANALYSIS ................. . 14

A. Effective Specific Power . . . . . . . . 17

APPENDIX A: CALORIMETRIC UNIT CIRCU $i^{-7}$ DIAGRAMS \#1-9 1 - . 27

APPENDIX B: DATA ACQUISITION SYSTEM (DAS) . . . . . . 37

I. Circuit Diagrams $\#_{1-7}$. . . . . . . . 38

II. Listing of Microprocessor Program . . . . 45

APPENMIX C: OPERATING INSTRUCTIONS WITH SAMPLE OUTPUT TAPE • - 85

I. Simplified Operating Instructions . . . . . 85

II. Explanation of Typical Output Tape . . . 87 
LIST OF ILLUSTRATIONS

Figure

Page

1. The four-meter calorimetric system . . . . . 2

2. Resistance thermometry and feedback control circuitry in ANL air-chamber calorimeters . . . 18

3. Data acquisition flowchart ...........20

4. The measurement-chamber temperature and power relations in ANL air-chamber calorimeters . 21 
ANL FOUR-METER CALORIMETER

DESIGN AND OPERATION MANUAL

by

R. B. Perry, R. N. Lewis, G. A. Youngdahl,

E. A. Jung, and C. T. Roche

\section{IVTRODUCTTOE}

The Four-Meter Fue1-Rod Calorimetric System (Fig. 1) is designed to measure the thermal power produced by radioactive decay of plutonium-containing fuel rods. The plutonium mass in a sample is related to the measured power through the weighted average of the product of the isotopic decay energies and the decay constants of the plutonium isotopes present. The uranium content of the fuel will not affect the measurement, since the thermal power produced by the uranium nuclides is insignificant when compared to plutonium. This is the result of the longer half-life of uranium relative to the $\mathrm{Pu}$ isotopes. The principal radiations from plutonium are alpha particles and low-energy photons. As a consequence of the low penetration power of this radiation, greater than $99.9 \%$ of the decay energy will be degraded to thermal energy measurable by the calorimeter. (A more detailed discussion of the physical principles involved in calorimetry is included in $A$ Portable Calorimeter System for Nondestmative Assay of Mixed-Oxide Fuels, ISPo-16.)

The four-meter calorimeter is capable of measuring samples producing power up to 1.5 watts at a rate of one sample every 120 minutes. The measurement precision for the baseline power $\left[\sigma\left(\mathrm{P}_{0}\right) / \mathrm{P}_{0}\right]$ is better than $0.1 \%$.

The instrument consists of three units: a data-acquisition module made up of a microprocessor with an 8K-byte nonvolatile memory, a control cabinet, and the calorimeter chamber. The calorimeter chamber is constructed in two halves so that it can be disassembled for shipping. 


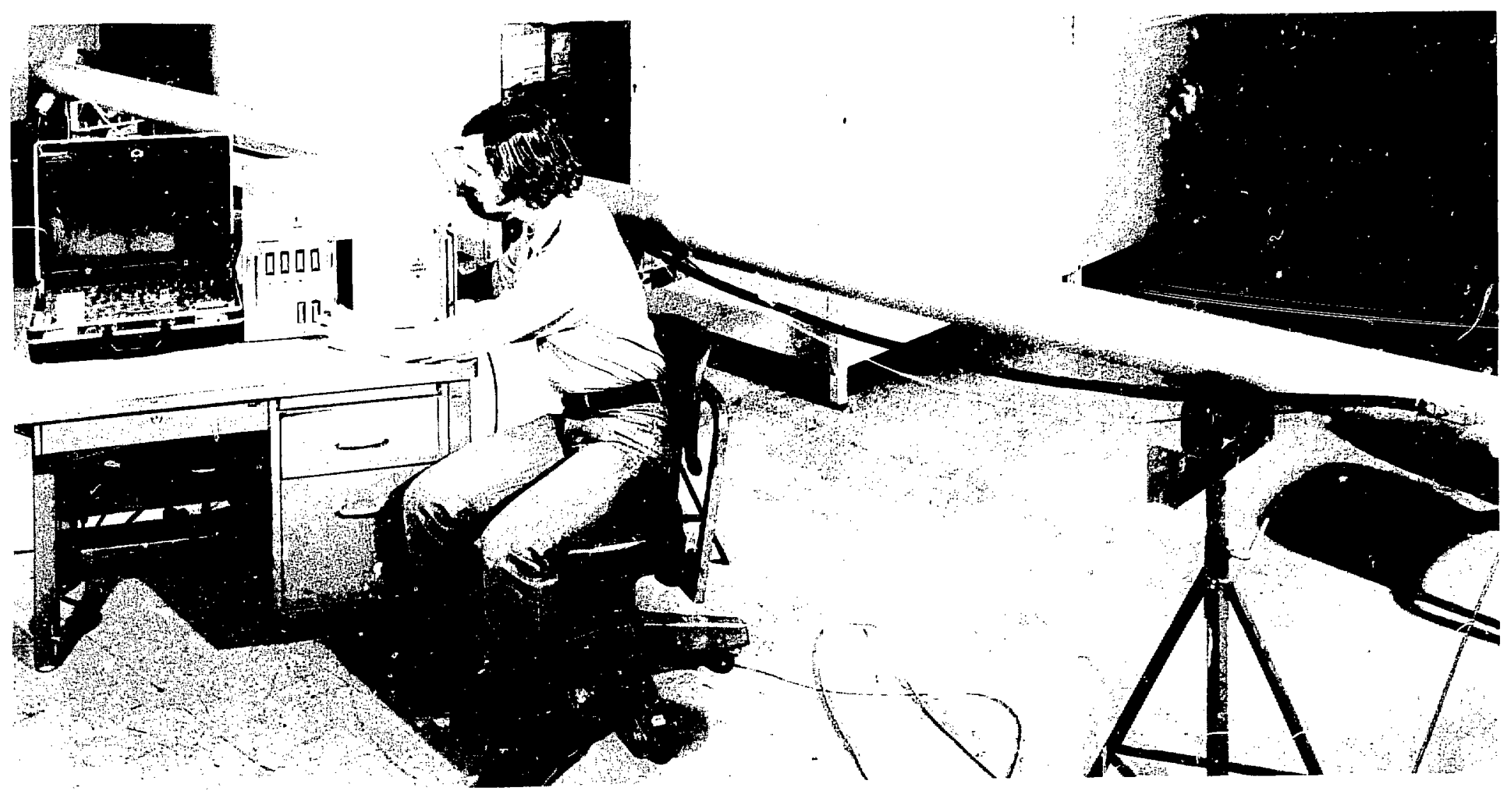

Fig. 1. The Four-Meter Calorimeter. 


\section{IAEA FÓUR-METLR CALORTMETRIC SYSTEM}

The Four-Meter Calorimetric System is designed for in-field operation. Care has been taken to minimize the effects of nonideal environments encountered during the course of a typieal assay. Field conditions have been simulated in the laboratory, and a set of operating conditions which ensure maintenance of a $0.1 \%$ measurement precision have been developed. Although these operating requirements are hroad and should not restrict the inspector, reasonable care should be exercised in choosing a sampling locaticil. Operation in any unfamiliar setting should be preceded by a calibration and a thorough check-out.

\section{A. Environmental Operating Conditions}

1. Temperature

The calorimeter unit is adjusted for a maximum sample power of 1.5 watts. The temperatures of the concentric chambers comprising this unit are: $\mathrm{T}_{3}, 44.1^{\circ} \mathrm{C} ; \mathrm{T}_{2}, 42.8^{\circ} \mathrm{C} ; \mathrm{T}_{1}, 41.6^{\circ} \mathrm{C} ; \mathrm{T}_{0}, 39.6^{\circ} \mathrm{C}$. The system was tested for ambient temperatures between $10.5^{\circ} \mathrm{C}$ and $35.0^{\circ} \mathrm{C}$. Over this temperature range, a drift in the measurement precision of less than $0.1 \% /{ }^{\circ} \mathrm{C}$ was experienced.

\section{Power Requirements}

The calorimeter is designed to be operated with a voltage of 230 $\operatorname{VAC}(50 \mathrm{~Hz})$. The device was tested for voltage fluctuation with a 230-VAC 1ine. Operation was unaffected by fluctuations under $20 \%$.

\section{B. System Setup}

\section{System Interconnection}

The calorimeter chamber halves must be coupled together, and the interconnecting cables must be in place. The calorimeter control and its data-acquisition system (DAS) MIST be connected prior to applying line volt- 
age. The uultipin connectors on the calorimetric unit, labeled P1, P2, should be connected to their respective receptacles on the DAS. Two Identical AMP cables, which are' stored in the DAS case, are provided for this purpose. The cables which connect the calorimeter chamber to the control inft must be in place.

\section{Power Up}

The power switch on the control cabinet applies power to the entire system. To avoid possible damage to the print head, the RESTART (RST) key on the DAS keyboard should be pressed immediately after the power is turned on. After the system has been set up, it must be allowed to reach equilibrium at operating temperature before assaying samples. This takes approximately four hours at $20^{\circ} \mathrm{C}$. The temperature-error meters on the control unit will give an indication of the progress toward warti-up for each control circuit.

\section{PHYSICAAL DESCRIPTION}

The calorimeter control unit is housed in an aluminum cabinet which $1 \mathrm{~s} 50.8 \mathrm{~cm}$ wide, $33.0 \mathrm{~cm} \mathrm{high}$, and $4.5 .7 \mathrm{~cm}$ deep. The cabinet contains a power supply and a NIM bin. The callibration module and the $T_{0}, T_{1}, T_{2}, T_{3}$ control circuits are each single-width NTM modules. The calorimeter chamber is contained in two 13.3-cm-diameter tubes that couple together to form a 490.2-cm-1ong chamber with a 1.9-cri inside diameter. The measurement chamber will accommodate fuel rods up to $4267 \mathrm{~mm}$ long with fuel colums of up to $4000 \mathrm{~min}$ in length. The calozimeter chamber is supported by four tripod stands that can be adjusted to a convenient height and that provide a means for leveling the calorimeter chamber. Detailed circuit schematics are provided In Appendix A.

\section{DATA ACQUISTTION SYSTEM}

\section{A. Physical Description}

The Data Acquisition System (DAS) 18 housed In a $47 \mathrm{~cm} \times 35 \mathrm{~cm} \times 16 \mathrm{~cm}$ attache case and has a total weight of $5 \mathrm{~kg}$. It $1 \mathrm{~s}$ a totally dedicated 
microprocessor-controlled device, designed around the INTEL 8085 . The system memory conststs of $8 \mathrm{~K}$ bytes of erasable, programmable, read-only memory (EPROM) and $1 \mathrm{~K}$ bytes of random-access memory (RAM). The program resides in the permanent memory, EPROM, and does not need to be reentered after the device 1s powered down. The EPROM is organized on four 2K-byte INTEL-2716 chips, the last $2 \mathrm{~K}$ bytes being exchangab1e. The RAM is organized on four 256-byte INTEL-8156 chils and serves as scratch-pad storage for the program. The microprocessor receives input either from the calorimeter through the 12-bit $\mathrm{ADC}$ or from the 25-key multifunctional keyboard. System output is through either the BOMAR TP3120-2 printer or the Liquid Crystal Display (LCD). A set of 6 LEDs are avaflable to reflect system status. Detailed schematics and a copy of the $\mu \mathrm{P}$ program are included in Appendix B.

\section{B. Keyboard Action-Response}

1. $\quad$ RST $\equiv$ Restart

Function: To place the system in an fdle mode, where it will monitor the keyboard for a user command. All data processing is stopped. System default values are restored. The results of any uncompleted calculation will not be available to the user. The system will return to this mode after completing any noncyclical routine.

Use: This key should be used when first powering-up the system or when aborting a particular routine.

\section{Status light: READY}

\section{Printer: CALORIMETER READY}

2. ENTR $\equiv$ En:er

Function: 'To signal the end of a numeric input.

Use: This key should be used when responding to a $\mu \mathrm{P}$ prompt statement with a numerical value. It also acts as a "No" in a situation 
requiring a YES/NO response.

Printer: Carriage return - Line feed

3. BS $\equiv$ Backspace

Function: To permit the user to erase an undesired response to a $\mu$ P Prompt statement.

Use: This key repositione the input ASCII array by one character each time it is pressed.

\section{Printer: Backspace}

4. EXT $\equiv$ Execute extcernal program

Function: To enable the user to expand the computational abilities of the DAS. The DAS is designed so that the last $2 \mathrm{~K}$ of the $8 \mathrm{~K}$ PROM memory is interchangeable by replacing the chip in the zero force socket with a different INTEL 2716 containing a new program.

Use: To be determined by user.

Status Light: EXT

Printer: Program dependent.

5. Tl $\equiv$ Diagnostic Test Points

Punction: To enable the user to examine the voltages of any of 32 selected locations within the calorimeter. (See Appendix A for TP locations within the calorimeter.)

Use: This routine may be used either to continuously. monitor a partlcular point on the Liquid Crystal Display or to obtain a printout of a11 32 points. To change TP during continuous monitoring, 
press "TT" and the number of the desired test point. Use' RST to exit from continuous monitoring.

Status Light: A/D

Liquid Crystal Display: TP voltage

Printer: "TEST PNTS"

$$
\begin{array}{ll}
\text { "ALL?" } & -\mu P \text { prompt statement } \\
\text { User Response } & - \text { YES - al1 TP's printed (Option 1) } \\
& - \text { \#, ENTR - individual TP displayed (Op- } \\
&
\end{array}
$$

6. PRINT $\equiv$ Print

Function: To allow user to obtain a printed record of a test point which is being continuously monitored or of a power which is being displayed on the Liquid Crystal Display.

Printer: Numeric output

7. INIT $\equiv$ Initial data input

Function: To permit the user to input parameters which will be used in the data analysis by the $\mu \mathrm{P}$.

Use: Input isotopic mass $\%+$ uncertainty, elapsed time since last isotopic analysis, default value of effective specific power, power normalization factor, system uncertainty.

Status Light: RSVP after $\mu \mathrm{P}$ prompts

Printer: "DATA INPUT MASS \%"

"AM241" - $\mu$ P prompt statement

A $\mu \mathrm{P}$ prompting statement will be printed for ${ }^{241} \mathrm{Am}$ and for each 
Isotope ${ }^{238-242} \mathrm{Pu}$. After each proupt, enter the Isotopic mase $\%$ and its uncertainty. [Note: 1 ) Include the leading zero in numbers 1ess than 1.0 , 1.e., type 0.01 , not .01. 2) Am \% is defined as [Mass $(\mathrm{Am}) / \mathrm{Mass}(\mathrm{Pu})] \times 100$.

\section{"TIME-DAYs"}

Enter the time elapsed since the last isotopic analyeis was performed.

$$
\text { " "POWER } \mathrm{mW} / \mathrm{g} \text { " }
$$

Enter a default value if it is decided not to calculate the Effective Specific Power from the Isotopic mass fractions.

"P NORM"

This parameter relates the measured thermal. power to the actual source-produced power ( $1 . e_{.}, P_{\text {measured }}=P_{\text {source }} \div$ PNORM). A value of 1.0 is Included as a default value. This value may be altered if necessary (see Sections V, VI).

"SIG(SY)"

This parameter contains the nonstatistical contributions to the measurement precision. (To be determined by user.) The default value is zero, meaning no systematic error is included. The components of this parameter are discussed in section VI. (NOTE: The default values of PNORM and SIG(SY) are restored after an RST).

NOTE: The remaining keys (FRAC, $S P, P_{0}$, RUN, and CAL) activate major subroutines used in data acquisition and analysis. Brlef descriptions are given below. More detailed discussions are avallable in the sectlons on Recommended Procedures and on Data Analysis. 
8. FRAC $\equiv$ Mass Fraction decay correction

Function: To calculate the changes in the mass percentages in a previously isotopically analyzed sample resulting from radioactive decay. A current set of mass \% will be generated which may be used to calculate effective specific power.

Use: The program requires that the inftial mass \% and : the elapsed time be entered through INIT prior to execution.

Printer: The decay-corrected isotopic mass \% are printed.

9. SP $\equiv$ Effective Specific Power calculation

Function: To determine the power emitted per gram of the material to be assayed as well as the uncertainty associated with this calculation.

Use: The program requires that the mass \% be available prior to execution.

Printer: The effective specific power and its uncertainty.

10. $P_{0} \equiv$ Empty chamber baseline analysis

Function: To determine the power supplied by the calorimeter to maintain a constant temperature when no heat-producing source is present; to compare this with the power when the sample is in place and derive the sample power and mass.

11. RUN $\equiv$ Sample assay

Function: To determitue the calorimeter-supplied power in the presence of a Pu-containing material. 
12. CAL $\equiv$ Electrical calibration

Function: To supply a serles of known electrical powers to the "electric fuel rod," and to determine the resulting measured powers, thus allowing the user to derive a relation between the measured and actual sample power.

NOTE: A simulated output tape showing the results of typical operations is given in Appendix C.

V. RECOMMENDED PROCEDURES

\section{A. Assay Procedure}

1. Reset microprocessor-controlled DATA ACQUISITION SYSTEM.

$$
\begin{aligned}
& \text { Operator Action: } \quad \text { Press RST } \\
& \text { System Response: "CALORIMETER READY" }
\end{aligned}
$$

\section{Rod Assay}

After inserting fuel rod and centering fuel column in sample chamber

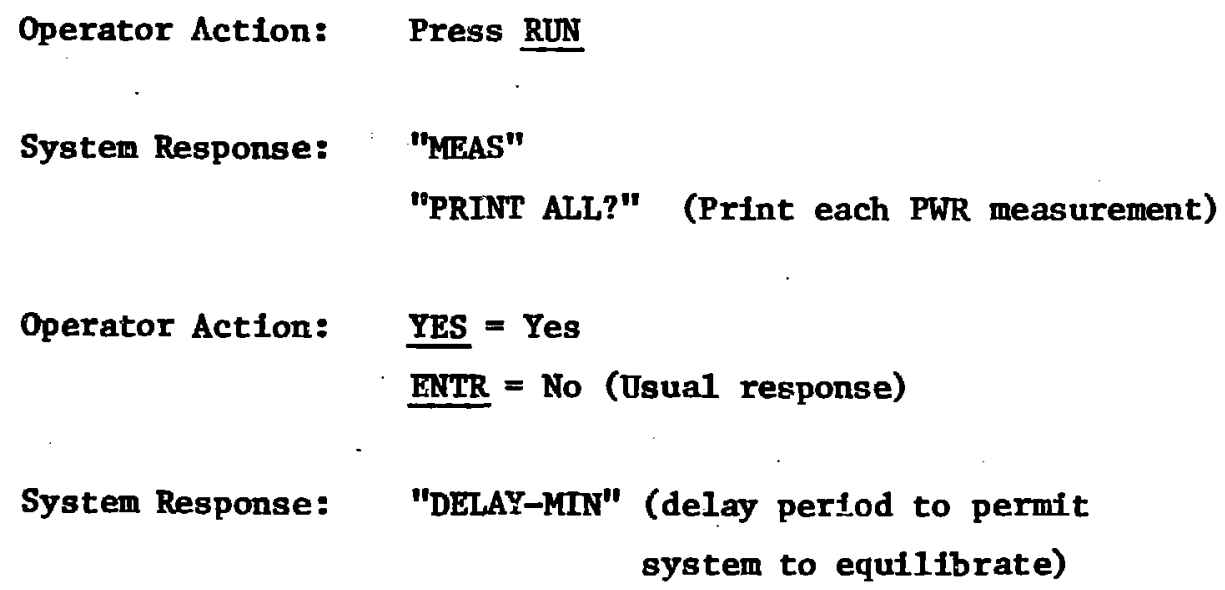


Operator Action: 60 ENTR (Note: This value w111 differ with rod diameter.)

System Response: "SIGMA-q" (Limit of acceptable precision on $\overline{\mathbf{P}}$ )

Operator Ac:Ion: $\quad \underline{0.05}$ ENTR $(2 \sigma$ limlt) If the operatur wishes the instrument to repeatedly measure the same sample, enter 0.

System Response: "\#DP/RUN" ( $25 \mathrm{DP} / \mathrm{m}$

Operator Action: 125 ENTR (5 min)

The system then enters the DATA ACQUISITION MODE, and the following sequence will occur:

1) The E.I products are monitored until $\overline{\mathrm{P}}<2 \mathrm{~W}$. This indicates that the heater circuits are no longer in saturation, and the system is approaching equilibrium.

2) The system enters an operator-determined wait period during which no data is accepied.

3) The iP accepts $E$, I digital data from the ADC. The E•I product is calculated. An operator-determined number of data points is collected. The value of the calorimeter applied power and the number of data points left to be acquired are alternately displayed on the liquid crystal display. $\overline{\mathrm{P}}$ and the sample standard deviation of the mean are calculated. The results are compared with "SIGMA\%". If the precision is acceptable, the data is stored and printed; otherwlse, a new set of data will be accumulated.

4) The system is reset if the experiment is noi to be repeated. 


\section{Sample Baseline Measurement}

After removal of fuel rod from the calorimeter,

$$
\text { Operator Action: Press } \underline{P_{0}}
$$

System Response: "EMPTY MEAS"

At this point, the operator's options are identical to those fust discussed in Section 2, above. An example of a set of typical responses and the results of an assay are shown ir Appendix C.

\section{B. Electrical Calibration Procedure}

1. Place electric fuel rod into calorimeter and plug the cable into the calibration module front panel connector.

2. Determine sample chamber power with the electrical fuel rod off, after allowing the calorimeter to settle, by pressing the RUN key. (See Section 2 for Recommended Assay Procedure.)

NOTE: This assay is not used in the calibration calculation. The purpose of this measurement is to ensure that the system is at equilibrium and to provide a check on the calibration-determined empty chamber intercept $\left(P_{0}\right)$.

3. Reset DAS (if necessary).

4. Electrically calibrate systen.

Turn the toggle switch on the cailbration moduie to the oN position.

Operator Action: Press CAL

System Response: "CALIBRATE"

"CAL PNTS" ( $\mu$ P prompt statement) 
Operator Action: 5 FNIR . This determines the number of points used to calculate the callbration parameters.

At this point, the same set of options discussed in Section 2 of the Recommended Procedures is avallable. The following responses are suggested.

$\mu P$ Prompt Statement Operator Response

CAL PNTS 5

DELAY MEN 20

SIGMA $\%$

\#DP/RUN 125

The $\mu \mathrm{P}$ determines the incremental salibration oltage by dividing the chamber power, with the electric fuel rod turned off, by the number of calibration points. This value will be added to the applied calibration voltage through a digital analog converter. The microprocessor w111 then enter the operator-selected delay perfod to permit the system to reach equilibrium. Since the measurement chamber is not disturbed by changing the fuel rod between calibration voltage increases, the time necessary to reach equilibrium is signiftcantly shorter than in an actual assay. The operator-determined 非P/RJNs are then collected and analyzed, and then the $\mu \mathrm{P}$ measures the input calibration voltage. The data is printed, and the process is repeated for the next calfbration point.

After the calibra:ion has been completed, the operator may extract the zero-power intercept; and the power 1inearity factor (slope) with a linear least squares fitting technique. This calculation is discussed in the Date Analysis section of the manual. Typical values of slope and intercept are given in Appendix C. 
A. Effective Specific Power

In order to obtain maximum utility from the calorimeter, the measured sample power must be combined with additional isotopic information to determine the plutonfim content of the sample. If the unknown contains cnly one isotope of plutonium, the generated heat is related to the sample mass by the equation

$$
W_{\mathrm{i}}=2.1193 \times \mathrm{M} \times Q / \mathrm{T}_{\frac{T_{2}}{2}} \times A
$$

where

$$
\begin{aligned}
& \mathrm{W}=\text { power }(\mathrm{mW}) \\
& \mathrm{M}=\text { mass of } \mathrm{Pu}(\mathrm{g}) \\
& \mathrm{Q}=\text { total disiniegration energy (MeV) } \\
& \mathrm{T}_{\frac{1}{\frac{1}{2}}}=\text { half-1ife of the isotope of } \mathrm{Pu}_{1}(\mathrm{yrs}) \\
& \mathrm{A}=\text { gram atomic weight }(\mathrm{g})
\end{aligned}
$$

Under normal assay conditions, nuclear fuel will contain a mixture of radionuclides, the principal power producers being $238-242 \mathrm{Pu}$ and ${ }^{241} \mathrm{Am}$. Consequently, the sample power may be obtained from

$$
\mathrm{W}_{\mathrm{U}}=\mathrm{M} \cdot \Sigma \mathrm{R}_{\mathbf{1}} \cdot \mathrm{P}_{\mathbf{i}}=\mathrm{M} \cdot \mathrm{P}_{\text {eff }}
$$

where

$$
\begin{aligned}
& \mathbf{R}_{1}=\text { mass fraction of the radionuclide } \\
& \mathbf{P}_{1}=\text { specific power of a } \mathrm{Pu} \text { isotope } \mathrm{mW} / \mathrm{g} \\
& \mathbf{P}_{\text {eff }}=\text { effective specific power of the sample }
\end{aligned}
$$

Two techniques are suggested for determining the effective specific power. 1 Representative samples may be subsequently analyzed chemically to determine the $\mathrm{Pu}$ content (mW/g). This method usually requires multiple measurements distributed in time to account for isotopic decay. The second 
technique requires that the isotopic composition be determined by gamma-ray or mass spectrometry. ${ }^{2}$ Determination of radionuclide abundances by gamma-rayr spectrometry has the advantage of being nondestructive and may be conducted concurrerity with a calorimetric analysis. While the method chosen may differ from assay to assay, the programs supplied will work with eiciser technique.

\section{Radioactive-Decay Correction}

The isotopic mass ratios are continually changing owing to radioactive decay within the sample. In particular, the beta decay of ${ }^{241} \mathrm{Pu}$ to ${ }^{241} \mathrm{Am}$, which is a short-1ived alpha emitter, results in an increase in the effective specific power with time. If a detailed isotopic anaiysis of the sample material has been made at an earlier date, an on-site determination of the mass fractions may be unnecessary. The present composition may be calculated by means of the following decay equations:

$$
\begin{aligned}
& F_{i}=F_{i}^{0} \cdot \exp \left(-\lambda_{i} t\right) / \Sigma F_{i}^{0} \cdot \exp \left(-\lambda_{i} t\right) \\
& F_{A M}=\left[1 / \Sigma F_{i}{ }^{0} \cdot \exp \left(-\lambda_{i} t\right)\right] \cdot\left\{F_{A M}{ }^{0} \cdot \exp \left(-\lambda_{A M} t\right)\right. \\
& \left.+\left[\lambda_{241} \cdot \mathrm{F}_{241} /\left(\lambda_{241}-\lambda_{\mathrm{AM}}\right)\right] \cdot\left[\exp \left(-\lambda_{\mathrm{AM}} \tau\right)-\exp \left(-\lambda_{241} t\right)\right]\right\}
\end{aligned}
$$

where

$$
\begin{aligned}
& \mathrm{F}_{1}{ }^{0}=\text { mass \% of } \mathrm{Pu} \text { isotope at last analysis } \\
& \mathrm{F}_{\mathrm{AM}}{ }^{0}=\text { mass \% of }{ }^{241} \mathrm{Am} \text { (relative to } \mathrm{Pu} \text { ) at last analysis } \\
& \lambda_{i}=\text { dacay constant of Pu isotope }\left(\text { day }^{-1}\right) \\
& \lambda_{\mathrm{AM}}=\text { decay constant of }{ }^{241_{\mathrm{Am}}} \text { (day }{ }^{-1} \text { ) } \\
& t=t \text { ime elapsed since last analysis (days) }
\end{aligned}
$$


Isotope

$2{ }^{28} \mathrm{Pu}$
$2{ }^{29} \mathrm{Pu}$
$2{ }^{40} \mathrm{Pu}$
$2{ }^{21} \mathrm{Pu}$
$24{ }^{2} \mathrm{Pu}$
$241_{\mathrm{Am}}$

Decay Constant $\left(\right.$ day $\left.^{-1}\right)$

3

$2.1617 \cdot 10^{-5}$
$7.880 \cdot 10^{-8}$
$2.903 \cdot 10^{-7}$
$1.322 \cdot 10^{-4}$
$5.08 \cdot 10^{-9}$
$4.372 \cdot 10^{-6}$

$7.880 \cdot 10^{-8}$

$.903 \cdot 10^{-7}$

$5.08 \cdot 10^{-9}$

$4.372 \cdot 10^{-6}$

The 8080- $\mathrm{PP}$ code for these calculations is given in Appendix B.

\section{Effective Specific Power Calculation}

The effective specific power is defined as the weighted sur of the isotopic specific powers. The uncertainty in this value is dependent upon the measurement errors in both the isotopic mass fractions and the specific power.

$$
\begin{aligned}
P_{\text {eff }} & =\sum_{i} F_{i} \cdot P_{i} / \Sigma_{i} F_{i} \\
\sigma^{2}\left(P_{\text {eff }}\right) & =\sum_{i}\left(\frac{F_{i} P_{i}}{F_{i}}\right)^{2}\left(\frac{\sigma^{2}\left(F_{i}\right)}{F_{i}{ }^{2}}+\frac{\sigma^{2}\left(P_{i}\right)}{P_{i}{ }^{2}}\right)
\end{aligned}
$$

where

$$
\begin{array}{ll}
F_{1} & =\text { mass \% of the radioisotope } \\
\sigma\left(F_{1}\right) & =\text { uncertainty in } F_{1} \\
P_{1} & =\text { isotopic specific power }(\mathrm{mW} / g) \\
\sigma\left(P_{1}\right) & =\text { uncertainty in } P_{1}(\mathrm{~mW} / \mathrm{g}) \\
P_{\text {eff }} & =\text { effective specific power }(\mathrm{mW} / \mathrm{g}) \\
\sigma\left(P_{\text {eff }}\right) & =\text { uncertainty in } P_{\text {eff }}(\mathrm{mW} / \mathrm{g})
\end{array}
$$




\begin{tabular}{lcl} 
Isotope & Specific Power (mW/ \\
\hline & & \\
$2{ }^{28} \mathrm{Pu}$ & $567.16 \pm 0.57$ \\
$2{ }^{39} \mathrm{Pu}$ & $1.9293 \pm 0.0053$ \\
$2{ }^{40} \mathrm{Pu}$ & $7.098 \pm 0.015$ \\
$2{ }^{21} \mathrm{Pu}$ & $3.390 \pm 0.002$ \\
$2{ }^{42} \mathrm{Pu}$ & $0.1146 \pm 0.0003$ \\
$2{ }^{41} \mathrm{Am}$ & 114.23 & \pm 0.16
\end{tabular}

In general there is a negligible increase in the uncertainty reported in the isotopie mass \% as a result of radioactive decay. This is not always the case for ${ }^{241} \mathrm{Am}$. If $241_{\mathrm{Am}}$ was absent at the time of the original analysis, or only present in minute ainunts, then changes in $\sigma\left({ }^{241} \mathrm{Am}\right)$ must be considered.

$$
\sigma^{2}\left({ }^{241} \mathrm{Am}\right) \simeq\left[1.034 t\left(\lambda_{241}-\lambda_{\mathrm{AM}}\right) \cdot \sigma\left({ }^{241} \mathrm{Pu}\right)\right]^{2}+\sigma^{2}\left({ }^{241} \mathrm{Am}\right)
$$

The $8080 \mu \mathrm{P}$ code for these calculations is given in Appendix B.

\section{B. Analysis of Sample Power}

\section{Data Acquisition}

The calorimeter feedback circuitry adjusts the power supplied to the inner cylinder coils so that a constant temperature environment for the sample chamber is maintained. (See Fig. 2.) The inner coll $\left(T_{3}\right)$ voltage and current are alternately monitorad by a 12-bit analog-to-digital converter (ADC), which transmits data to the microprocessor at a rate of ten readings/ sec. Software multiplication of each voltage-current pair produces an "instantaneous" $\mathrm{T}_{3}$ power. Ten such measurements are averaged to produce a two-second reading which is displayed on the 1iquid crystal display. The system will then calculate the average power $\left[E\left(P_{1}\right)\right]$ supplied by the calorimeter, and the sample standard deviation $\left[s\left(P_{1}\right)\right]$ associated with the measure ment. Since the microprocessor performs floating-point arithmetic with 5digit software (NOVONICS FP 7.0B), it is necessary to use the following biasedaverage approach to maintain sufficient accuracy. 


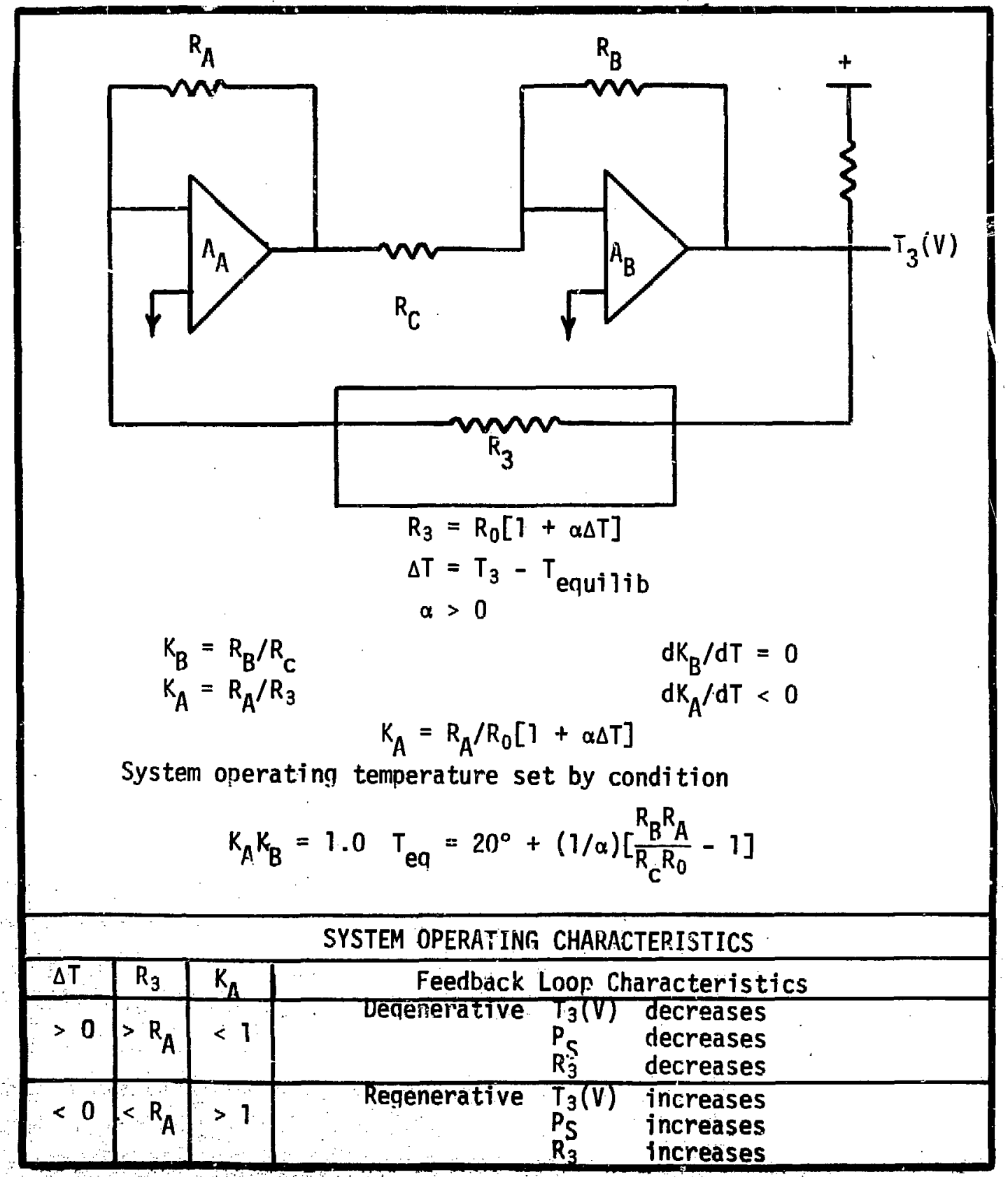

FIg. 2. Reslstance thexmometry and feedback control circultry in ANL alr-chamber calorimeters. 
Given a set of power measurements

$$
P_{1} \quad 1=1, N
$$

Define a new set

$$
\hat{\vec{P}}_{1} \quad=\left(P_{1}-P_{1}\right) \quad 1=1, N
$$

then

$$
\begin{aligned}
E\left(\hat{P}_{1}\right) & =\sum \hat{P}_{1} / N=E\left(P_{1}\right)-P_{i} \\
E E\left(P_{1}\right) & =E\left(\hat{P}_{i}\right)+P_{1}
\end{aligned}
$$

and

$$
\begin{aligned}
\sigma^{2}\left(\hat{\mathrm{P}}_{1}\right) & =\mathrm{E}\left(\hat{\mathrm{P}}_{1}{ }^{2}\right)-\left[E\left(\hat{\mathrm{P}}_{1}\right)\right]^{2}=\sigma^{2}\left(\mathrm{P}_{1}\right) \\
s^{2}\left(\mathrm{P}_{1}\right) & =(\mathrm{N} / \mathrm{N}-1) \cdot \sigma^{2}(\hat{\mathrm{P}}) \\
& \equiv \sum\left[\mathrm{PI}-\mathrm{E}\left(\mathrm{P}_{1}\right)\right]^{2} /(\mathrm{N}-1)(\mathrm{N})
\end{aligned}
$$

A flowchart describing the data-acquisition process is given in Fig. 3 .

\section{Arialysis of Data}

The inner sample chamber is held at a constant temperature of $44.1^{\circ} \mathrm{C}$. When no heat-producing source is present, the calorimeter supplies a constant power, $P_{0}$, of $1.7 \mathrm{~W}$ to maintain this temperature. If a sample containing heat-producing plutonium is placed in the calorimeter, the power which the circultry must supply to maintain $44.1^{\circ} \mathrm{C}$ drops to a lower value, $P_{c}$. Consequently, we may determine the power produced by the plutonium as shown graphically in Fig. 4. Using the effective specific power, $P_{\text {eff }}$ (see Section VI-A), we may determine the plutonium mass by: 
DATA ACNUISITION ROUTINE

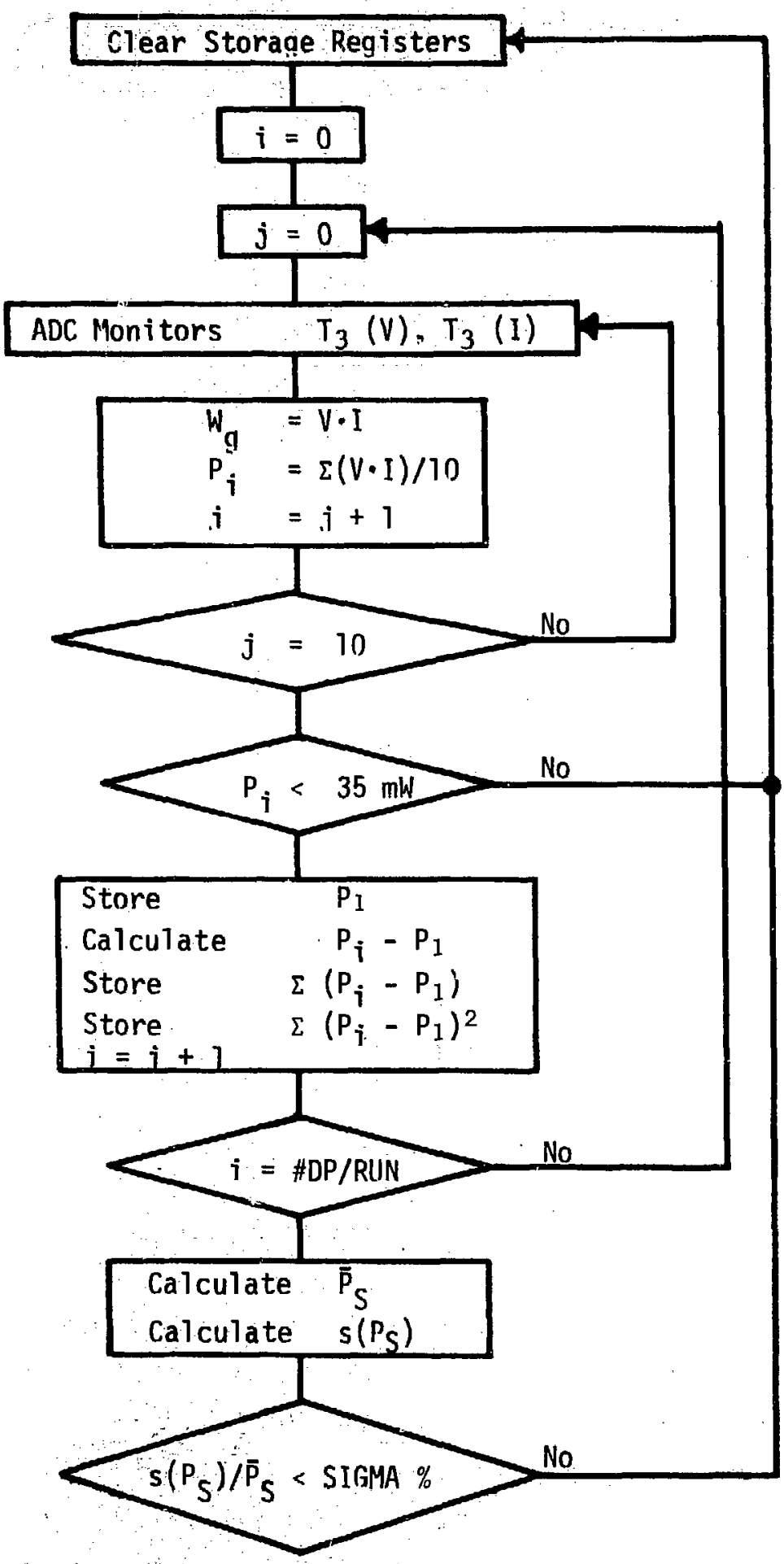

F1g - 3. Data acquigition flowchart. 

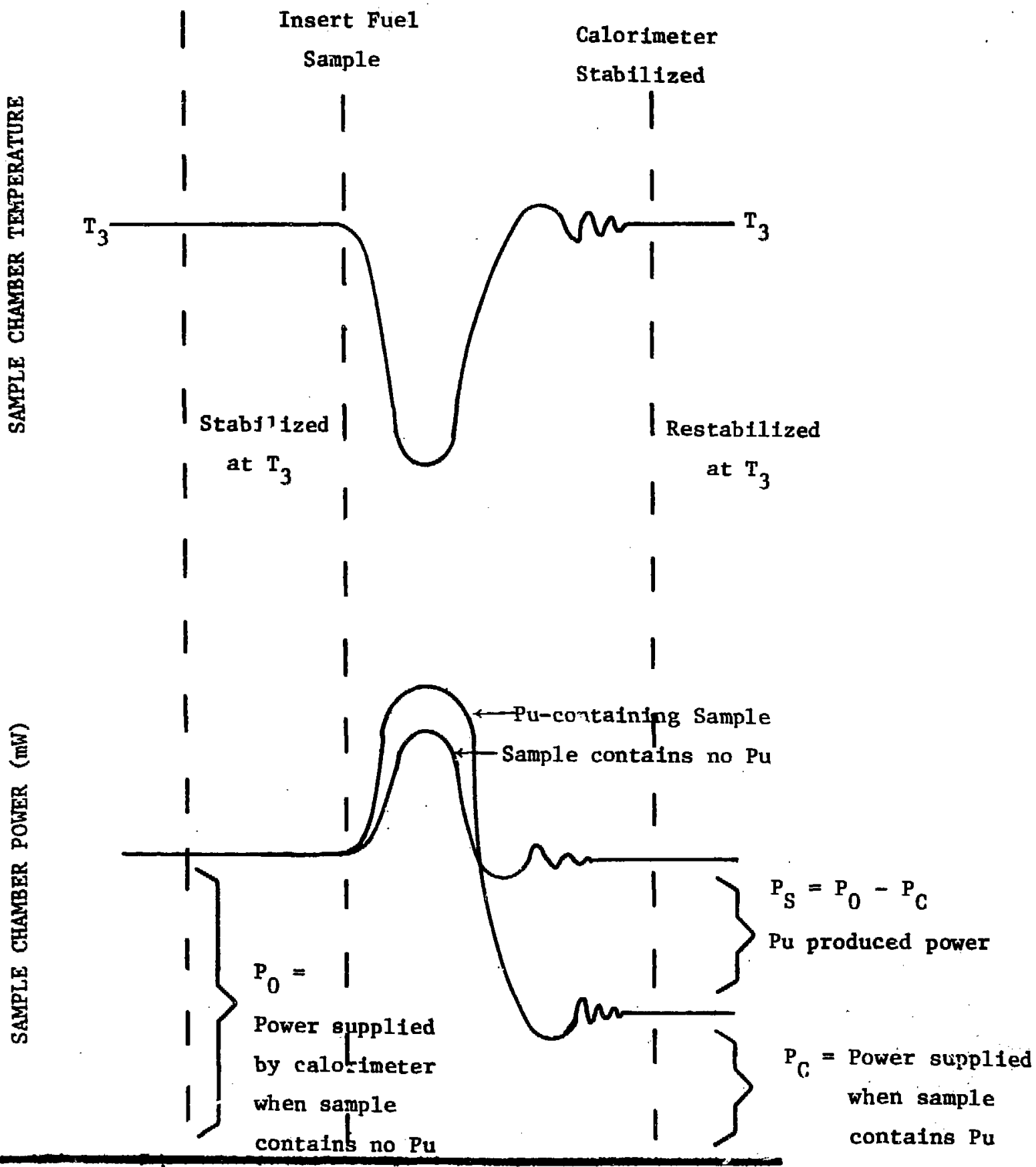

TME

Fig . 4. The measurement-chamber temperature and power relations in ANL alr-chamber calorimeters. 


$$
\mathrm{M}_{\mathrm{PU}}=\overline{\mathrm{P}}_{\mathrm{PU}} / \overline{\mathrm{P}}_{\text {eff }}
$$

where

$$
\begin{aligned}
& \overline{\mathrm{P}}_{\mathbf{P}_{\mathbf{1}}}=F\left(\overline{\mathrm{P}}_{0}-\overline{\mathrm{P}}_{\mathrm{c}}\right) \\
& F=\text { Pu normalization factor }=1,0 \\
& \text { (determined from an electrical calibration } \\
& \text { and a Pu callbration) }
\end{aligned}
$$

The measurement precision is defined by

$$
s^{2}(P)=s^{2}(\mathrm{SYS})+s^{2}(\mathrm{STAT})
$$

where

s(STAT) is the uncertainty of the mean which is defined as (standard deviation) $/ \sqrt{\mathrm{N}}$

$s$ (SYS) is the uncertainty due to systematic imprecision

the components of which are

a) system reproductbility error, $s$ (REP)

b) sample heat distribution error, $s$ (HDE)

c) calibration uncertainty, $s$ (CALIB)

d) thermal interferences, 8 (TEMP)

$$
\mathbf{s}^{2}\left(\overline{\mathrm{M}}_{\mathrm{Pu}}\right)=\mathrm{M}_{\mathrm{Pu}}{ }^{2}\left[\frac{\mathrm{s}^{2}\left(\overline{\mathrm{P}}_{\mathrm{eff}}\right)}{\overline{\overline{\mathrm{P}}}_{\mathrm{eff}}{ }^{2}}+\frac{\mathrm{s}^{2}\left(\overline{\mathrm{P}}_{\mathrm{Pu}}\right)}{\overline{\mathrm{P}}_{\mathrm{Pu}}{ }^{2}}\right]
$$

The code for the calculation of the sample mass and uncertainty is included in Appendix $B$. 
A more rigorous analysis which may be performed off-line by the user is presented below.

1) Electrical ralibration

$$
\widetilde{\mathrm{P}}_{\mathbf{M}} \quad=\quad \mathbf{A}+\mathbf{B} \cdot \overline{\mathbf{P}}_{\mathbf{A}}
$$

where

$$
\begin{aligned}
& \overline{\mathrm{P}}_{M}=\text { measured power }=\frac{\sum \mathrm{P}_{\mathrm{M}_{i}} / \mathrm{s}_{1}{ }^{2}}{\sum 1 / \mathrm{s}_{i}{ }^{2}} \\
& \overline{\mathrm{P}}_{\mathrm{A}}=\text { app1ied power }=\frac{\sum \mathrm{P}_{\mathrm{A}_{i}} / \mathrm{s}_{1}^{2}}{\Sigma 1 / \mathrm{s}_{i}^{2}} \\
& s_{1}=\text { uncertainty in the mean of } \mathrm{P}_{\mathrm{M}_{1}} \text { (statistica1) }
\end{aligned}
$$

The sample statistical uncertainty is defined as

$$
s^{2}(\overline{\bar{P}}) \quad=\quad \Sigma\left[P_{1}-E\left(P_{1}\right)\right] / n(n-1)
$$

which is

$$
s^{2}(\overline{\mathrm{P}}) \quad=\quad s^{2}\left(\mathrm{P}_{1}\right) / \mathrm{n}
$$

This is the uncertainty in the mean of the power distribution, rather than the uncertainty in a single measurement $\left[s\left(P_{1}\right)\right]$.

$$
B=\frac{\sum\left(P_{A_{1}} / s_{1}-\bar{P}_{A} / s_{1}\right)\left(P_{M_{1}} / s_{1}-\bar{P}_{M} / s_{1}\right)}{\sum\left(P_{A_{1}} / s_{1}-\bar{P}_{A_{1}} / s_{1}\right)^{2}}
$$




$$
\mathbf{A}=\overline{\mathbf{P}}_{\mathbf{M}}-\mathbf{B}_{\mathbf{A}}
$$

2) Sample Power

$$
\overline{\mathbf{P}}_{\mathbf{S}}=\left(\overline{\mathbf{P}}_{\mathbf{M}}-\mathbf{A}\right) / \mathbf{B}
$$

relating the power $\left(P_{A}\right)$ actually measured to the source-produced power $\left(\mathbf{P}_{\mathbf{M}}\right)$.

$$
\left.\mathbf{s}^{2}\left(\mathbf{P}_{A}\right)=\frac{\partial P_{A}}{\partial P_{M}}\right)^{2} s^{2}\left(P_{M}\right)+\Sigma\left(\frac{\partial P_{A}}{\partial P_{1}}\right)^{2} s^{2}\left(P_{1}\right)
$$

where

$$
\begin{aligned}
& P_{1} \quad \equiv \quad \text { measured calibration observations } \\
& \mathbf{s}^{2}\left(P_{M}\right) \quad \equiv \quad \text { includes statistical and all other source } \text { of error }
\end{aligned}
$$

$$
\left(\frac{\partial P_{A}}{\partial P_{1}}\right)=\frac{\partial\left[\left(P_{M}-A\right) \cdot B^{-1}\right]}{\partial P_{1}}=-\left(\frac{P_{S}}{B} \times \frac{\partial B}{\partial P_{1}}+\frac{1}{B} \times \frac{\partial A}{\partial P_{1}}\right)
$$

$\therefore \quad \Sigma\left(\frac{\partial P_{A}}{\partial P_{i}}\right)^{2} s^{2}\left(P_{I}\right)=\Sigma \frac{s^{2}\left(P_{I}\right)}{B^{2}}\left[\frac{1}{n}+\frac{\left(P_{S}-\bar{\mu}\right)^{2}}{q \mu^{2}}\right]$

where $\bar{\mu}=(\mathbf{I n})\left(\Sigma \mathbf{P}_{1}\right)$

$$
q \mu^{2}=\Sigma\left(P_{i}-\mu\right)^{2}
$$

and $\left.\quad \frac{\partial P_{A}}{\partial P_{M}}\right)^{2} s^{2}\left(P_{M}\right)=\underset{B}{\left(\frac{1}{)^{2}}\right)^{2} s^{2}\left(P_{M}\right)}$ 
3) Source Normalization

$$
\mathrm{K}_{\mathrm{Pu}}=\left(\mathrm{u}_{\mathrm{STD}} / \mathrm{P}_{\mathrm{STD}}\right) \cdot \mathrm{P}_{\mathrm{A}}
$$

where

W $_{\text {STD }}$ represents the actual power output of a callbrated ${ }^{238} \mathrm{Pu}$ source

$P_{\text {STD }}$ represents the calorimeter-determined output of the calibrated source

4) Sample Mass

Thus, by combining the above

$$
\overline{\mathbf{M}}_{\mathrm{Pu}}=\mathrm{K}_{\mathrm{Pu}}\left(\overline{\mathrm{P}}_{\mathrm{M}}-\mathrm{A}\right) / \mathrm{BP}_{\text {eff }}
$$

and the unieertainty is obtained from

$$
\mathrm{s}^{2}(\mathrm{M})=\mathrm{s}^{2}\left(\overline{\mathrm{P}}_{\mathrm{Pu}}\right)+\mathrm{s}^{2}\left(\mathrm{P}_{\mathrm{eff}}\right)
$$

where

$$
\begin{aligned}
\frac{\mathrm{s}^{2}\left(\overline{\mathrm{P}}_{\mathrm{Pu}}\right)}{\overline{\mathrm{P}}_{\mathrm{Pu}}{ }^{2}}= & \frac{\mathrm{s}^{2}(\mathrm{HDE})}{\overline{\mathrm{P}}_{0}{ }^{2}}+\frac{\mathrm{s}^{2}(\mathrm{REP})}{\overline{\mathrm{P}}_{0}^{2}}+\frac{\mathrm{s}^{2}(\mathrm{CALIB})}{\overline{\mathrm{P}}^{2}} \\
& +\frac{\mathrm{s}^{2}\left(\overline{\mathrm{P}}_{\mathrm{M}}\right)}{\overline{\mathrm{P}}_{\mathrm{M}}{ }^{2}}+\frac{\mathrm{s}^{2}(\mathrm{TEMP})}{\overline{\mathrm{P}}_{0}{ }^{2}}
\end{aligned}
$$


5) System Baseline Check

During multiple sample analysis, the system baseline should be checked periodically by using the relation

$$
t=\left|\bar{P}_{0}-A\right| /\left[s^{2}\left(P_{0}\right)+s^{2}(A)\right]^{\frac{7}{2}}
$$

where

$\overline{\mathbf{P}}_{0}$ is the current calorimeter-supplied power to an empty chamber.

If
$t>1.95$

then a baseline shift must be assumed to have occurred, and a correction should be made to the zero-power intercept (A). 


\section{APPENDIX A}

\section{CALORIMETRIC UNIT CIRCUIT DIAGRAMS \#1-9}

IAEA FOUR METER CALORIMETER:

1. Calorimeter section

2. Coll assembly block diagram

3. DC filter mode

4. $\mathbf{T}_{0}$ control module

5. $T_{1}$ control module

6. $T_{2}$ control module

7. $T_{3}$ control module

8. $T_{3}$ preamplifier

9. Test point table 
NOTES:

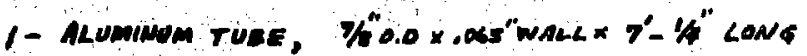

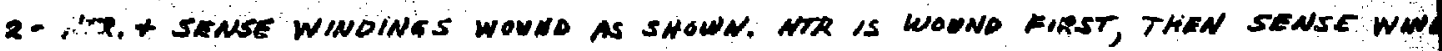

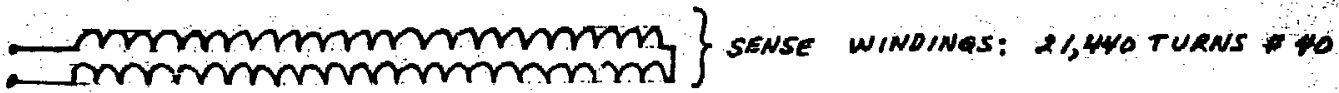

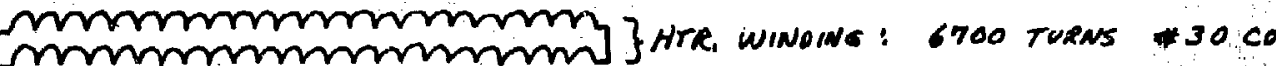
O. SEE NATE

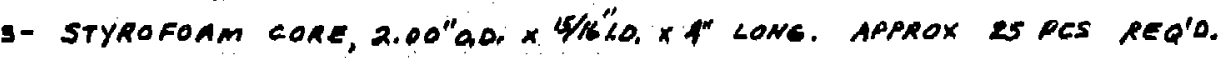

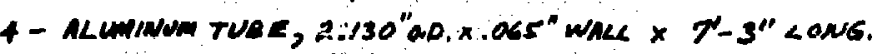

5- ATR ASERNE WINOINGS AS SHOWN, HTR WOUNO FIRST, TWEN SENSE WINOING

O

mmmmmmm SENSE WINDINS: NICKEL. RT $=3,436 \Omega$

mimm ATR, WINDING: 3,460 TURNS of 24

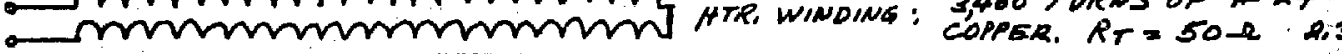

Q SEE NOTE 4

6 - STYROFOAM CORE, 3.004D $\times 2.20$ T.D. $\times 4^{*} \angle A N G$ APPROX. 25PCS. REQD.

7 - ALUMINUM TUBE, $3.166^{\prime \prime} \times .083$ "WALLX7'- 6" LONG

8 - HTR. WINDING + THERMISTORS AS SHOWN. HTR, WOUNO FIRST THEN 16 FENWAL GB 3/P2 THERM/STORS (IDOQN EACH) EPOXIED ON $/ 2$ " CENTER,

0.mmmmmmmmm HTR. WINDING: 3580

ammmmmmmmm TURNS $\$ 24$ COPAER

$\therefore R \Omega R \quad . . . . . . R \Omega R \Omega \quad R_{T}=\pi \Omega \quad 3,63165$.

Q SEE NOTE 7

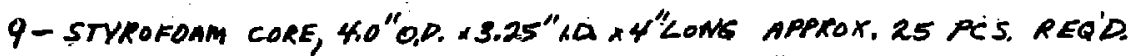

10- ALUMINUM TUBE $\$ 25$ "DD.XV25" WALL $\times 7^{\prime}-9^{\prime \prime}$ LONG.

11 - HTR. WINDING + THERMISTORS SIMILAR TO NOTE 8, EXCEPT

IIT IS 2keT TURNS 26 COPPER, $R_{T}=100 \Omega$

12 - STYYROFAAM CQRE, 5,Q"0.0. $\times 4.25 "$ LD. 25 PES. REQ'D.

13- ALUMINUM TUAE, SK" OD, $\times .125 "$ WALL $\times$ " LONG

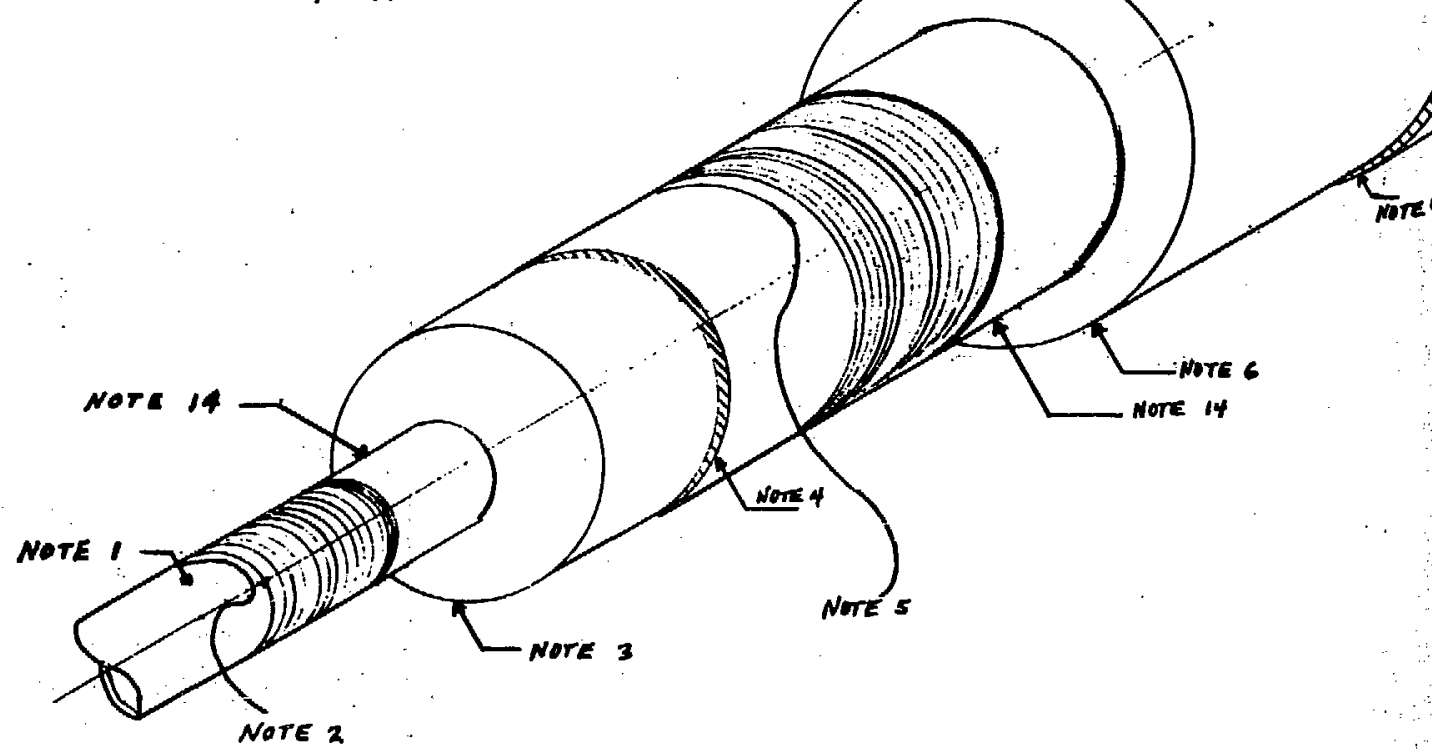




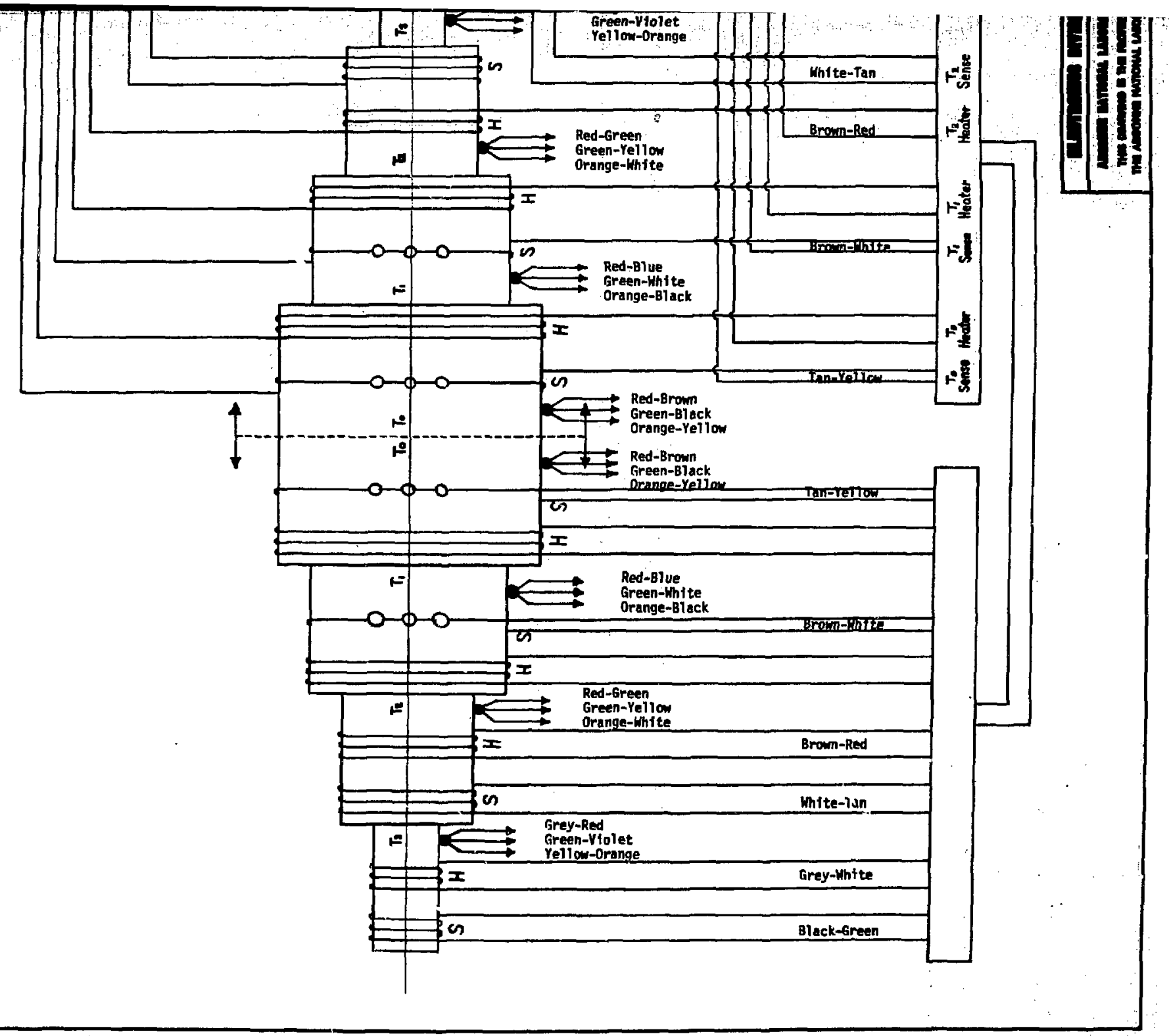




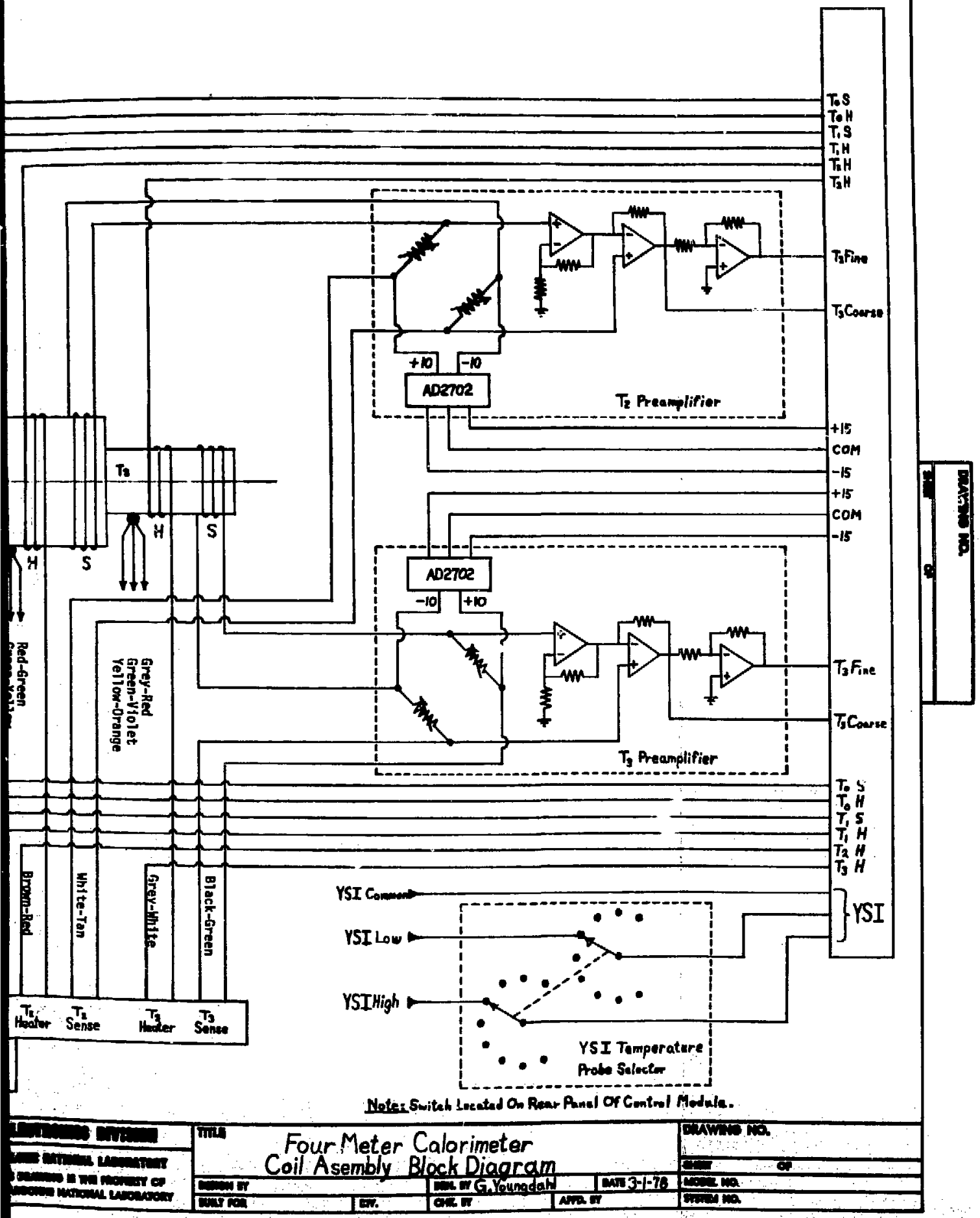




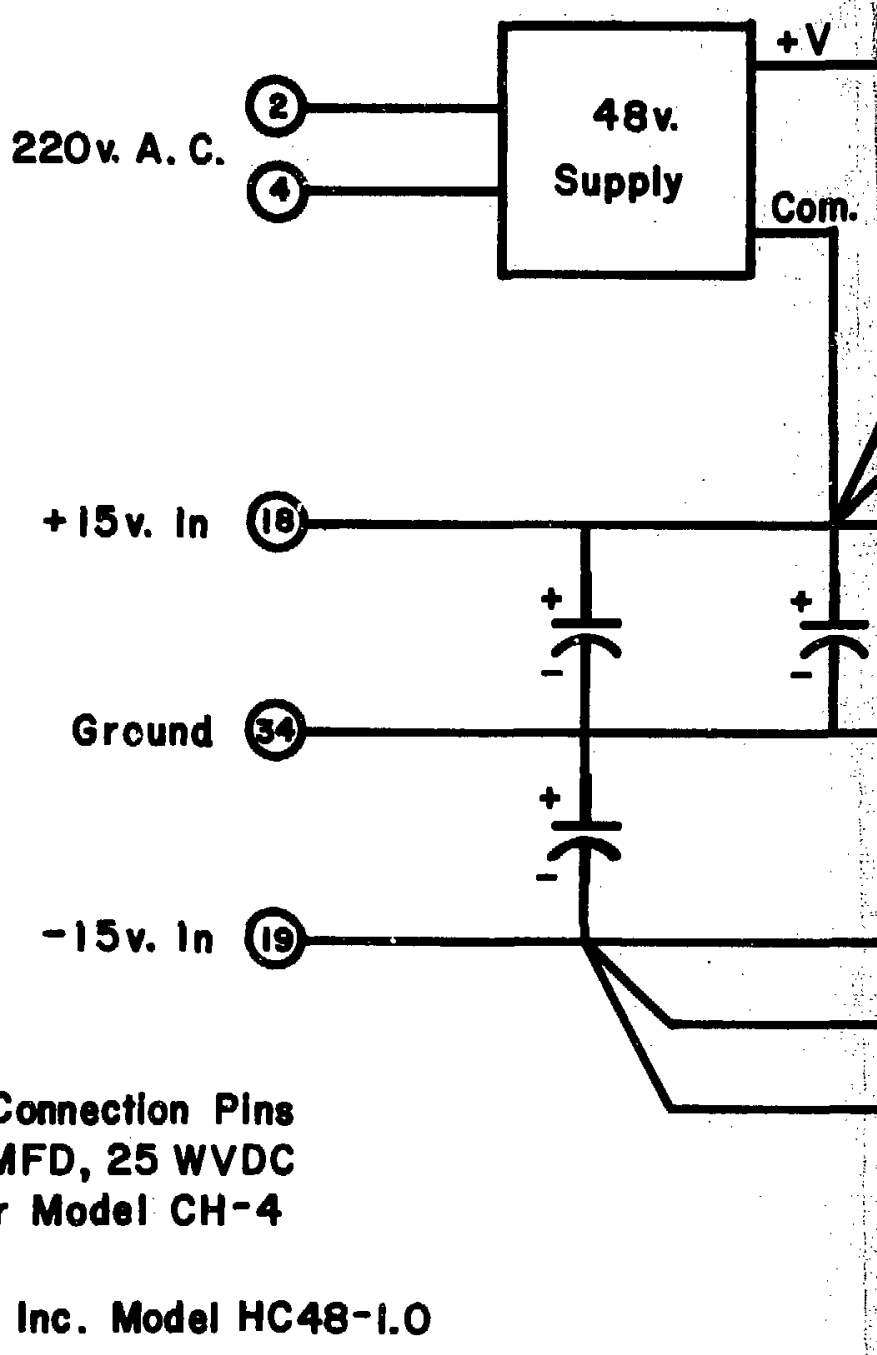

NOTES:

1- $O$ Refers To NIM Bin Connection Pins

2- All Capacitors Are 2000 MFD, 25 WVDC

3-Choke ls Slgnal Transformer Model CH-4

70 MHY. , 4 A. , . $6 \Omega$ DC

4- 48v. Supply ls Power-One Inc. Model HC48-1.0 


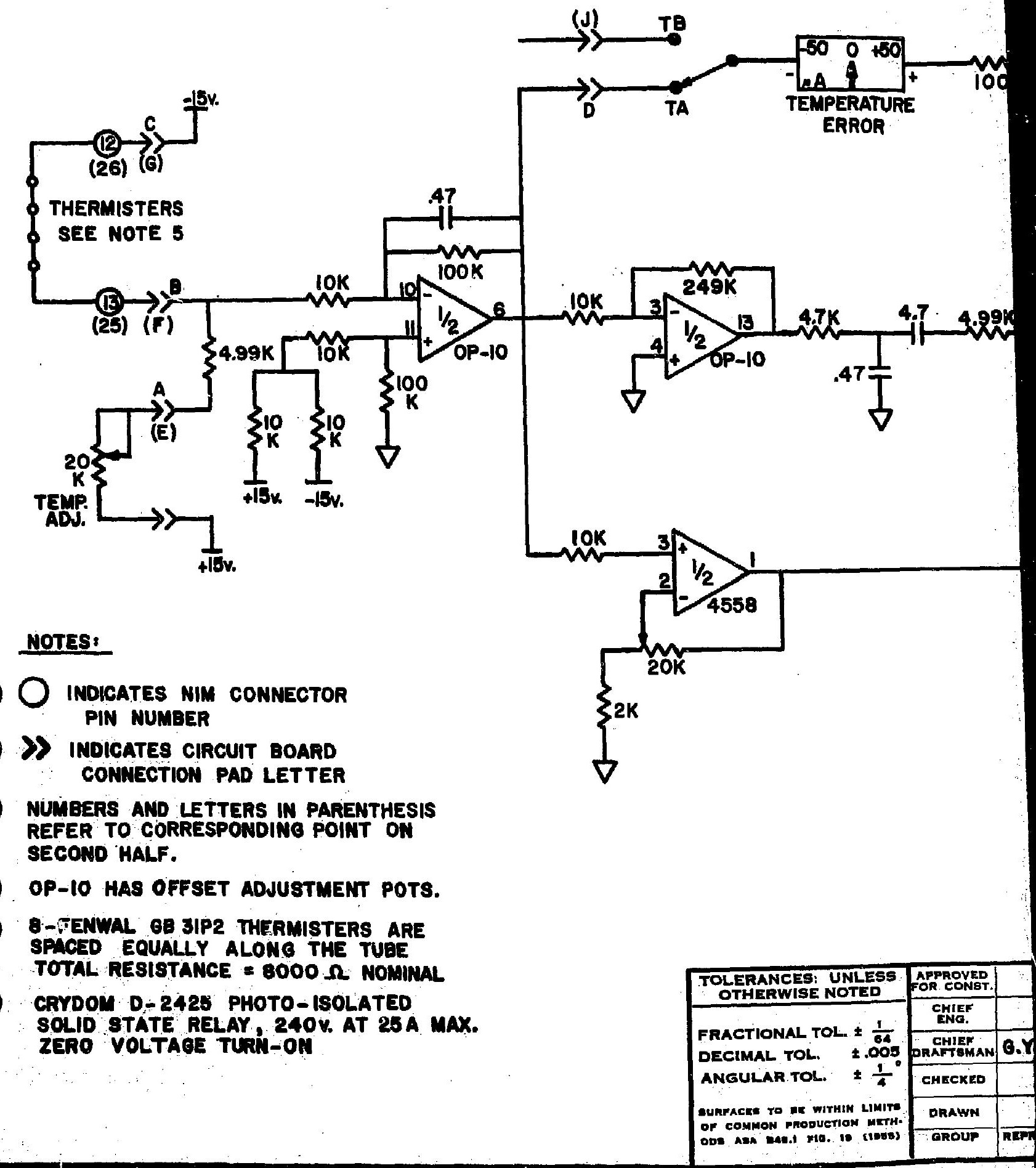




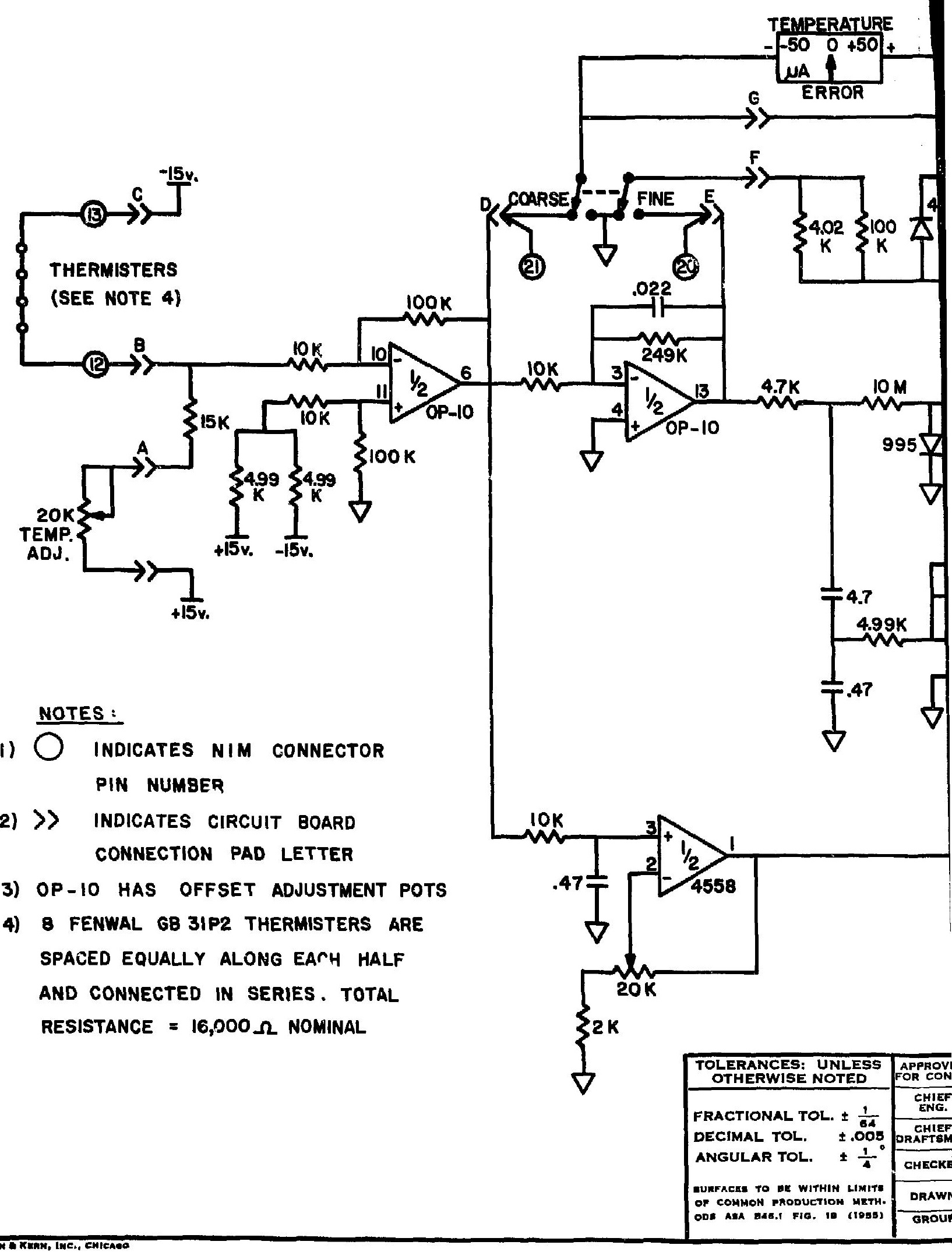




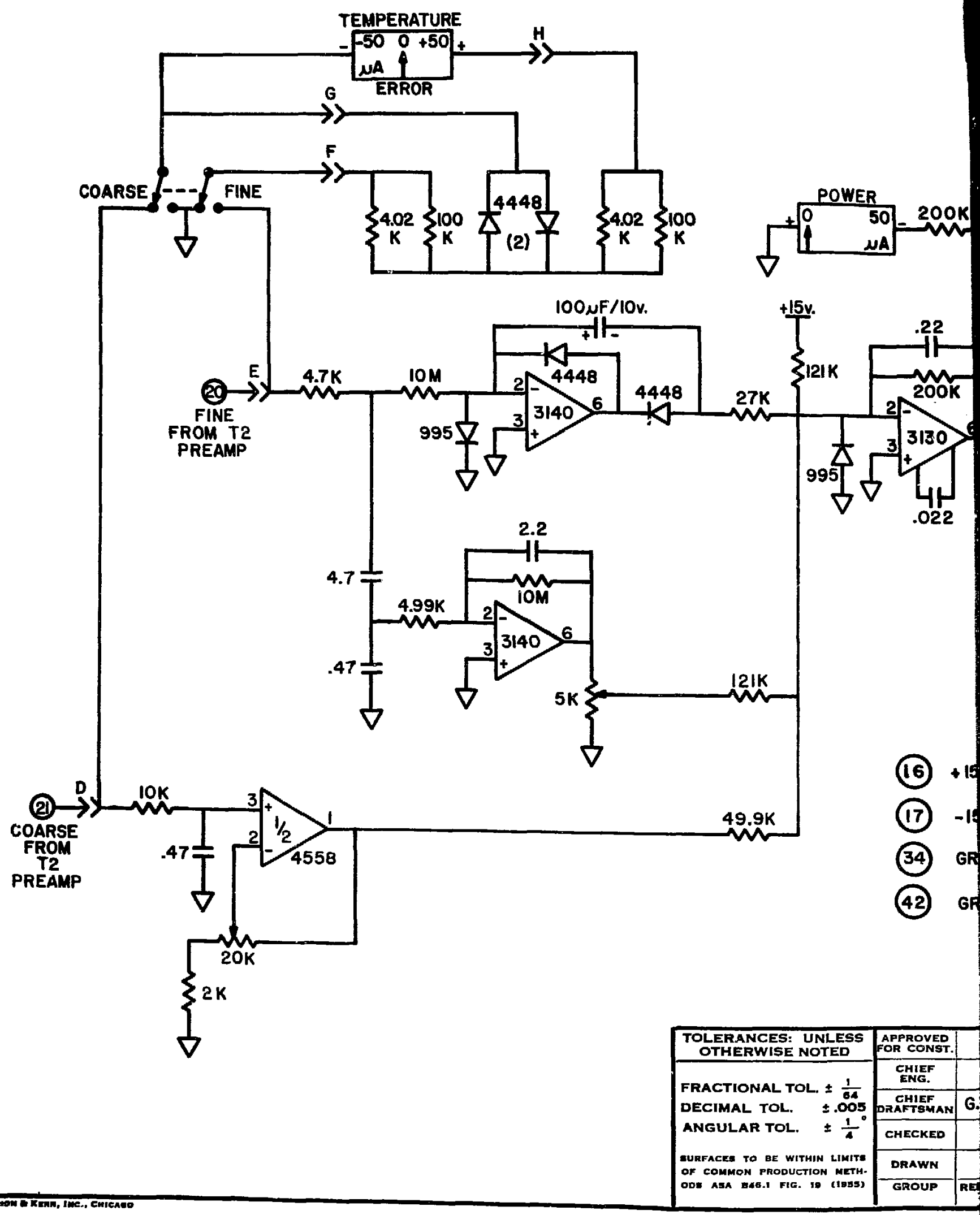



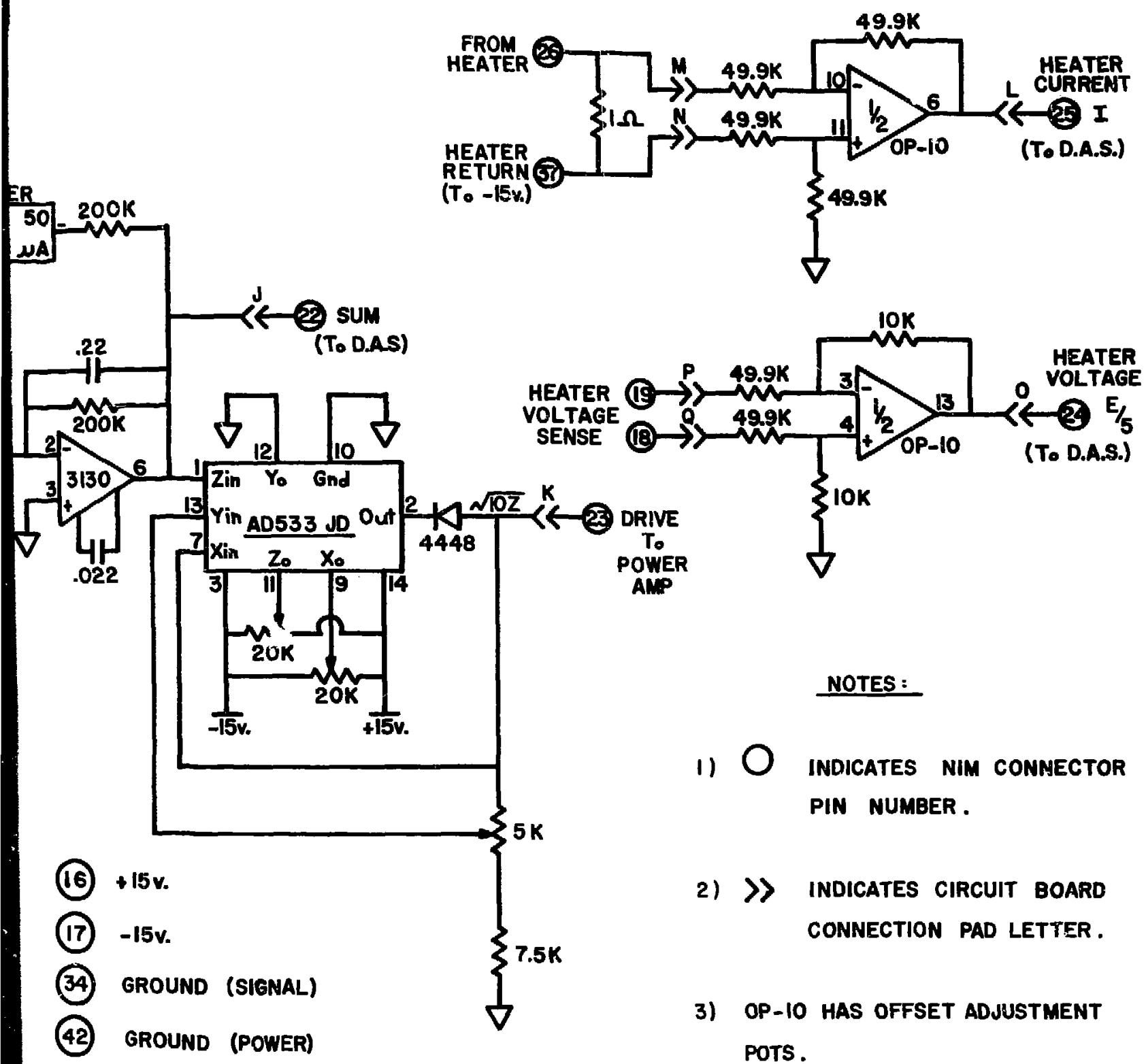

NOTES :

1) O InDicates NIM cONhEctor PIN NUMBER .

$5 K$

2) \) INDICATES CIRCUIT BOARD CONNECTION PAD LETTER.

3) OP-10 HAS OFFSET ADJUSTMENT POTS.

\begin{tabular}{|c|c|c|c|c|c|c|c|c|}
\hline $\begin{array}{l}\text { APPROYED } \\
\text { FOR CONST. }\end{array}$ & & \multirow{2}{*}{\multicolumn{3}{|c|}{ AREONNE NATIONAL LABORATORY }} & \multicolumn{2}{|r|}{ CHANGE } & $\overline{\text { DATE }}$ & \multirow[t]{2}{*}{ BY } \\
\hline CHIEF & & & & & \multicolumn{3}{|c|}{ PART T2 CONTROL MODULE } & \\
\hline PRAFIEF & G.Y. & \multicolumn{3}{|c|}{$\begin{array}{l}\text { This drawing is the property } \\
\text { of } \\
\text { the Argonne National Loboratory }\end{array}$} & \multicolumn{4}{|c|}{$\begin{array}{l}\text { ABSEMELY } \\
4 \text { - METER CALORIMETER }\end{array}$} \\
\hline CHECKED & & \multirow[t]{3}{*}{ ECALE } & \multirow{3}{*}{ matL. } & \multirow{3}{*}{ NO. NEQD. } & \multirow{3}{*}{$\begin{array}{l}\text { SHEET } \\
\text { OF }\end{array}$} & \multirow[t]{3}{*}{ DRWG. NO. } & \multirow{3}{*}{\multicolumn{2}{|c|}{ ITEM NO. }} \\
\hline DRAWN & & & & & & & & \\
\hline GROUP & REPRE & & & & & & & \\
\hline
\end{tabular}




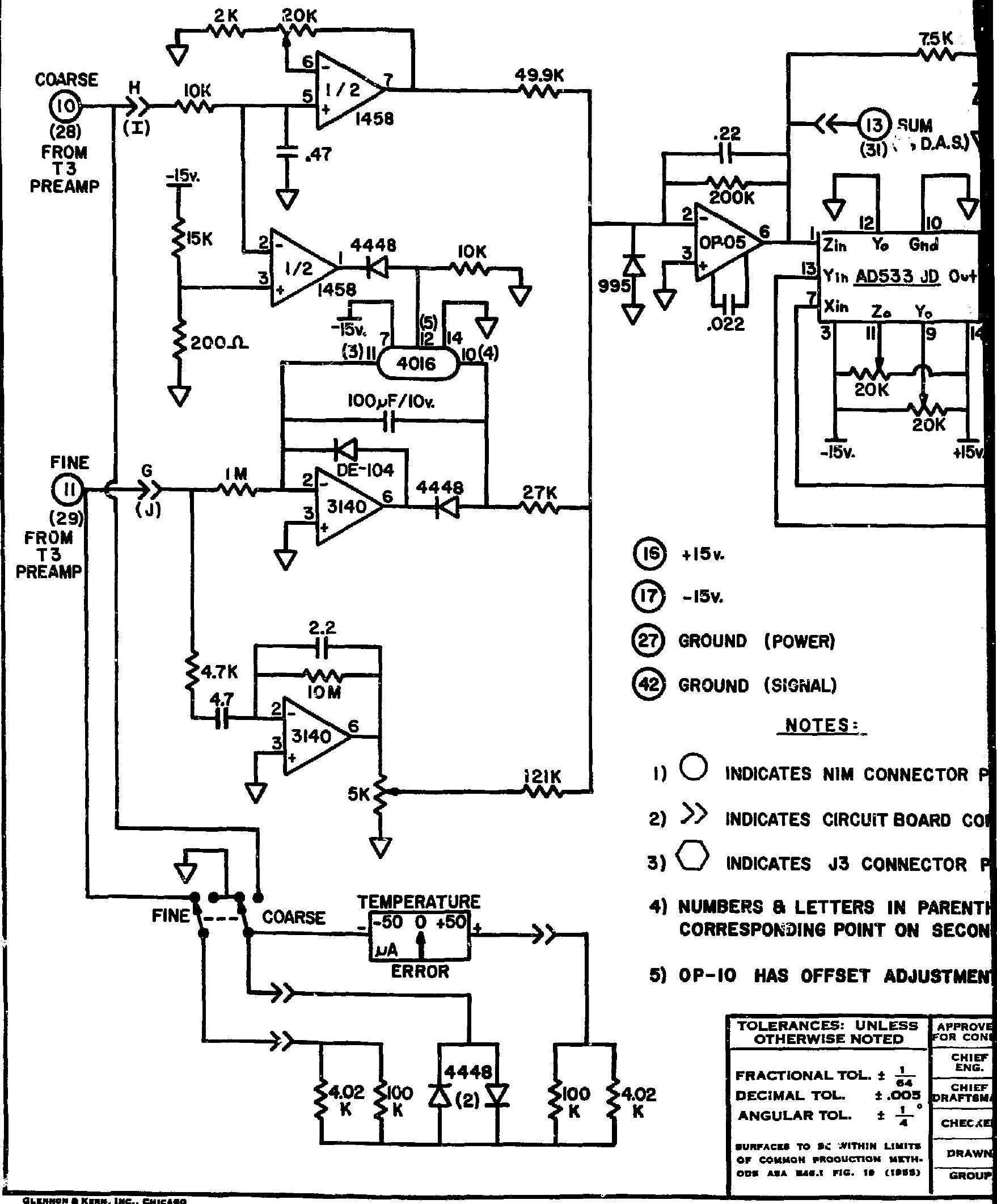




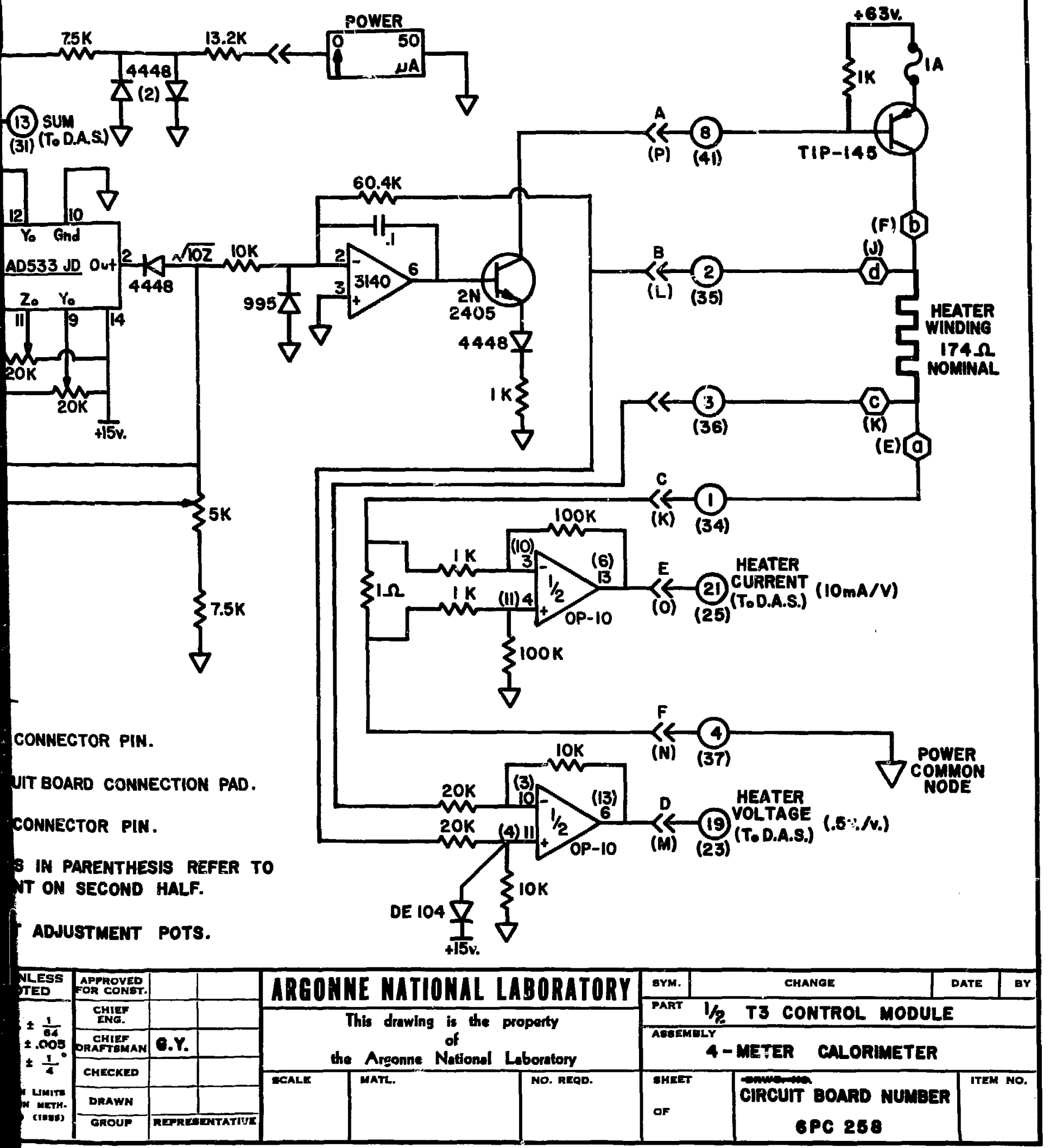



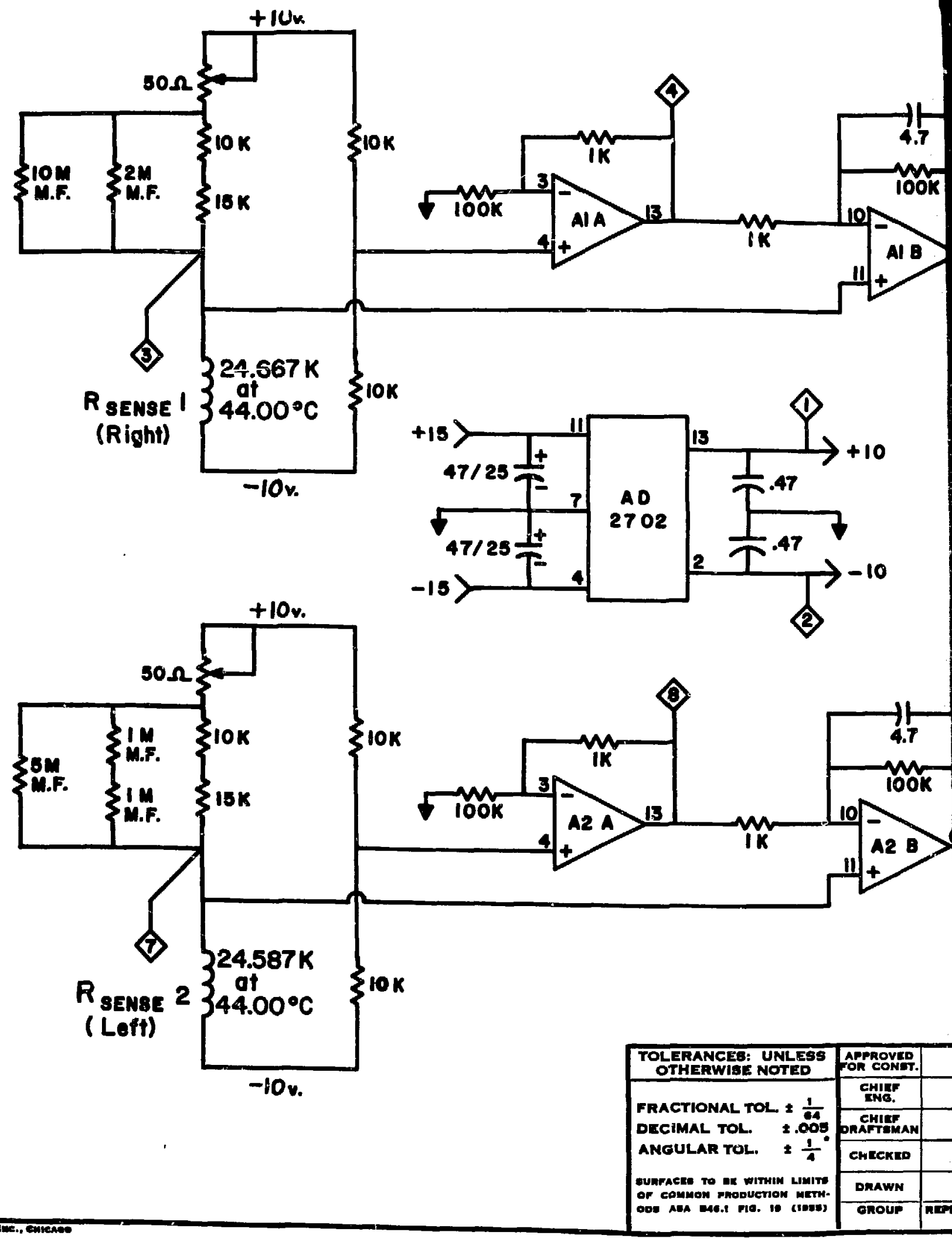
TEST POINT TABLE

Test Point Number
Signal Description
DAS Connector

PIn Number

\begin{tabular}{|c|c|c|}
\hline $\begin{array}{l}1 \\
2 \\
3 \\
4 \\
5 \\
6 \\
7 \\
8 \\
9 \\
10 \\
11 \\
12 \\
13 \\
14 \\
15 \\
16 \\
17 \\
18 \\
19 \\
20 \\
21 \\
22 \\
23 \\
24 \\
25 \\
26 \\
27 \\
28 \\
29 \\
30 \\
31 \\
32\end{array}$ & $\begin{array}{l}\mathrm{T}_{3} \text { Right Heater Voltage } \\
\mathrm{T}_{3} \text { Right Heater Control } \\
\text { Calibration Voltage } \\
\text { Calibration Current } \\
\mathrm{T}_{3} \text { Left Heater Voltage } \\
\mathrm{T}_{3} \text { Left Heater Current } \\
\mathrm{T}_{2} \text { Heater Voltage } \\
\mathrm{T}_{2}^{2} \text { Heater Current } \\
\mathrm{T}_{3} \text { Right Coarse (Preamp) } \\
\mathrm{T}_{3} \text { Right Fine (Preamp) } \\
\mathrm{T}_{3} \text { Left Coarse (Preamp) } \\
\mathrm{T}_{3} \text { Left Fine (Preamp) } \\
\mathrm{T}_{2}^{3} \text { Coarse (Preamp) } \\
\mathrm{T}_{2}^{2} \text { TFine (Preamp) } \\
\mathrm{T}_{1}^{2} \text { Coarse } \\
\mathrm{T}_{1} \text { Fine } \\
\mathrm{T}_{3} \text { Right Summing Point } \\
\mathrm{T}_{3} \text { Left Summing Point } \\
\mathrm{T}_{2} \text { Summing Point } \\
\mathrm{T}_{1} \text { Summing Point } \\
\text { Calibration Power Amp Drive } \\
\text { Calibrator Power Amp Output } \\
\mathrm{T}_{2} \text { Power Amp Drive } \\
\mathrm{T}_{2}^{2} \text { Power Amp Output } \\
\mathrm{T}_{1}^{2} \text { Power Amp Drive } \\
\mathrm{T}_{1} \text { Power Amp Output }\end{array}$ & $\begin{array}{l}\mathrm{J}_{1}-8 \\
\mathrm{~J}_{1}-7 \\
\mathrm{~J}_{1}-6 \\
\mathrm{~J}_{1}-5 \\
\mathrm{~J}_{1}-4 \\
\mathrm{~J}_{1}-3 \\
\mathrm{~J}_{1}-2 \\
\mathrm{~J}_{1}-1 \\
\mathrm{~J}_{1}^{1}-9 \\
\mathrm{~J}_{1}-10 \\
\mathrm{~J}_{1}^{1}-11 \\
\mathrm{~J}_{1}^{1}-21 \\
\mathrm{~J}_{1}-22 \\
\mathrm{~J}_{1}^{1}-23 \\
\mathrm{~J}_{1}-24 \\
\mathrm{~J}_{1}-25 \\
\mathrm{~J}_{2}-3 \\
\mathrm{~J}_{2}^{2}-4 \\
\mathrm{~J}_{2}-5 \\
\mathrm{~J}_{2}^{2}-6 \\
\mathrm{~J}_{2}-7 \\
\mathrm{~J}_{2}^{2}-8 \\
\mathrm{~J}_{2}^{2}-9 \\
\mathrm{~J}_{2}^{2}-10 \\
\mathrm{~J}_{2}-2 \\
\mathrm{~J}_{2}^{2}-20 \\
\mathrm{~J}_{2}^{2}-19 \\
\mathrm{~J}_{2}-18 \\
\mathrm{~J}_{2}^{2}-17 \\
\mathrm{~J}_{2}-16 \\
\mathrm{~J}_{2}^{2}-15 \\
\mathrm{~J}_{2}-14\end{array}$ \\
\hline
\end{tabular}




\section{APPENDIX B \\ DATA ACQUISITION SYSTEM}

\section{CIRCUIT DIAGRAMS \#1-7}

1. Keyboard layout and connections

2. Keyboard decode

3. Analog multiplexer

4. Display

5. Analog vutput

6. Printer output

7. 8085 microprocessor system 


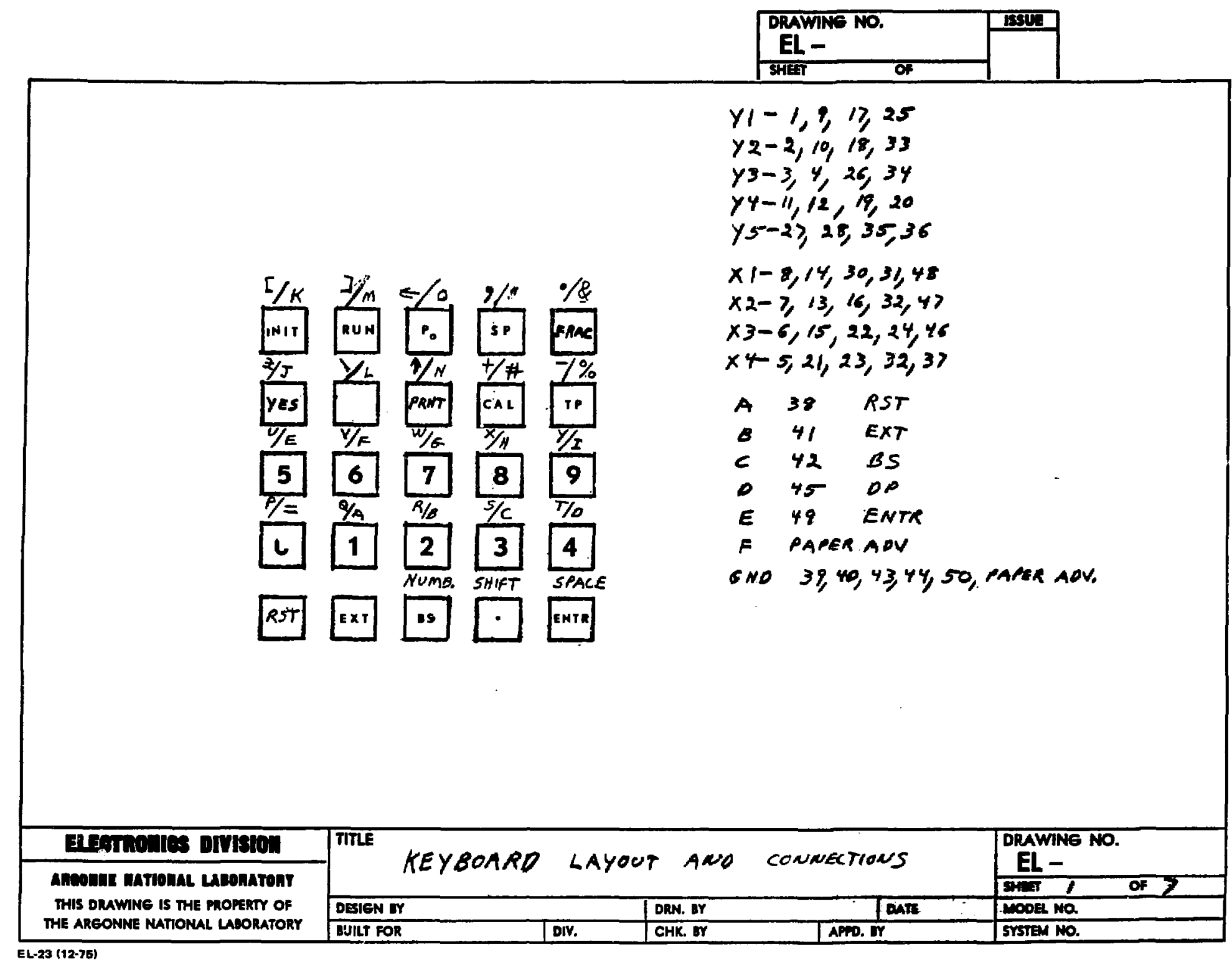




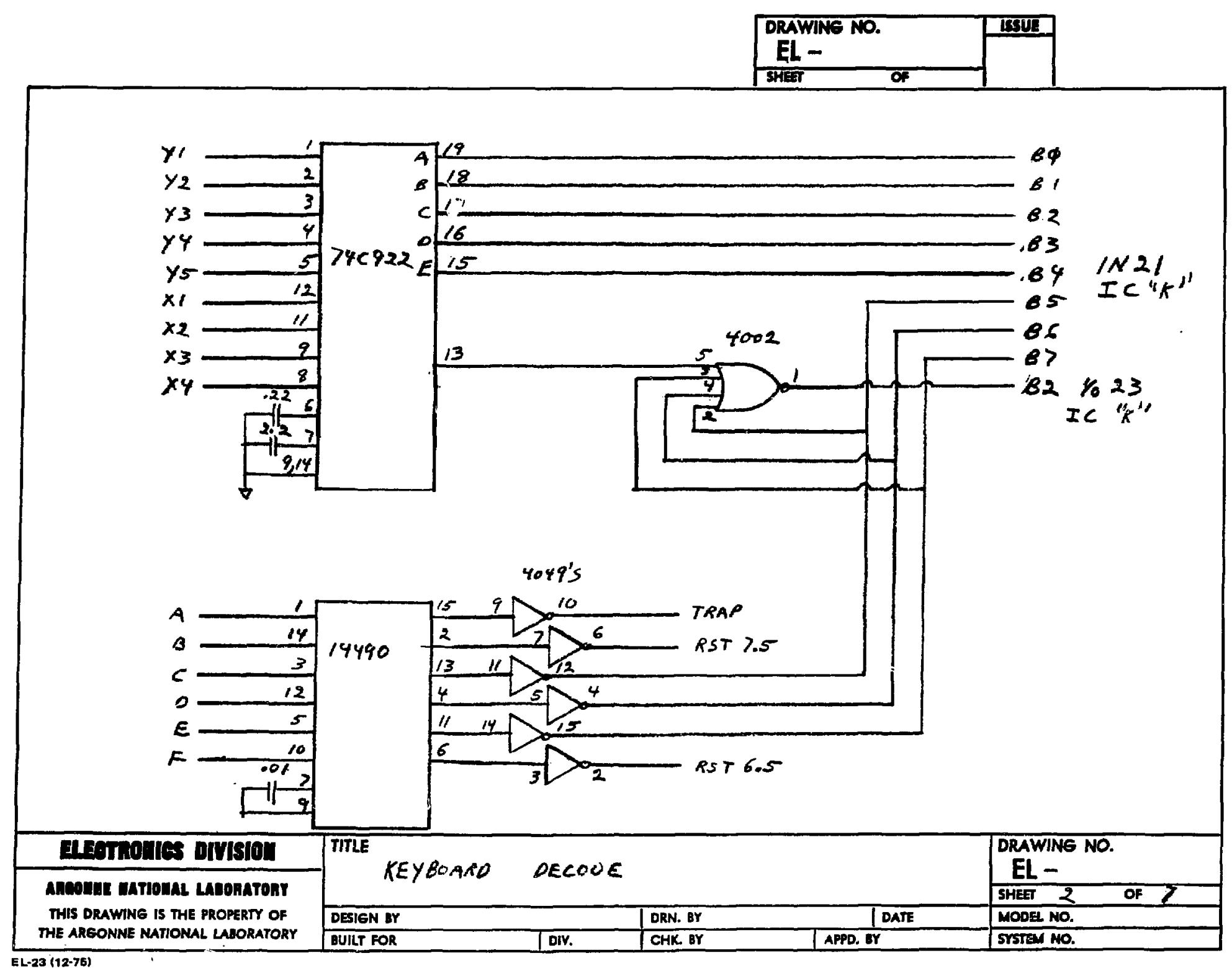




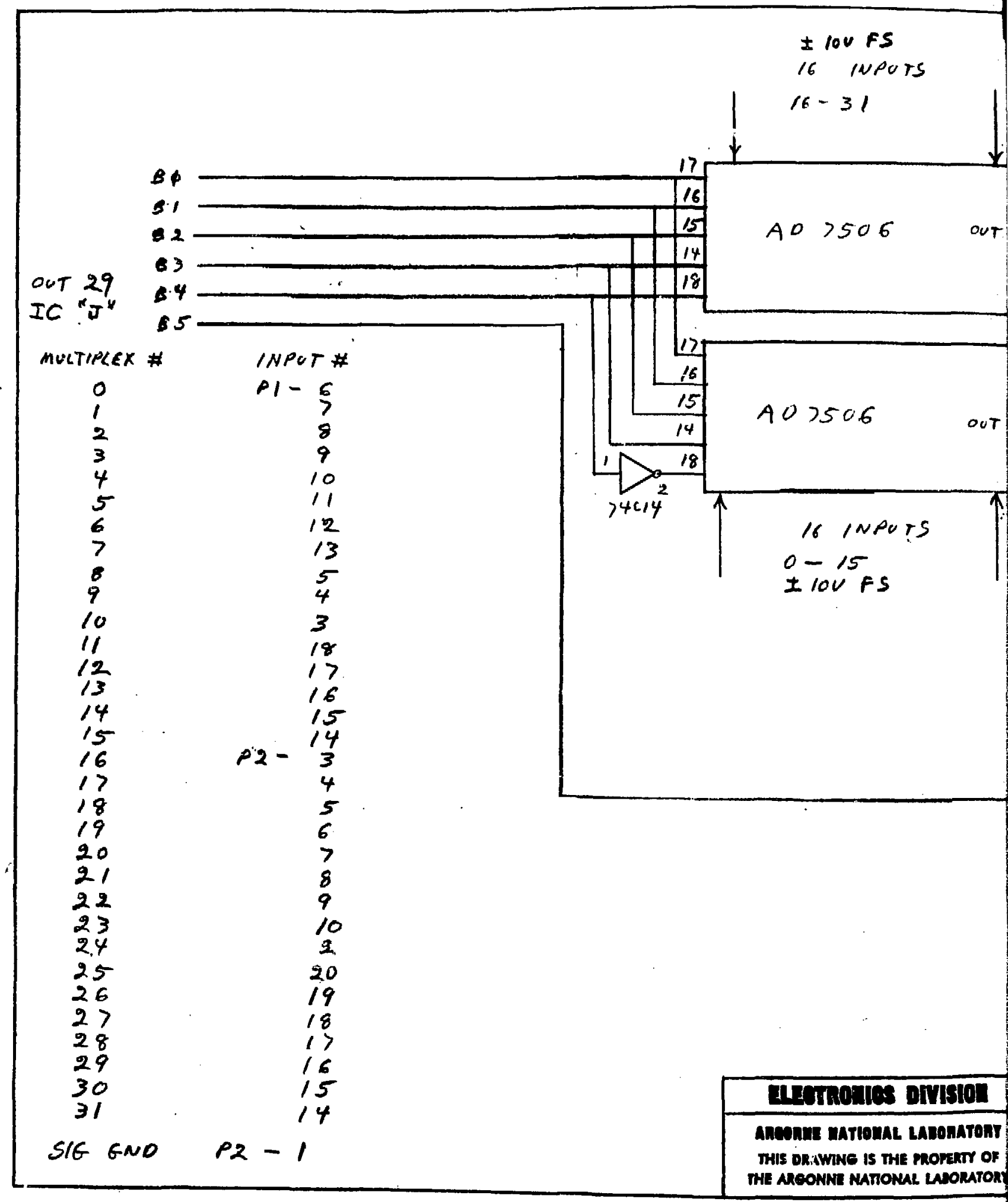




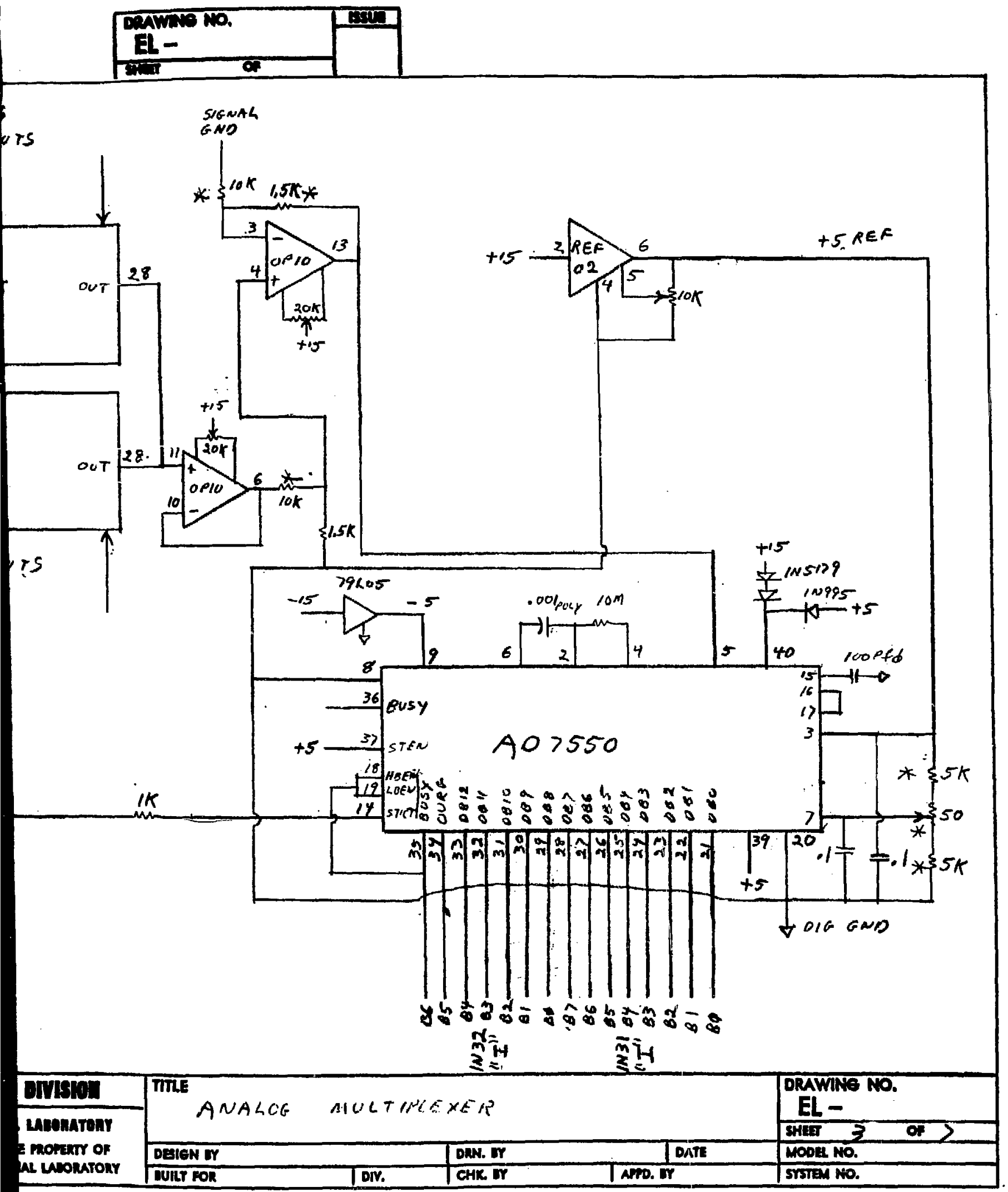




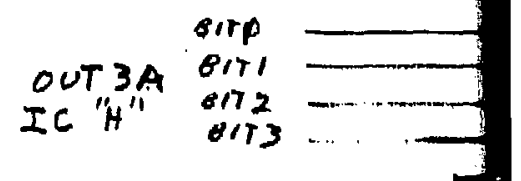

OUT 39

IC "H".
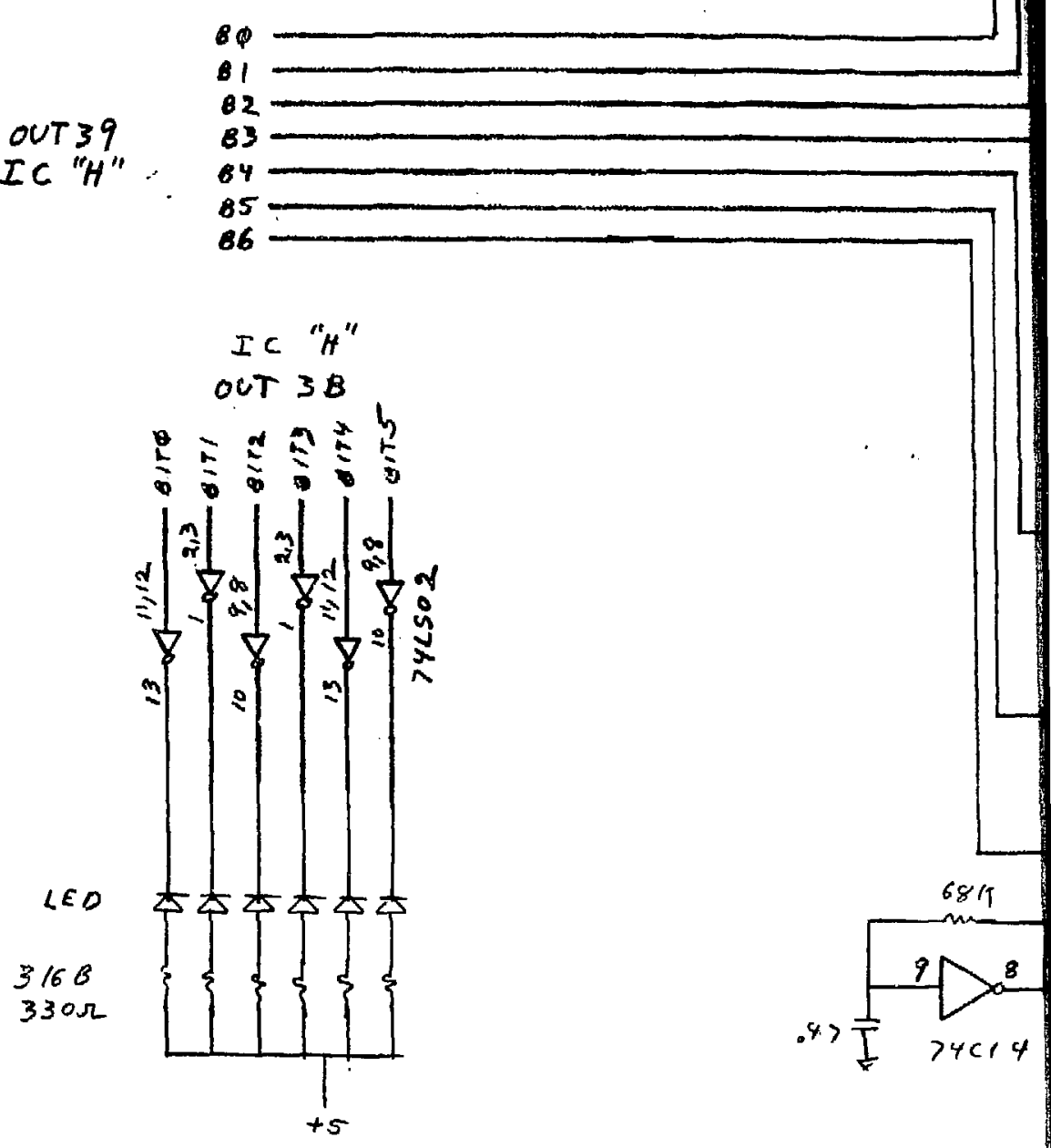

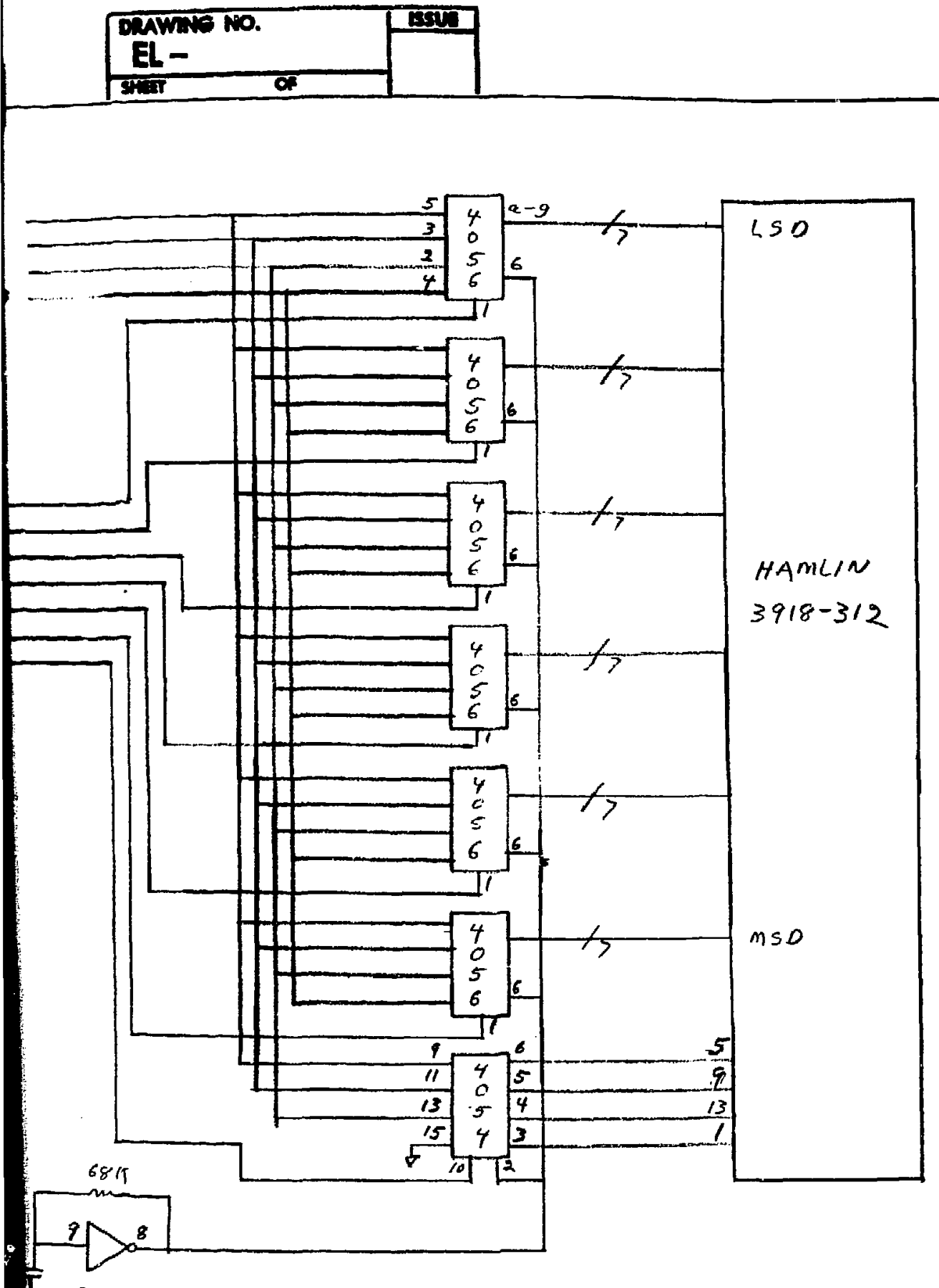

I 74014

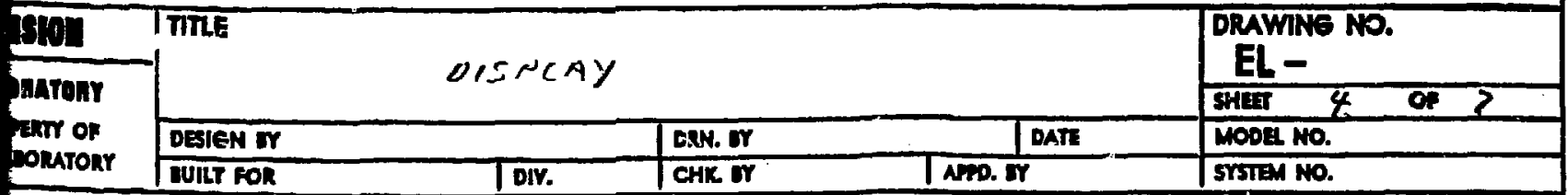




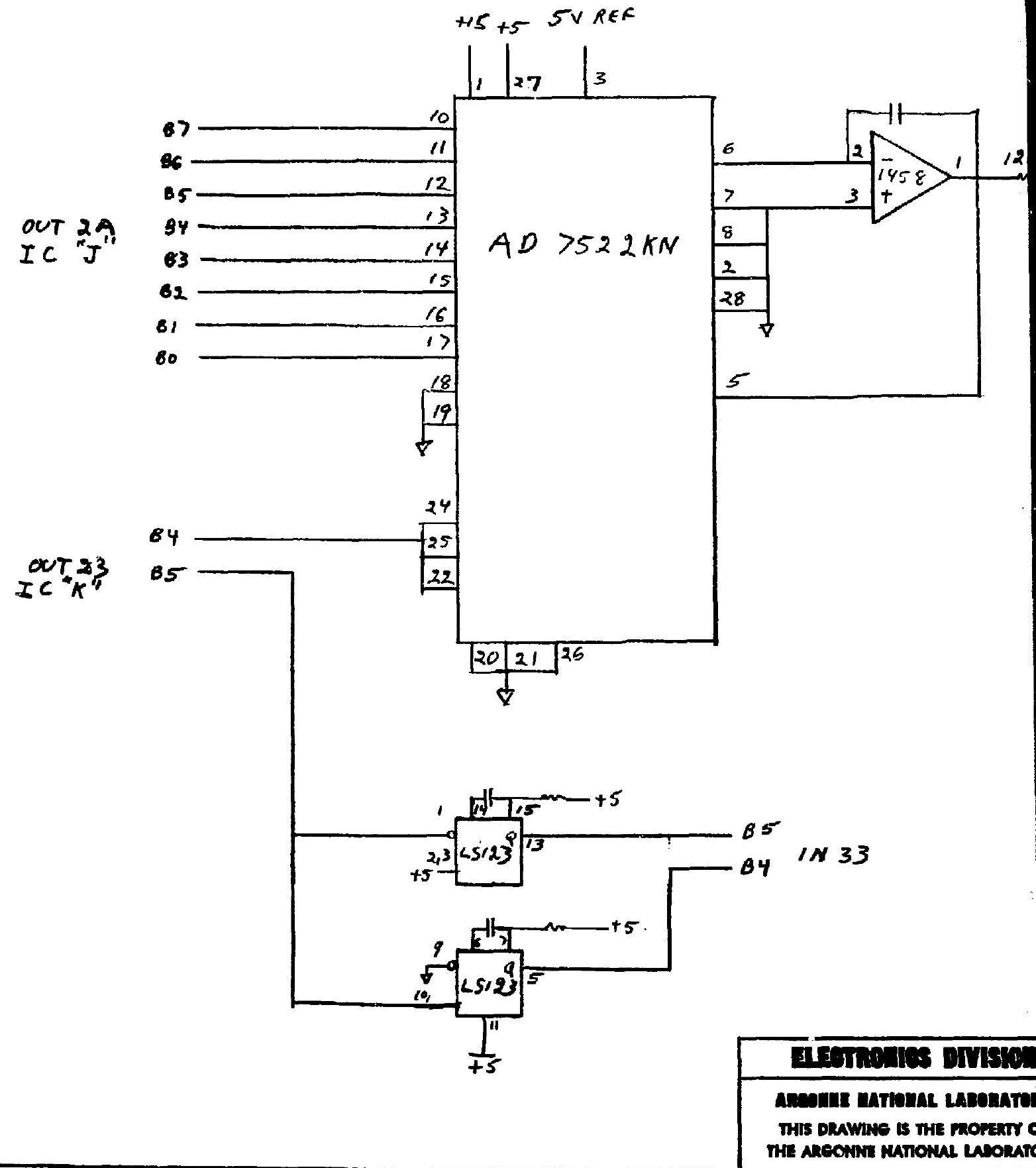




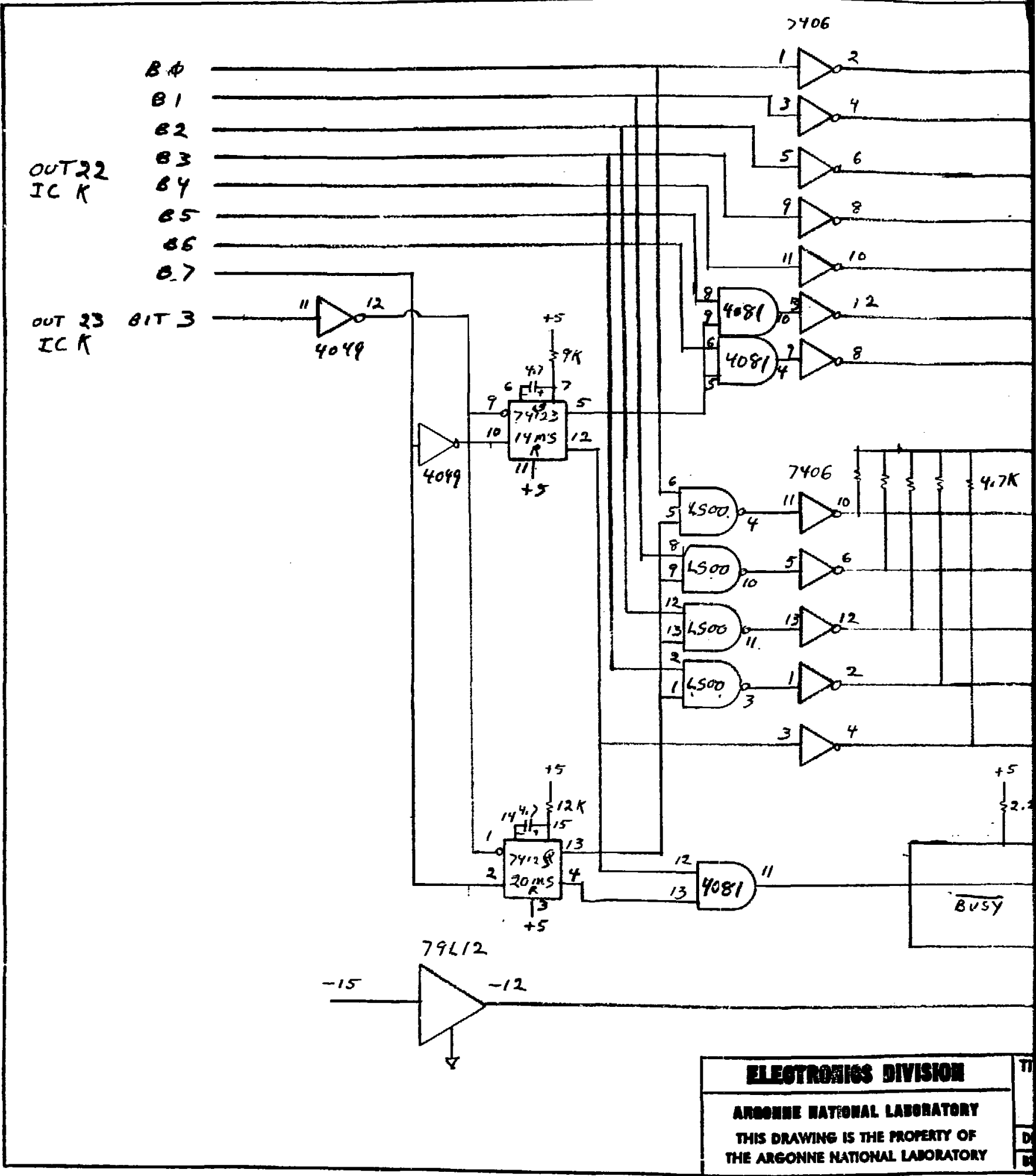




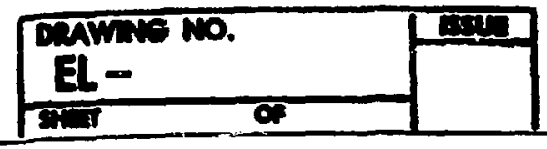

DIP SOCKET

(8) $B 2$

(7) 84

(5) 85

(4) 86

(6) $B>$

(3) 88

(10) $B 9$

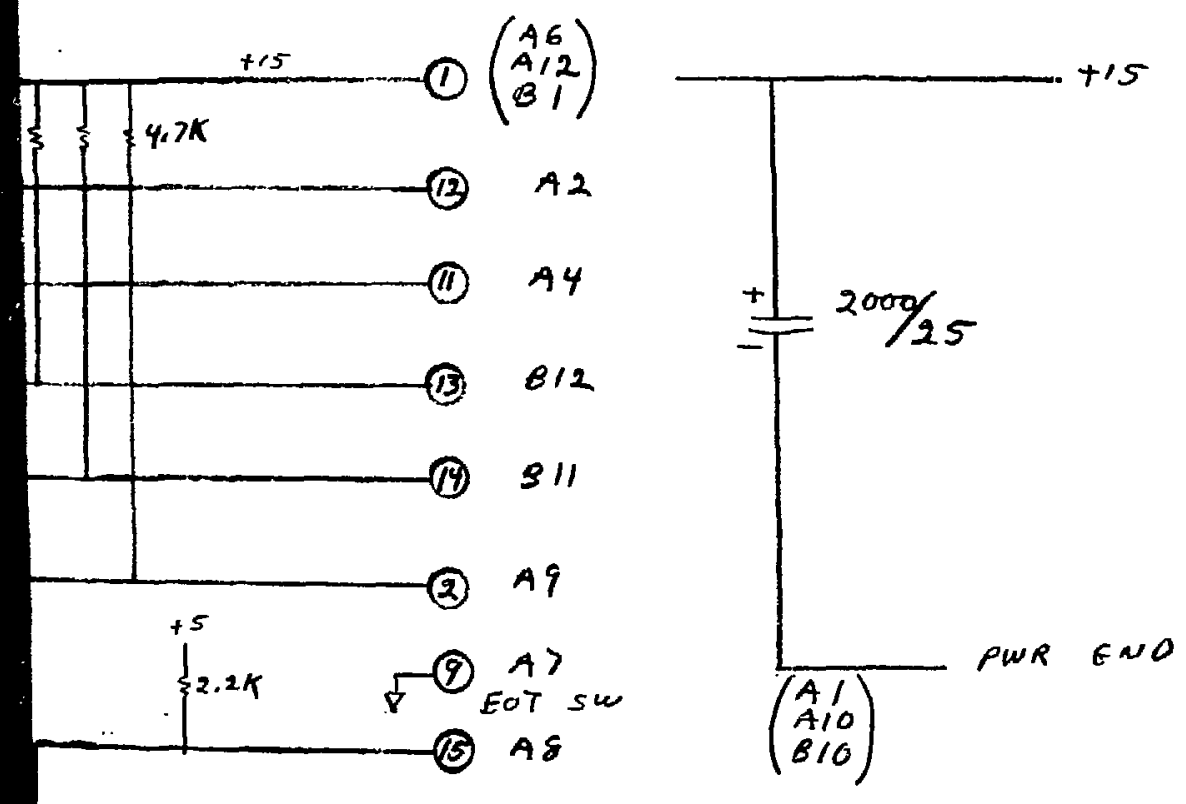
$\overline{B V S Y} B I$
$1 N 33$
$I C$ " $I$ "
84

(16) AII

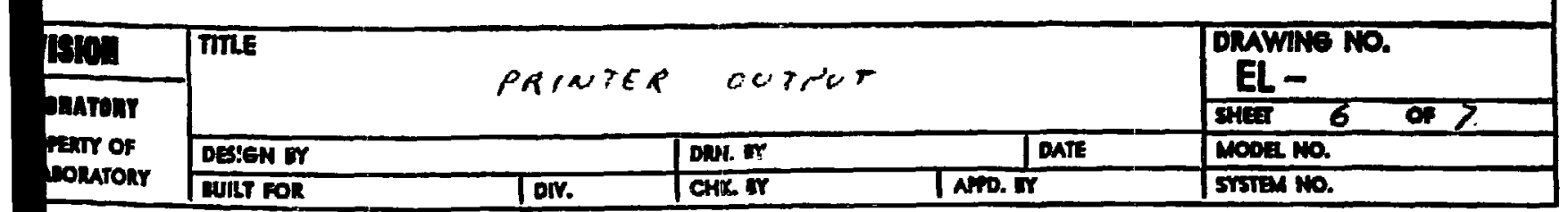




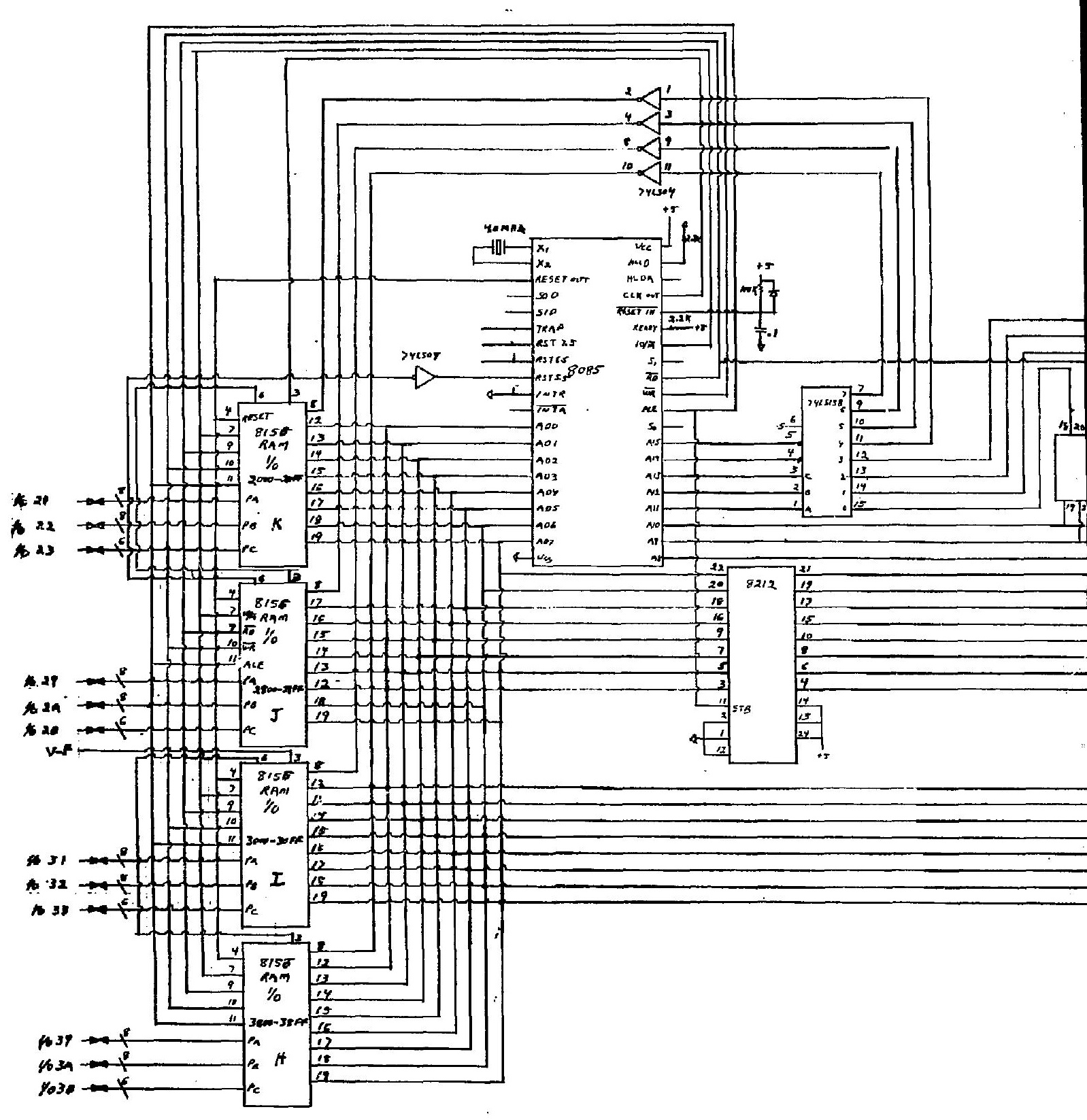




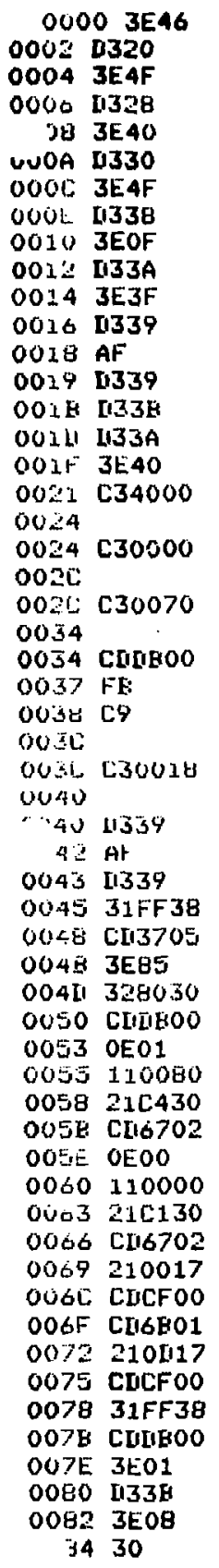

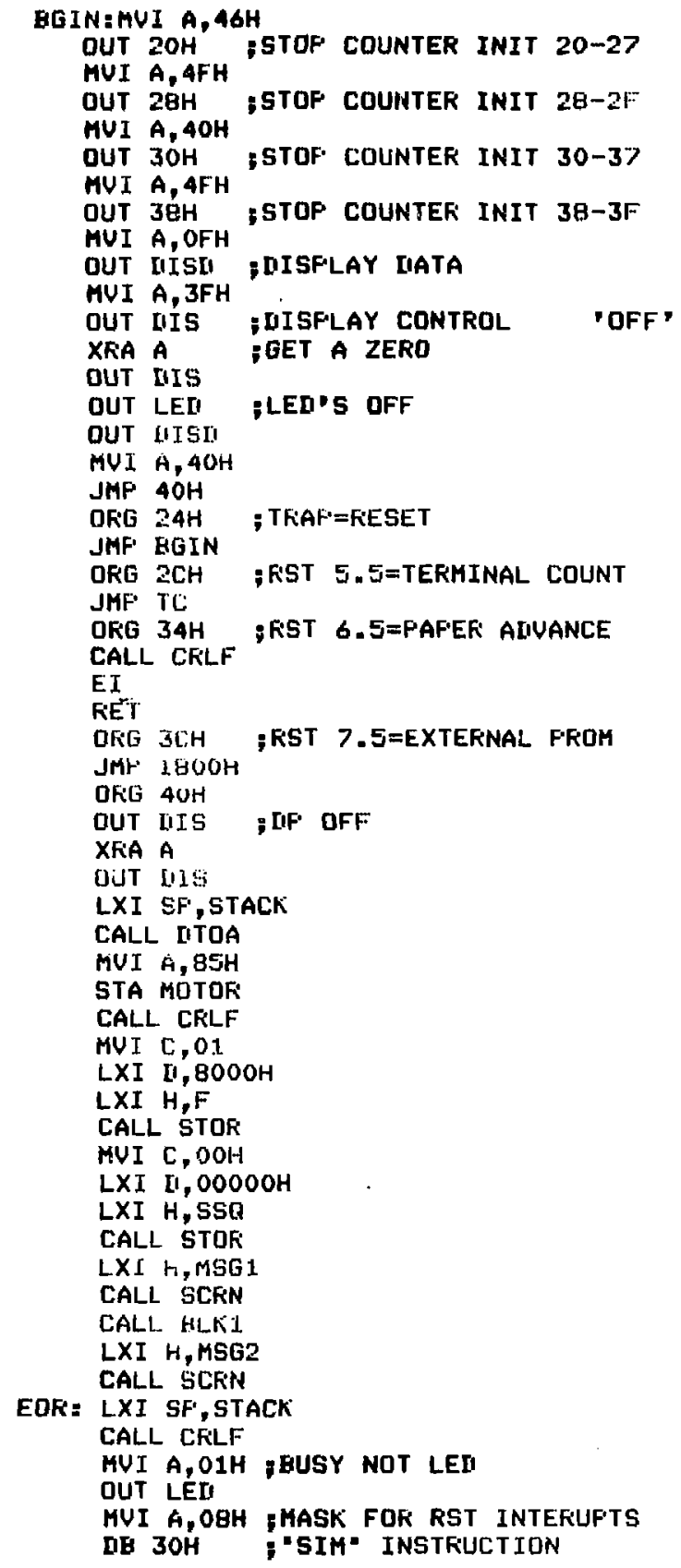




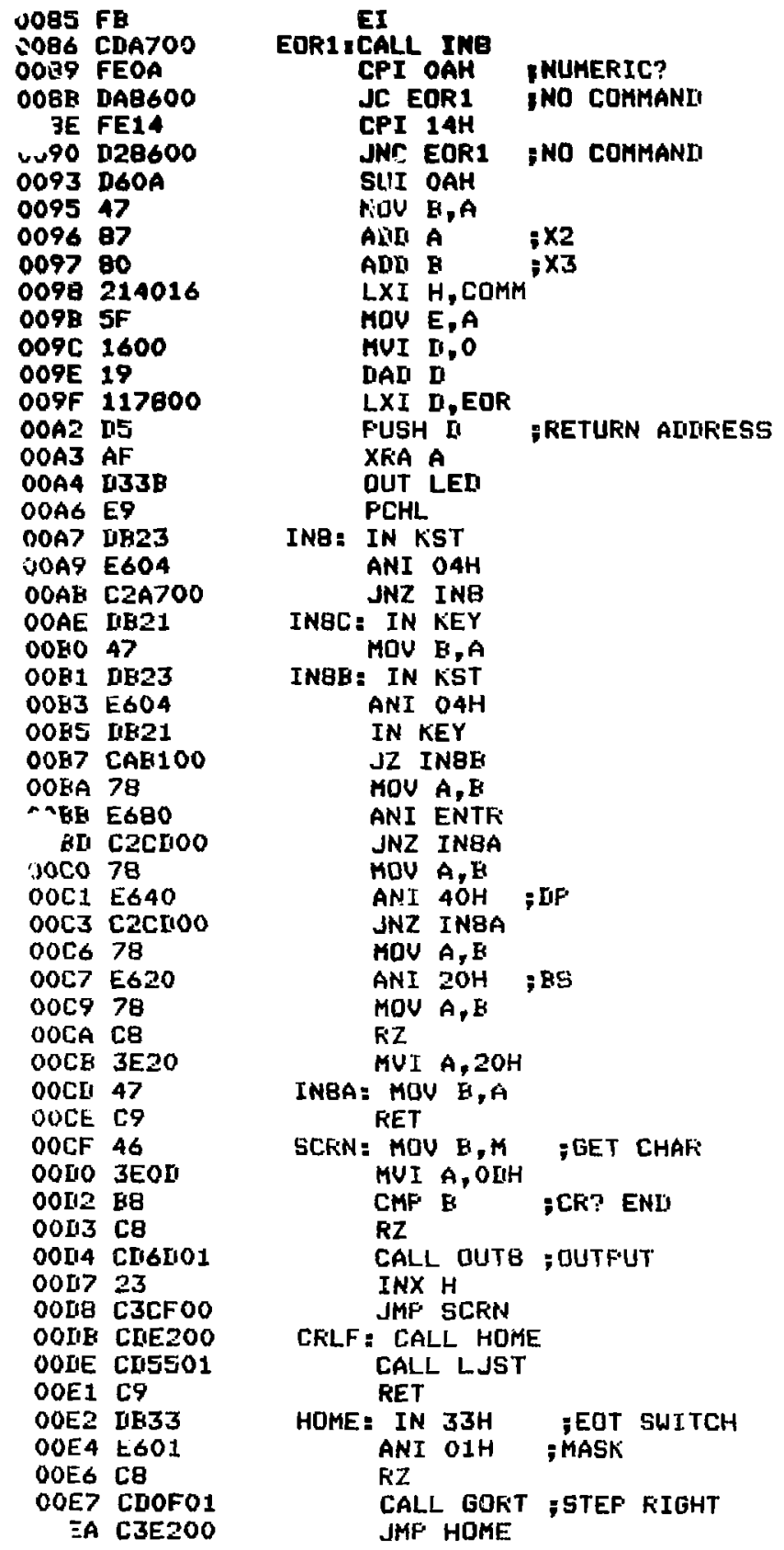




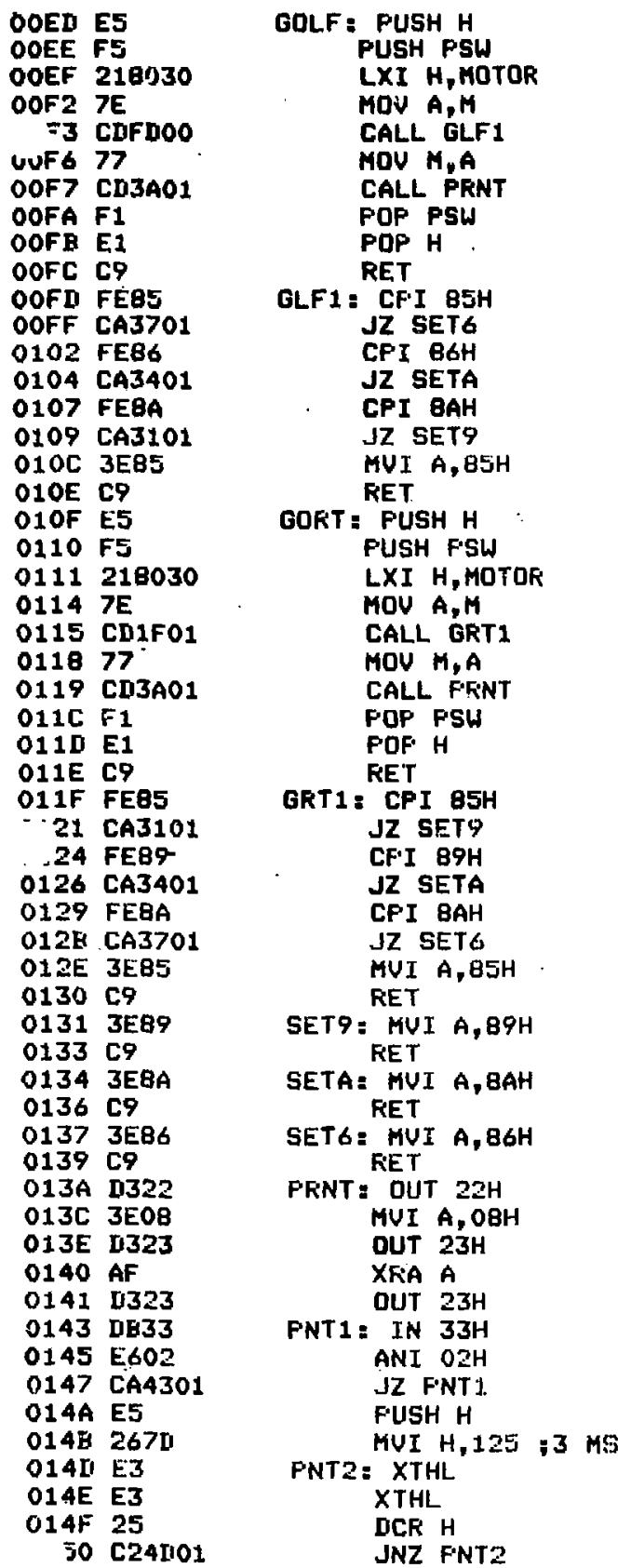




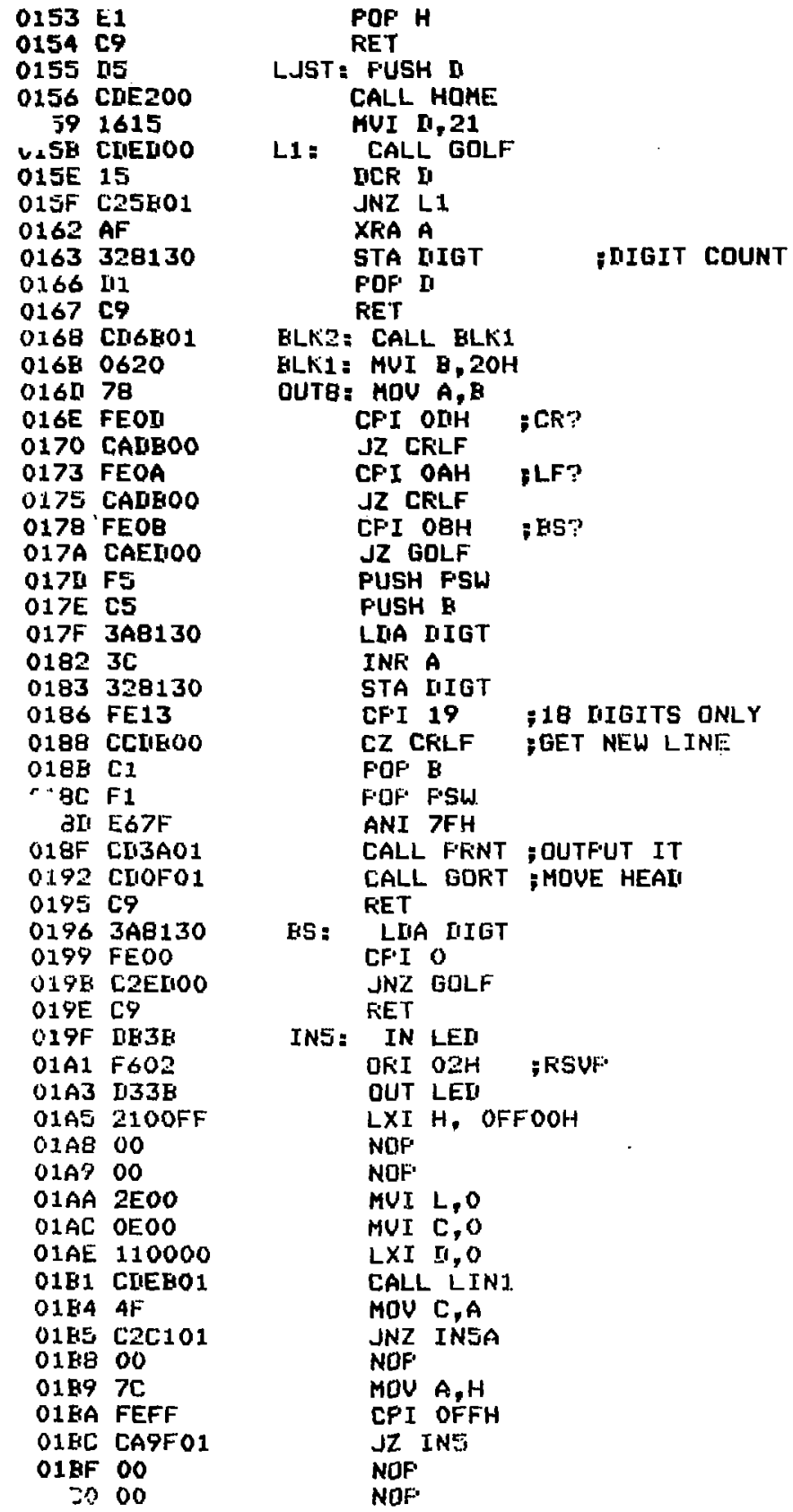




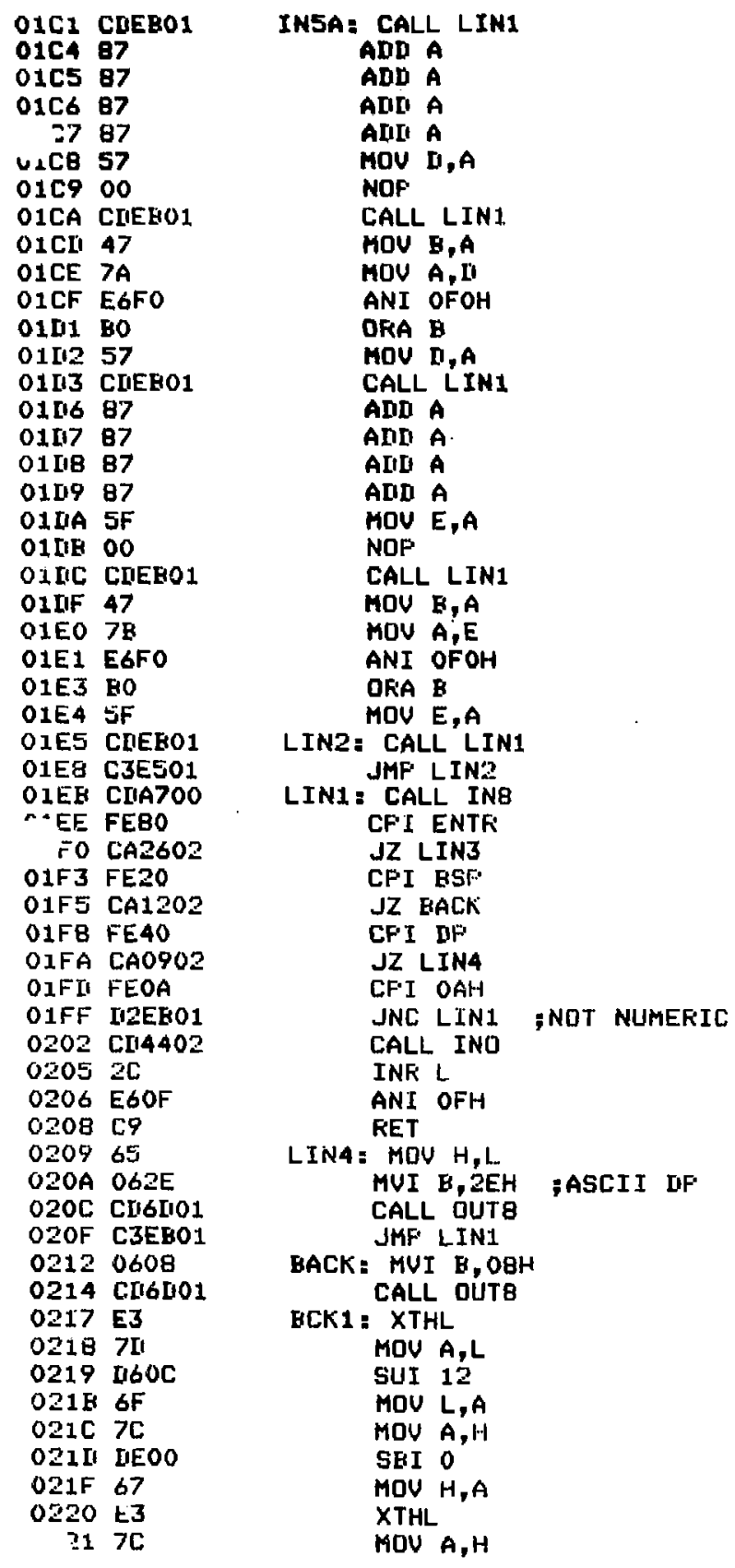




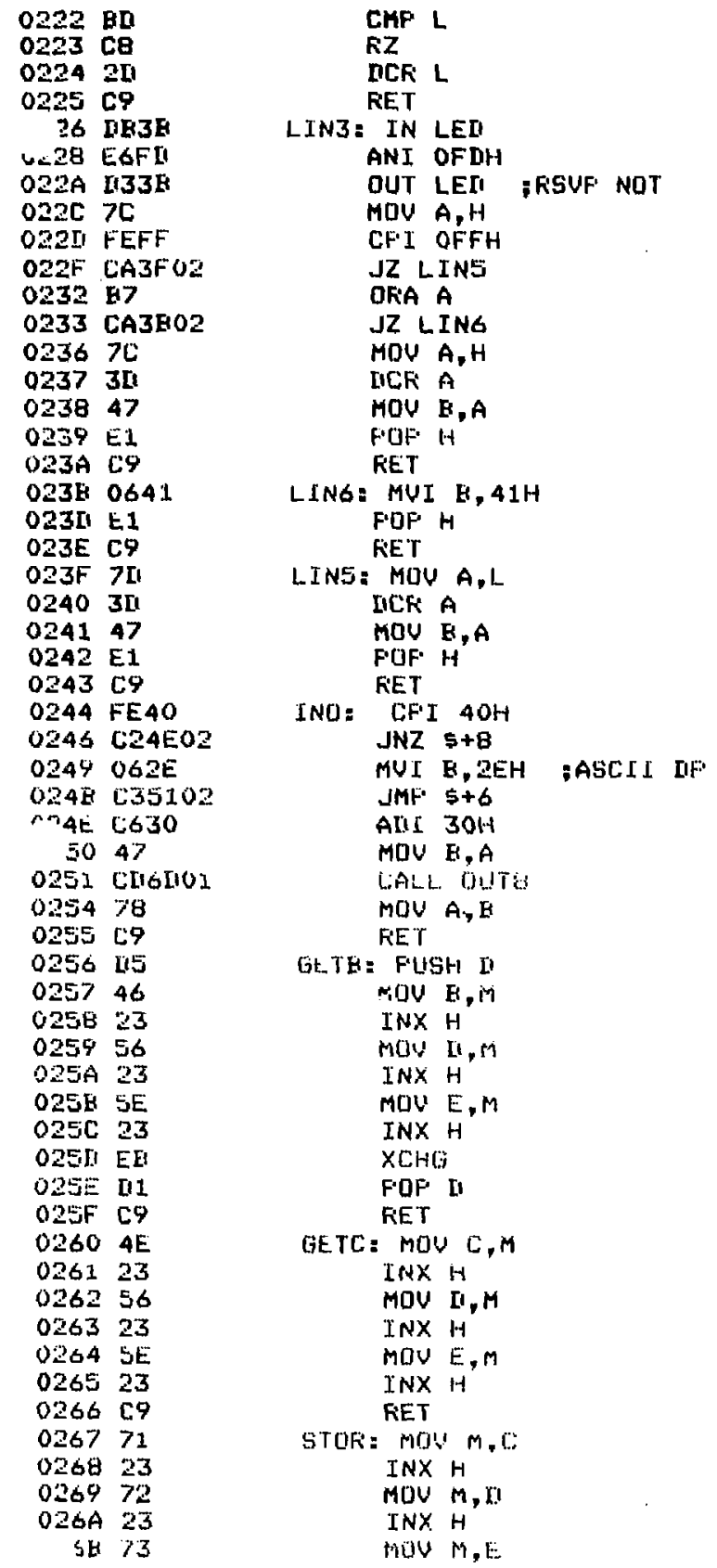




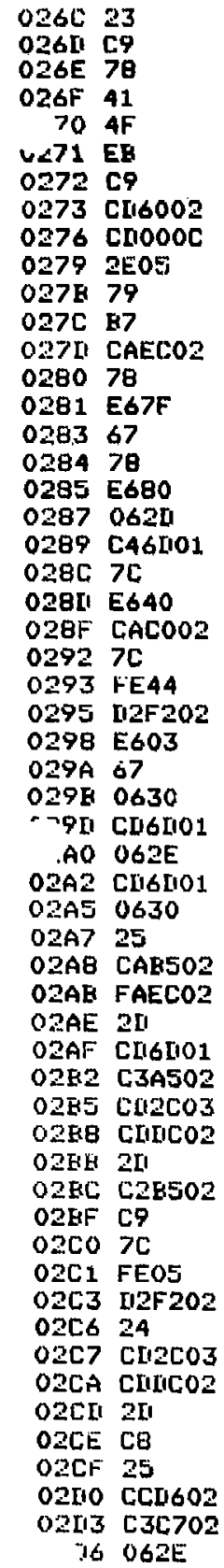

INX H

RET

SWAP: HOU A,B

$\operatorname{MOV} B, C$

MOU $C, A$

XCHG

RET

OUTH: CALL GETC, GET IIATA

OUTE: CALL HEXB , HAKE BCD

OUTI: MUI $L, 5$ i OF DIGITS

HOU A,C

OKA A

JZ ZERO

MOU A, F

ANI 7FH

MOU $H, A$

MOV A, E

ANI $80 \mathrm{H}$

HUI B, $B$

CNZ DUTR

MOU $A, H$

ANI $40 \mathrm{H}$

dZ DUT3

MOU A,H

CFI $44 \mathrm{H}$

JNC OUTF-1 ;FLOAT FT DUT

ANI $03 \mathrm{H}$

MOV $H, A$

MUI $\mathrm{B}, \times O$ '

CALL OUTE

HUI $E, \cdots$

CALL OUTE

OUT1: MUI $\mathrm{B}, \mathrm{O}^{\prime}$

ICK $H$

JZ OUT2

JM ZERO

IICK L

CALL OUTB

JMF OUT 1

DUT2: CALL OUF

CALL IIIGIT

IICF L

JNZ OUT2

RET

OUT3: MOU A,H

CFI 5

JNC DUTF-1 FLLOAT $F T$ OUT INF $\mathrm{H}$

OUTA: CALL DUF2

CALL IIIGI'T

IICK L

KiZ

IICF H

C.Z. OUT:

JMF OUT4

DUTS: MUI E,.". 


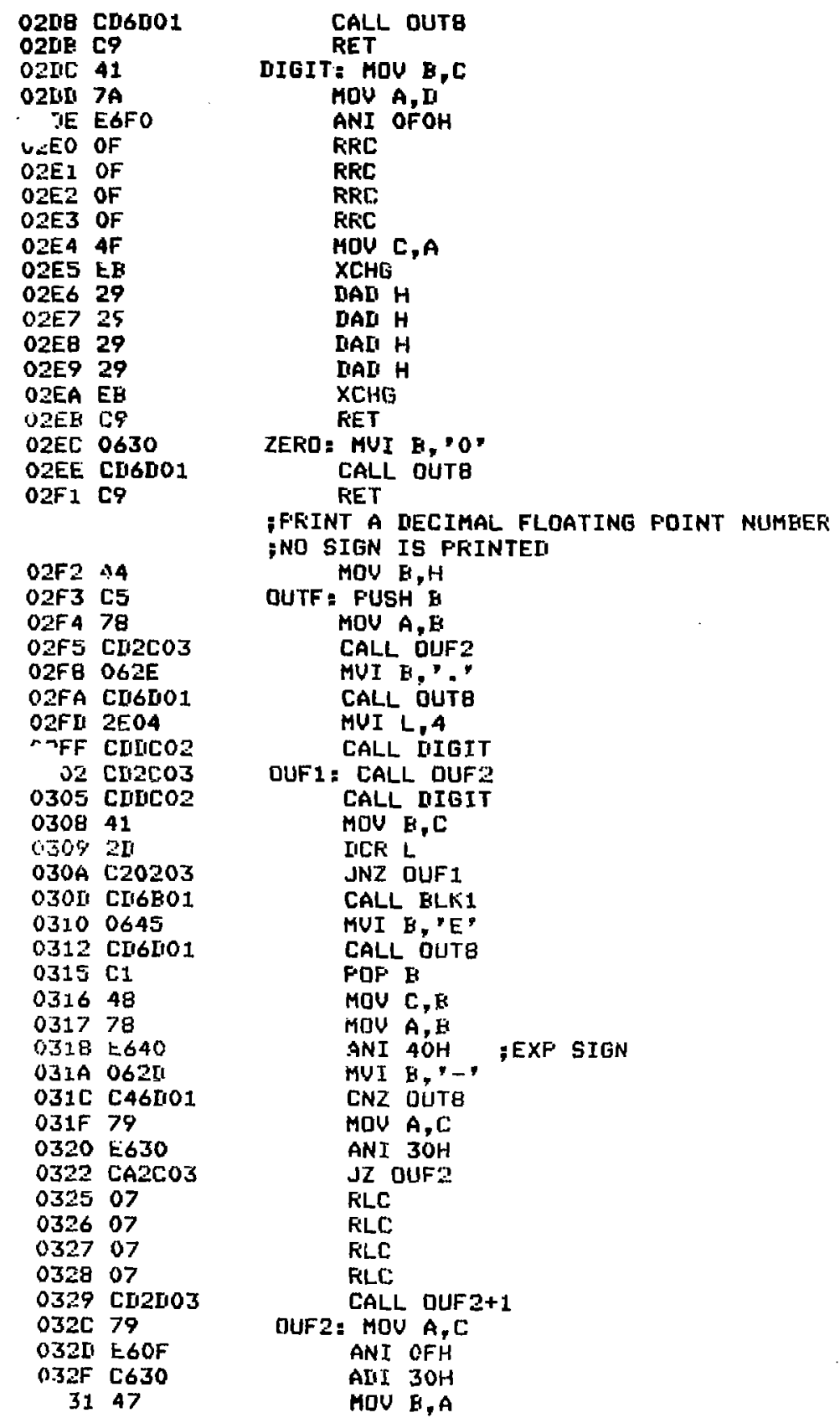




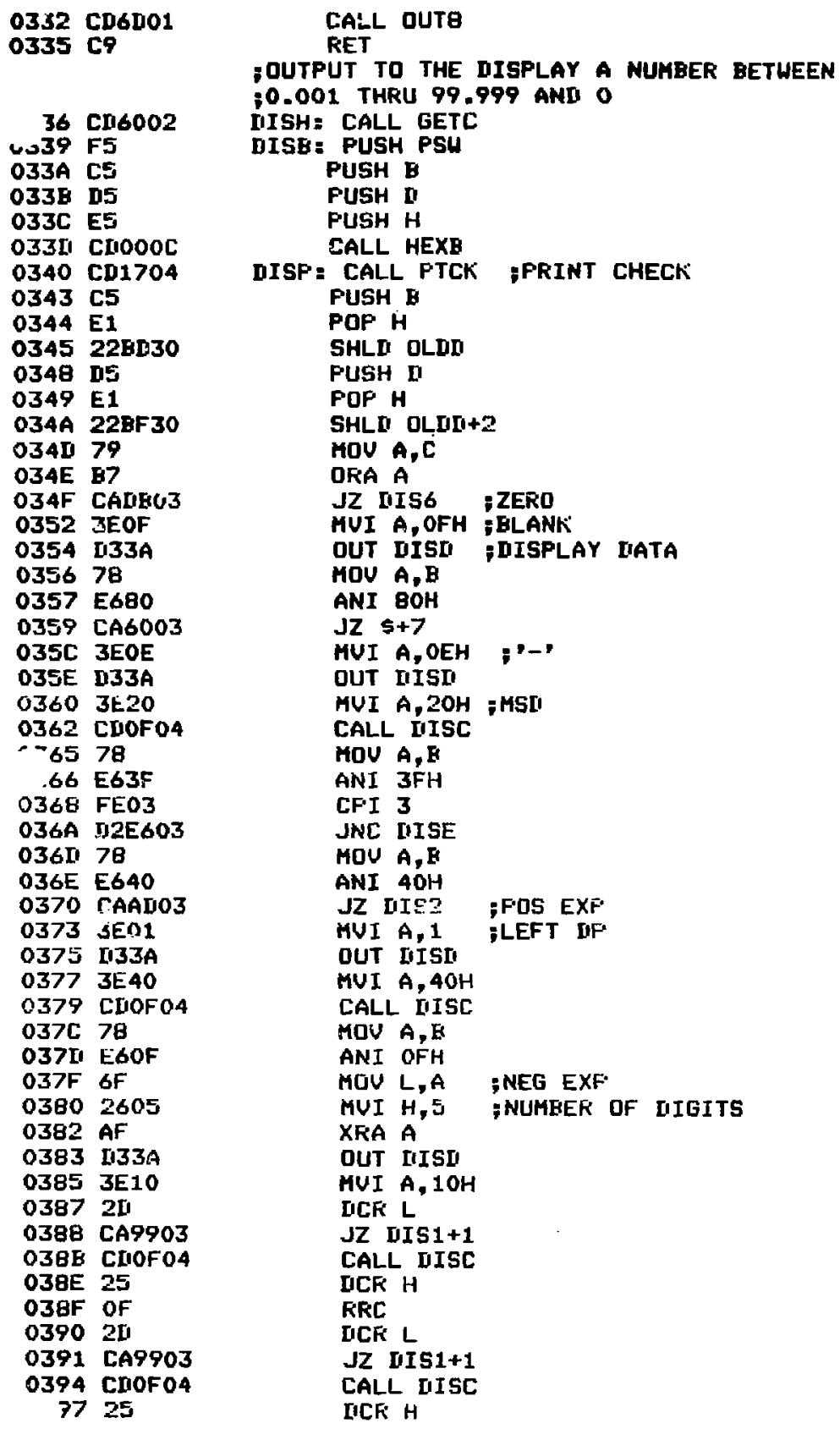




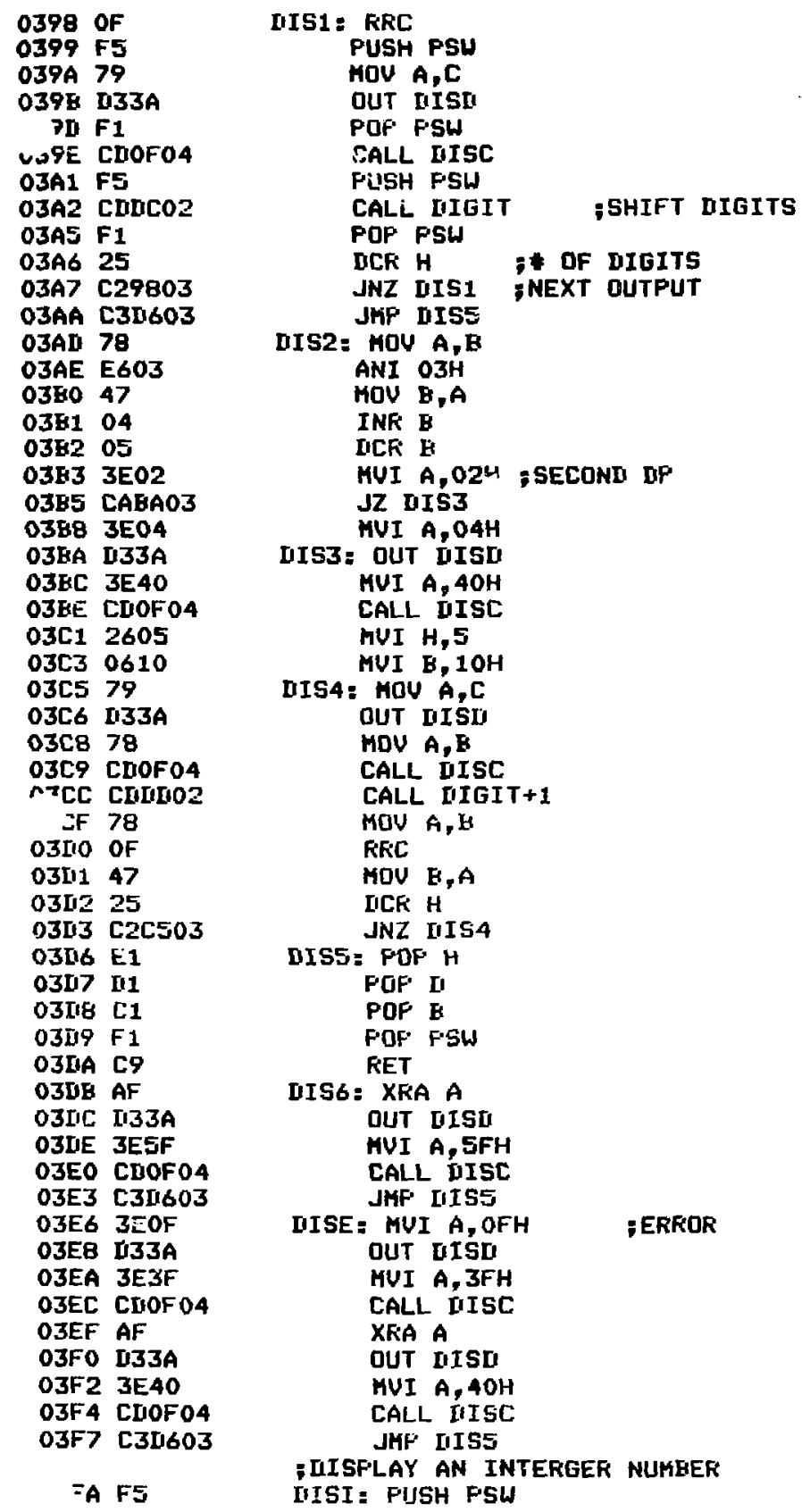




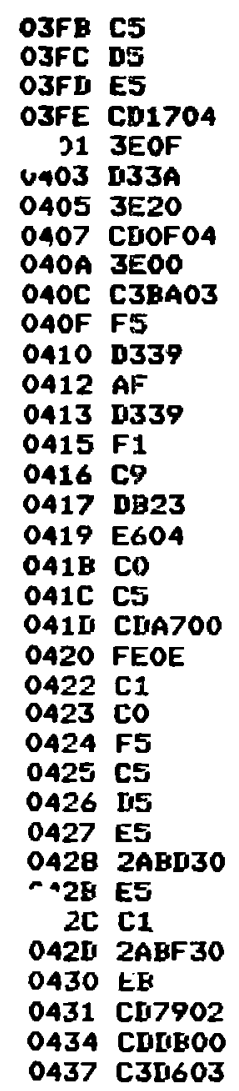

043A E61F

$043 C 11329$

043E F5

$043 F$ IIE3B

0441 F608

0443 1133B

0445 3E85

0447 3I

$0448 \quad 24104$

0448 IIB29

044U F620

$044 F$ I329

0451 E6.1F

$0453 \quad 11329$

0455 JE32

$0457 E 640$

39 CA5504
PUSH B

PUSH y

PUSH H

CALL PTCK

HUI A.OFH

FFRINT CHECK

OUT IISI

HUI A,2OH

CALL IISC

MUI A, 0

JMP DIS3

IISC: PUSH FSU

OUT 39H ,CONTROL PORT

XRA A

DUT 39H

POP PSH

RET

PTCK: IN KST

ANI $04 \mathrm{H}$

RNZ

PUSH E

CALL IN8

CPI OEH IPRINT?

POF $\mathrm{B}$

KNZ

PUSH FSW

PUSH E

PUSH I

PUSH H

LHLII OLII

FUSH H

POF $B$

LHLD OLEII+2

XCHG

CALL DUTI ;FKINT

CALL CFLF

JMF IISS

;GET ANALOG UDLTAGE ANI KETURN IN BI FF

; 'A' CONTAINS MULTIFLEXER INFUT NUMEEK

; OUEFFLUW OF A/I KETURNS FF OF 1FFFH

ATOI: ANI 1FH

OUT HUL

FUSH FSW

IN LED

OKI OBH

DUT LEI

MUI A,133;1 MS DELAY

LCR A

JNZ $\$-7$

IN MUL

OFI $20 \mathrm{H}$

DUT MUL FSTART A/I

ANI 1FH

DUT HUL

AD1: IN $A \bar{I}+1$

ANI $40 \mathrm{H}$

JZ AII FA/D BUSY 


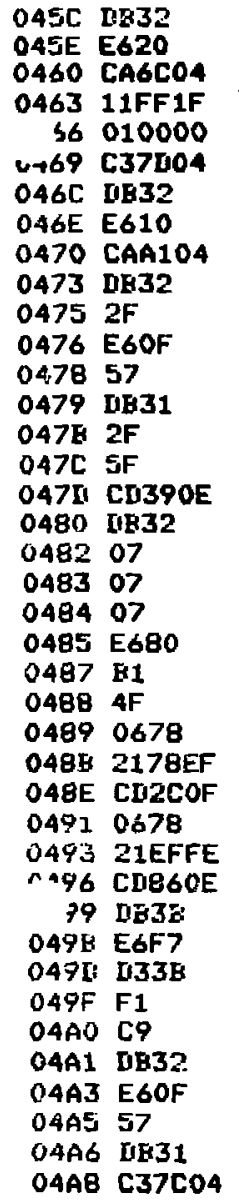

O4AE 328530

OAAE CII97OF

O4B1 218230

0454 C.16702

$04 B 7$ 3EOA

$04 E 9+5$

04BA 3AB:30

O4BII CH1905

$04 C 0 \quad 3 A 8530$

$04 C 3$ FEOO

I5 C2UU04
IN $A D+1$

ANI $20 \mathrm{H}$

$\mathrm{JZ} \mathrm{AD2}$

LXI D, IFFFH BOUERFLOW

LXI $B, 0$

JMP ADB

AI2: IN $A D+1$

ANI 1OH STEN

JZ ALA FPOSITIVE

IN All+1

CHA

ANI OFH \#S BITS

HOU I,A

IN $A D$

CMA

HOV E,A

AD3: CALL FLOT FFP DF A/D

IN $A[1+1$

RLC

RLC:

RLC

ANI $80 \mathrm{H}$-SIGN

ORA C

MOU $C, A$

MUI $B, 78 H$

LXI H,0EF78H ; 4096 FOR 15V FS

CALL MUET

MUI $\mathrm{B}, 78 \mathrm{H}$

LXI H,OFEEFH

CaLL AUU1

IN LED

ANI OF7H

OUT LED

FOF F'SW

KET

AI4: IN AD+1

ANI OFH IMS BITS

MOU D,A

IN AII

JMF ALI3-1

;GET TWD A/LISS ANI MULTIFLY TDGETHEK

;ALSO MULTIFLY BY FOWER CONSTANT

; MAKE 10 MEASUREMENTS ANU AVERAVE ANI UISPLAY THEM

;ASSUKE "E" HULTIFLEX COHES IN 'A'

"ASSUKE ' $I$ " MULTIPLEX $=" E *+1$

F'WF: $=$ STA FLEX

CALL CLK ;ZERO REGISTERS

LXI H,FOWEF

CALL STOR

MUI $A, 10$

FWR 1 : PUSH FSW

LLAA PLEX ; HULTIPLEXEK OUTFUT

CALL FWR3

LIA PLEX ; WHICH COIL?

CPI OOH

JNZ FWK4 


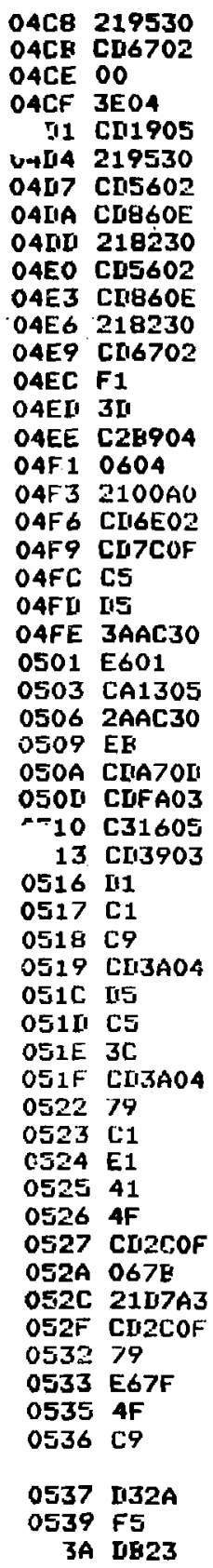

LXI H,HFP CALL GTOR NOP

MUI A, 04H

CALL PUR3

LXI H,HFF

CALL GETE

CALL AIIII IPUR=RT-FWR+LT-FUF

FWR4 : LXI H,FOWEK

CALL GETH

CALL AIIII

LXI H,POWEF:

CALL STOR

POF PSW BNUMEER OF AIIDS

IICR A

JNZ FWR1

MUI $\mathrm{B}, 04 \mathrm{H}$

LXI H,OAOOOH ITEN

CALL SUAF

CALL IIIU

PUSH B

PUSH II

LIIA IICNT

ANI $01 \mathrm{H}$

JZ FWF2

LHLII DCNT

XCHG

CALL BINII

CALL UISI

JHP PUF2+3

FWR2: CALL IIISE FIISFLY ALT FUK \& P'T FOF II

FOF $\mathrm{B}$

RET

FWR3 : CALL ATOI ; MEAS E

FUSH I

FUSH E SAUE MEASUREMENT

INF $A$

CALL ATOI ;MEAS I

MOU $A, C$

FOF $\mathrm{B}$

FOF $H$;GET $15 T$ MEASHY

MOU $\mathrm{B}, \mathrm{C}$

MOU C,A

CALL MULT ; $\mathrm{PHF}=E X I$

MUI $B, 7 E H$

LXI H,OA3LITH ;FWK CONST.

CALL MULT

MOU A,C

ANI 7FH FOSITIVE PUFE ONLY HOU $C, A$ RET

;OUTPUT /A/ TO THE D TO A CONUERTER

ITOA: DUT IIA

FUSH FSW

IN 23H 
053C F610

OS3E D323

0540 EGEF

$0542 \square 323$

$14 \mathrm{Fl}$

U45 C9

1660

1660 C37800

1663 C3A700

1666 C39F01

1669 C36D01

$166 \mathrm{C}$ C3CFOO

$166 \mathrm{~F}$ C3DEOO

1672 C36R01

1675 C36801

$1678 \mathrm{C37302}$

167E C37602

167E C37902

1681 C3F302

$1684 \mathrm{C33603}$

$1687 \quad 033903$

168A C3FAO3

1685 C33A04

$1690 \quad 033705$

1693 C3ABO4

1696 C3BEOS

$1699 \mathrm{C} 35005$

$169 \mathrm{C} \mathrm{C36002}$

169F C35602

- A2 C36702

A5 C36E02

16AB C3C101

16AE C34402

16AE C3AEOO

1640

$1640 \quad 37800$

1643 C36I113

$1646 \quad \mathrm{C3} 7800$

1649 C38008

164C C37800

$164 F \quad C 38607$

1652 C3F009

$1655 \quad \mathrm{C32712}$

1658 C330OE

$165 \mathrm{~B} \quad 30010$

38FF =

$003 A=$

$0039=$

$003 \mathrm{~B}=$

$170 \mathrm{II}=$

$7000=$

$0023=$

$0021=$

$0080=$

$0020=$

$30=$
ORI $10 \mathrm{H}$

DUT 23H LOAD D/A

ANI OEFH

DUT $23 \mathrm{H}$

FOP PSW

RET

ORG $1660 \mathrm{H}$

JMP' EOF:

JMF INB

JHF' INE

JMP OUTB

JMP SCRN

JMP CRLF

JMP BLK1

JMP BLK2

JMP OUTH

JMF QUTB

JMF DUTA

JMF OUTF

JMP DISH

JMP DISE

JHP IIISI

JMP ATOD

JHP ITOA

JMP FUK

JMP SIIEU

JHF AUE

JMF GETC

JMF GETE

JMF" STOFS

JMF SWAF

JMP INSA

JMF IND

JHF INAC

DFG $1640 \mathrm{H}$

COMM: JMF EOF:

JMF INIT

JMP EOF

JMP RUN

JMF EOR

JMF FO

JMF CAL

JHF SPOW

JMF TEST

JMP FRAC

STACK EQU 38FFH

UISII EQU उAH

IIS EQU $39 \mathrm{H}$

LEI EQU 3EH

MSG2 EQU 170 DH

TC EQU $7000 \mathrm{H}$

KST EQU 23H

KEY EQU 21H

ENTK EQU $80 \mathrm{H}$

BSF EQU 20H

HEXE EQU OCOOH 


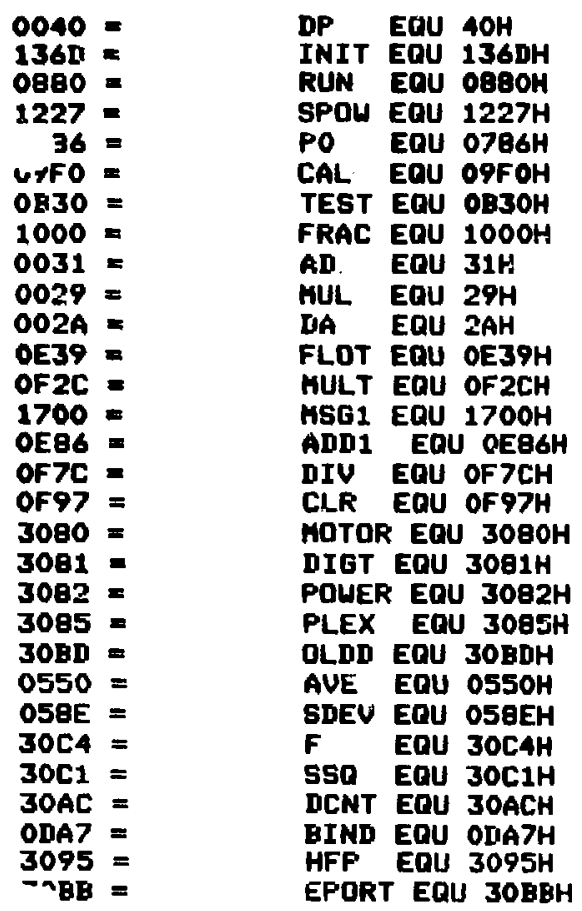




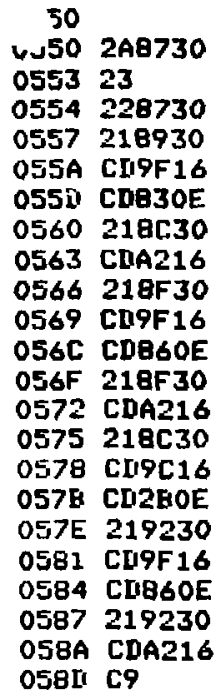

O58E $2 A 8730$ $0591 \mathrm{~EB}$ 0592 CU390E 0595219530 0598 CDA216 059E 218F30 OS9E CUI9F16 OSA1 CUTCOF 05A4 218C30 05A7 CLIA216 OSAA CIIHOE OSAL 219530 O5BO CII9F 16 OSE3 CnZCOF 0586219530 05E9 CIIA216 OSBC $218 C 30$ 05EF CD9C16 OSC2 218930 OSLE CLI9F 16 OSCB CIB30E OSCE 219830 OSCE CIAA216 $05[112 A 8730$ $942 \mathrm{~B}$
- THIS STOKES SUM OF FO-FM \& SUM (PO-FM)SQ iN IS THE MUMBER OF SAMPLES

IASSUME POWER IS IM CDE IN BINARY FP ORG $0550 \mathrm{H}$

AVE: LHLD H

INX $H$

SHLI $N$

LXI H,PO

CALL GETB

CALL SUE 1

LXI H,PI

CALL STOR

LXI H, SUH

CALL GETE

CALL ADIII

LXI H,SUM

CALL STOR

LXI H,PI

CALL GETC

CALL SQ

LXI H,SMSQ

CALL GETH

CALL ALIII

LXI H,SHSQ

CALL STDR

RET

; THIS ROUTINE CALCULATES THE HEAN

FAND THE DEVIATION FROM THE MEAN

F'AUE $=F O-S U M\left(F^{\circ} O-F^{\prime} N\right) / N$

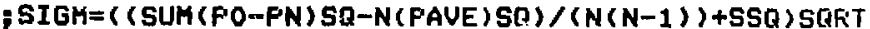

SIEU: LHLI $N$

XCHG

C.ALL FLOT

LXI H, TEMU

CALL STGFi

LXI H,SUM

CALL GETF

CALL IIIV

LXI H,FI

CALL STOK

CALL SQ ; (AVE) SD

LXI H,TEMV

CALL GETE

CALL MULT FN(AVE)SG

LXI H, TEMU

CALL STOR:

LXI H,FI

CALL GETC

LXI H,FO

CALL GETB

CALL SUEI

LXI H, FAVE

CALL STOF FTIRE AUERAGE FOWEF

LHLII $N$; OF SAMFLES

IICX $\mathrm{H}: \mathrm{N}-\mathrm{I}$ 

0652 C22FO

0655 IIE38

0657 E6DF

0659 D338

3A $\mathrm{CP}$

065C AF

065II 32A030

$0660210 F 00$

$0663229 E 30$

0666 OE7D

O66B 11CCCC

066B 21A130

066E CDA216

0671218400

0674224430

0677213017

067A CI6C16

0670 C117516

0680 CnIOF07

$068332 A 030$

0686 FEOA

0688 CA9406

O68B 21E917

O68E CI6C16

0691 C39A06

$069421 E 517$

0697 CI6C16

069A Cn6F 16

-9I 212517

AO CII6C16

06A3 C117516

O6A6 CDOFO7

06A9 IIAE906

06AC CIIFFOC

O6AF CI630E

06E2 EE

06E3 229E30

06B6 CउEF06

O6B9 2A9E30

06BC CL4307

06BF CII6F 16

$06 \mathrm{C2} 211817$

06C5 CII6C16

06C8 CII516

O6CE CLOFO 7

O6CE IIALDOS

06III CIFFOC

$06 I 421 A 130$

06 II7 CIIA216

O6IIA C3E30G

OGDI $21 A 130$

O6EO CU7816

06E3 CLGF16

06E6 211317

$\equiv$ CD6C16
JNL DELO GNOT TIHE

IN LED

ANI OTFH

OUT LEII

RET

GGET ANI STOKE POWER PROMF'TS

FKIMT : XFIA A

STA FLAG1

LXI H,1S DEFAULT TIME.

SHLII TIHE

MUI C, 7DH

LXI II, OCCCCH FIJEAULT SIGMA=0.1

LXI H,SIGF

CALL STOR

LXI H.1BO ;IIEFAULT \&IF/FUN

SHLI DAFT

LXI H,MSG6 FFRINT ALL?

CALL SCRN

CALL BLK2

CALL RSUF

STA FLAG 1

CPI YES

JZ F'RMO

LXI H, HSGQ ;NO

CALL SCEN

JHF' F'RMI1

FFitio: LXI H,MSGF ; YES

CALL SCFN

FFMM1: CALL CFILF LXI H, HSGS ;IIELAY-MIN

CALL SCFNN

CALL ELKK?

CALL F'SUF

JC F'F'M2

CALL HCLIH

CALL FIXX

XCHG

SHLL TIME

JMF FRMOZ

FR'M2: LHLII TIME

CALI. DUT $Y$

FFIM3: CALL CFILF

LXI H,MSG4 ,SIGMA-X

CALL SCRN

CALL BLKZ

CALL RSUF

JC F'RMA

CALL BCIIH

LXI H,SIGF

CALL STOR

MHir FRMS

PRIMA : LXI H,SIGF CALL DUUTH

FRIHS: CALL CFILF

LXI H, MSG3 ; \#IF/ /FUN

CALL SCFN 


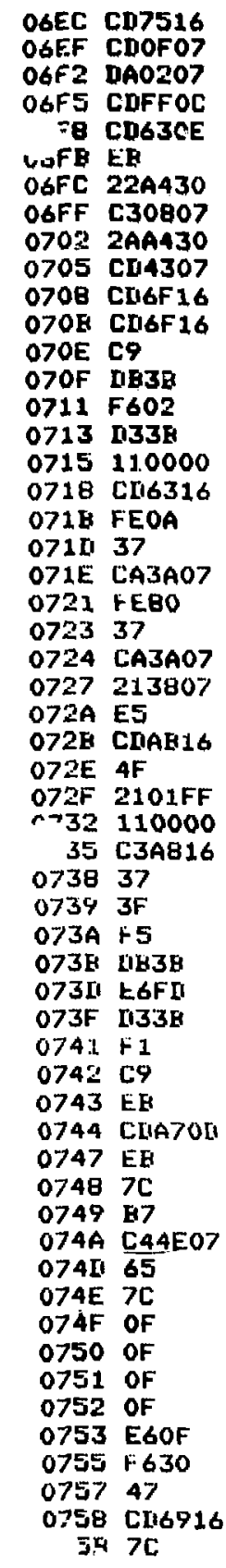

CALL BLK2

CALL RSUP

JC PRMG

CALL BCDH

CALL FIXX

XCHG

SHLI IIAPT

JMF PRM7

PRM6: LHLI IIAPT

CALL OUTI

PRH7: CALL CRLF

CALL CRLF

RET

RSUP: IN LED

ORI O2H

OUT LEI

LXI D, O

CALL INB

CFI YES

STC

JZ RSUI

CPI ENTR

STC

JZ FSU1

LXI H,RSU2

PUSH H FRETUKN ALIIKESS

CALL INO

MOU $C, A$

LXI H,OFFO1H

LXI 10,0

JMF INEA

RSU2: STC

CMC

FSU1 : FUSH FSW

IN LED

ANI OFIH

OUT LEII

FOF F.SW

RET

DUTI: XCHG

CALL ECII

XCHG

MOU A, H

DFA A

CNZ OUT1

MOU $\mathrm{H}, \mathrm{L}$

DUT1: $\operatorname{MOV} A, H$

RKC

FRRC

FFEC

FRR:

ANI OFH

ORI $30 \mathrm{H}$ MAKE ASCII

MOU $\mathbf{E}, \boldsymbol{A}$

CALL UUTB

HiOU $A, H$ 


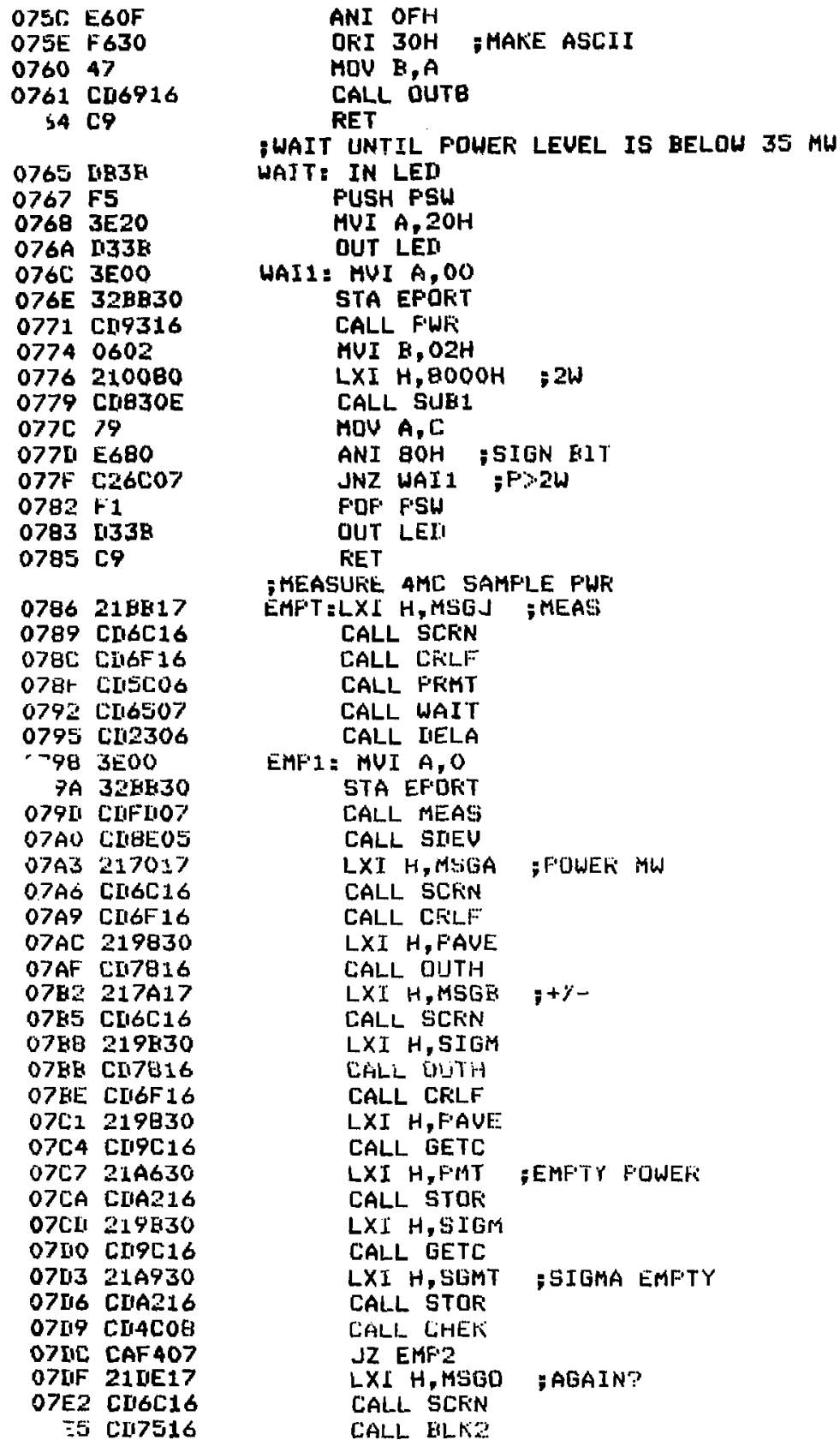

ANI OFH

OFI $30 \mathrm{H}$ HAKE ASCII

MDV $B, A$

CALL DUTB

RET

- WAIT UNTIL POWER LEUEL IS BELOW $35 \mathrm{MW}$

WAIT: IN LED

PUSH PSW

HUI A, 2OH

OUT LEI

WAI1: MUI A, 00

STA EPÓRT

CALL F'WF

MUI $\mathrm{B}, \mathrm{O} 2 \mathrm{H}$

LXI H,800OH $; 2 \mathrm{~W}$

CALL SUE1

MOU A, C

ANI $80 \mathrm{H}$ \#SIGN EIT

JNZ WAI1 ;P\$2W

FOF F'SW

OUT LEI

RET

- MEASUFE 4MC SAMFLE PWF

EMFT:LXI H,MSGJ ;MEAS

CALL SCEN

CALL CFILF

CALL PFHT

CALL WAIT

CALL IIELA

EMF1: MUI $A, O$

STA EF'DFT

CALL MEAS

CALL SIIEV

LXI H,MLGA \#FOWEK HW

CALL SCFIN

CALL CF'LF

LXI H,FAUE

CALL DUTH

LXI H,MSGB ;+\%-

CALL SCKN

LXI H,SIGM

CALL UUTH

CALL CRLF

LXI H,F'AUE:

CALL GETC

LXI H,FIT ;EMFTY FOWEF

CALL STOR:

LXI H,SIGM

CALL GETC

LXI H,SLMT ;SIGMA EMFTY

CALL STOR

CALI CIHEKK

JZ EMF'2

LXI H, MSGO \#AGAIN?

CALL SCFN

CALL BLKE 


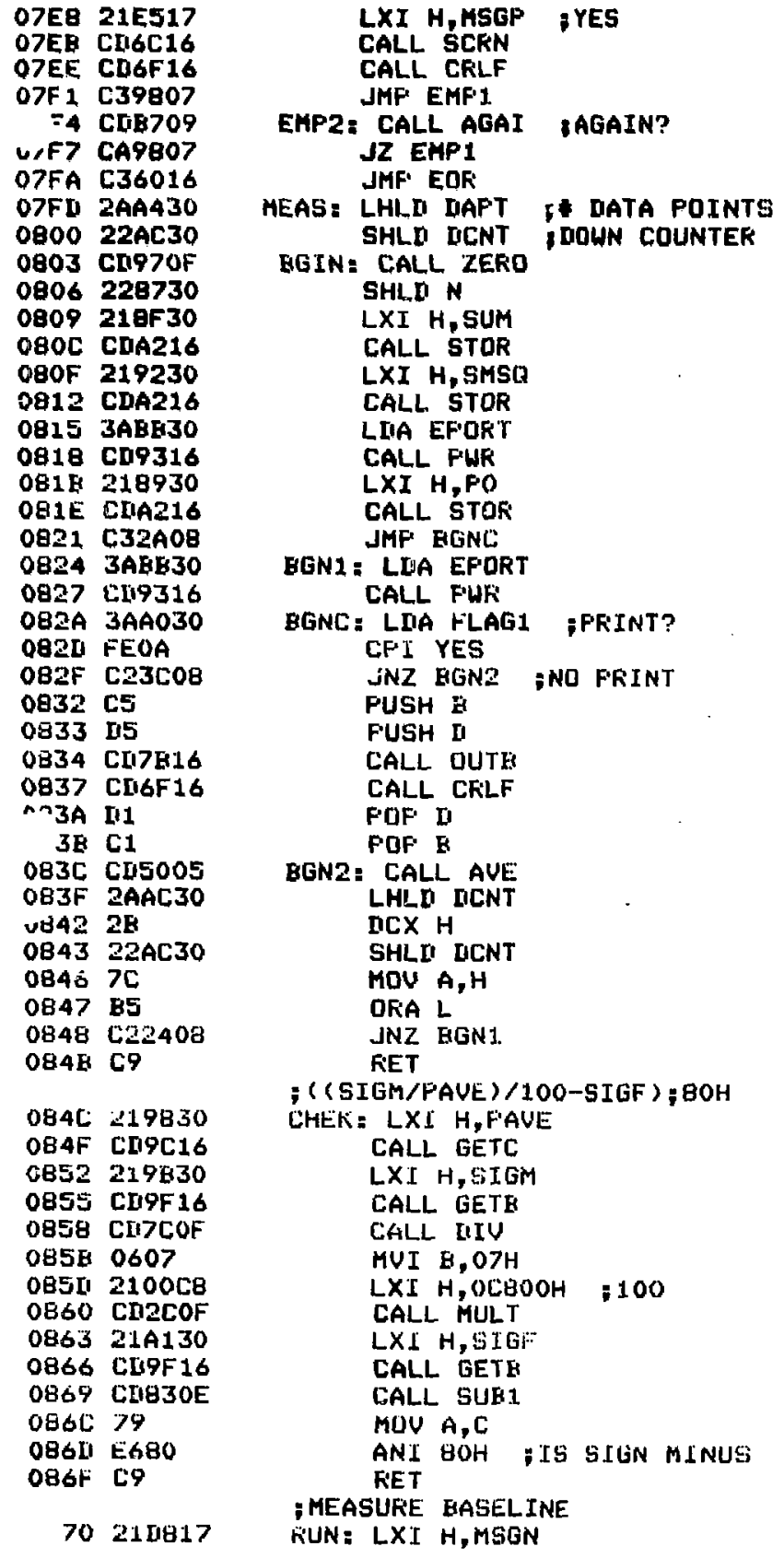


0873 CI6C16 0876 CD7216

$087921 \mathrm{BE} 17$

087C CJ6C16

7F CDGF 16

U882 CL5C06

0885 C 16507

088 CL12306

088B CI1940B

OBBE CALCOE

0891 C3C708

$08943 E 00$

$089632 B B 30$

0899 CIIFI107

O89L CLIBEOS

089F 21J817

08A2 CD6C16

08A5 217017

OBAB CULC 36

OBAE CLI6F16

OBAE 219830

OBE1 CD7816

08E4 217A17

0887 CII6C16

O8BA 219B30

OAHI CI7816

$08 C 0$ CLIGF 16

OBC3 CLIACOB

08C6 C9

"C7 21LE 17

CA CII6C16

08CII CII7516

OBIIO 21E517

0813 CL6C16

0816 CIBF 16

0819 C38Lios

OBIIC 217017

O8IF CH6C16

OBE? CLIGF16

OQEE 21A630

OBER CLI9C16

OQEE 219830

OBEE CIIFF 16

O8F 1 CDI830E

OBF 4 21C430

ORF7 CLI9F 16

OBFA CII2COF

OBFI Z1AE30

0900 CIIA216

0903 CU7E16

0906 Cl16F 16

$0909216[117$

090C CD6C16

$090 \mathrm{~F} \mathrm{CII7216}$

$091221 \mathrm{E317}$

(5) CISC 16
CALL SCRN

CALL ELKI

LXI H,MSGJ

CALL SCRN

CALL CFILF

CALL FFIMT

CALL WAIT

CALL IIELA

RUNO: CALL RUNI

JZ RUNZ

JMP RUN3

RUN1: MUI A,O

STA EFORT

CALL MEAS

CALL SIEV

LXI H,MSGN

CALL SCFN

LXI H,MSGA \#POWER MW

CALL SCFIN

CALL CFILF

LXI H,F'AUE

CALL OUTH

LXI H, MSGE ;+/-

CALL SCRN

LXI H,SIGM

CALL OUTH

CALL CFILF

CALL CHEK

RET

RUN3: LXI H,MSGO ;AGAIN?

CALL SCFIN

CALL ESKR

LXI H,MSGF ; YES

CALL SCEN

CALL CF'LF

JMF" RUNO

FUN2: LXI H,MSGA FPOWER HW

CALL SCFN

CALL CFILF

LXI H,FMT

CALL GETC

LXI H, FGUE

CALL GETE

CALL SUEI

LXI $H, F$

CALL GETS

CALL MULT

LXI H,PMEA ;F MEASURE

CALL STOF

CALL OUTI:

CALL CELF

LXI H,MSG FFU

CALL SCFN

CALL BLKJ.

LXI H, MSGH+I ;G

CALL SCKN 


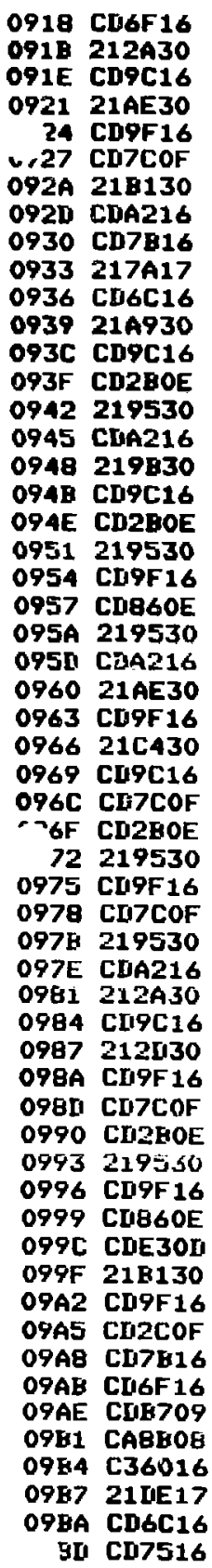

CALL CRLF

LXI H, AUSF

CALL GETC

LXI H,PHEA

CALL GETB

CALL IIIU

LXI H,MASS

CALL STOK :(PO-PH)/SF"

CALL DUTB

LXI H,HSGB ;+/-

CALL SCRN

LXI H,SGMT

CALL GETC

CALL $\mathbf{5 a}$

LXI H, TEKV

CALL STOF

LXI H,SIGH

CALL GETC

CALL SQ

LXI H,TEKU

CALL GETB

CALL AIUII

LXI H, TEKV

CALL STOK

LXI H, PHEA

CALL GETE

LXI H,F

CALL GETC

CALL IIV

CALL SR

LXI H,TEMV

CALL GETB

CALL IIIV

LXI H,TEMU

CALL STOK ;((SGKT)SQ+(SIGM)SQ)/(FHEA); 2

LXI H, AUSF

CALL GETC

LXI H, SGSF

CALL GETE

CALL IITU

CALL $5 Q$

LXI H,TEMU

CALL GETE

CALL ALUI

CALL SQRT

LXI H, MASS

CALL GETH

CALL MULT

CALL OUTE

CALL CFILF

CALL AGAI ;AGAIN?

JZ FUNO

JHF EOF

AGAI: LXI H,MSGO ;AGAIN

CALL SCRN

CALL BLK? 


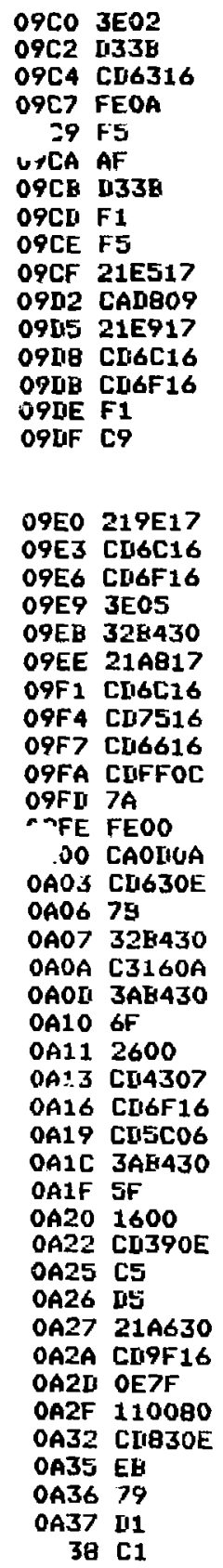

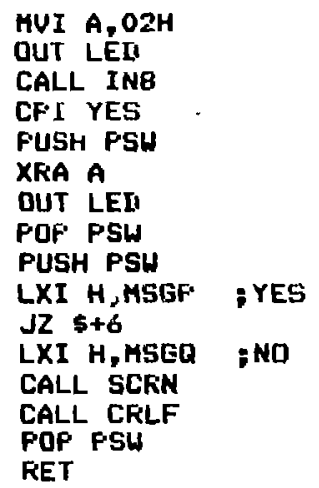

CALL SCRN

CALL CRLF

HUI $A, 5$

STA CLFT

LXI H, MSGG GCAL FNTS

CALL SCKN

CALL BLK2

CALL INS

CALL ECIH

MOU A, II

CF'I 0

$J Z$ CALO

CALL FIXX

MOU $A, E$

STA CLFT JMF CALI

CALO: LIIA CLFT

MOU $L, A$

HUI $\mathrm{H}, \mathrm{O}$

CALL QUTI

CAL1: CALL CRLF

L.ALL FFT̃MT

LIIA CLFT

MON $E, A$

MUI $I, 0$

CALL FLOT

FUSH B

PUSH II

LXI H,FMT

CALL GETE

MUI $C, 7 F H$

LXI $\amalg, 8000 \mathrm{H} \quad 0.25 \mathrm{~W}$

rALL SUE1

$\therefore=H G$

MOU A, C

POF II

FOF $\mathrm{B}$ 


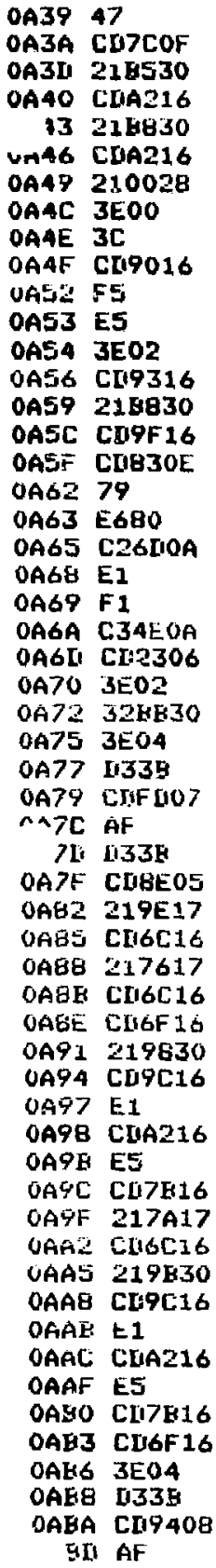

MOU B.A

CALL IIV B (PMT-0.25W)/CLFT

LXI H,FSTP

CALL STOR

LXI H,FSET

CALL STOR

LXI H,CALS

MUI $A, 0 O H$, QUEKCOME IIOLE UROF

CAL2: INK A

CALL DTOA

FUSH F.SW

PUSH $H$

MUI A,O2H :CALI VOLTAGE

CALLL PUR

LXI H,FSET

CALL GETE

CALL SUB1, FSET-FOUT

MOU A,C

ANI $80 \mathrm{H}$

JNZ CAL3

FOF $H$

FDF FSU

JMF CAL?

CAL3: CALL DELA

CALS: MUI A,02H, CAL VOLTAGE

STA EFOKT

$M V I, A_{1}, \mathrm{HH}$

DUT LEII

CALL MEAS

XRA A

DUT LETI

CALL SUEU

LXI H, MSGF "CALIHFATE

CALL SCFIM

$L X \perp H$, MSGA+6 ; thW

CALL SCFIN

CAALL CFILF

LXI H,FAUE

CALL GETC

FOF $t$

CALL STOF:

FUSH H

CALL OUTE

LXI H,MSGB ;+i-

CALL SCKN

LXI H,SIGM

CALL GETC

POF' $H$

CALL STOF:

FUSH H

CALL OUTE

CALL CKILF

CAL4: MUI A, O4H

OUT LEII

CAL: RIUN:

XF'A $\mathrm{Ft}_{t}$ 


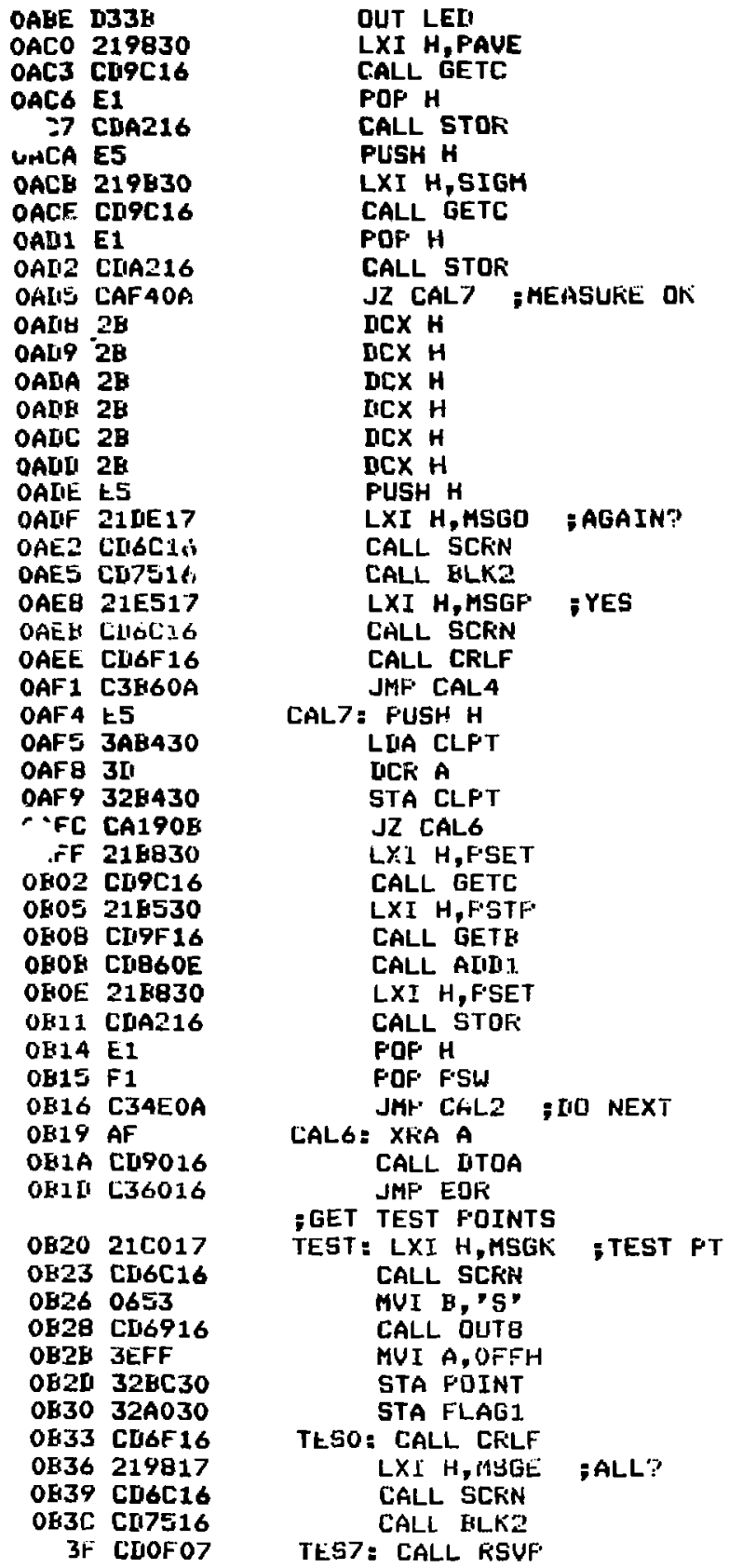




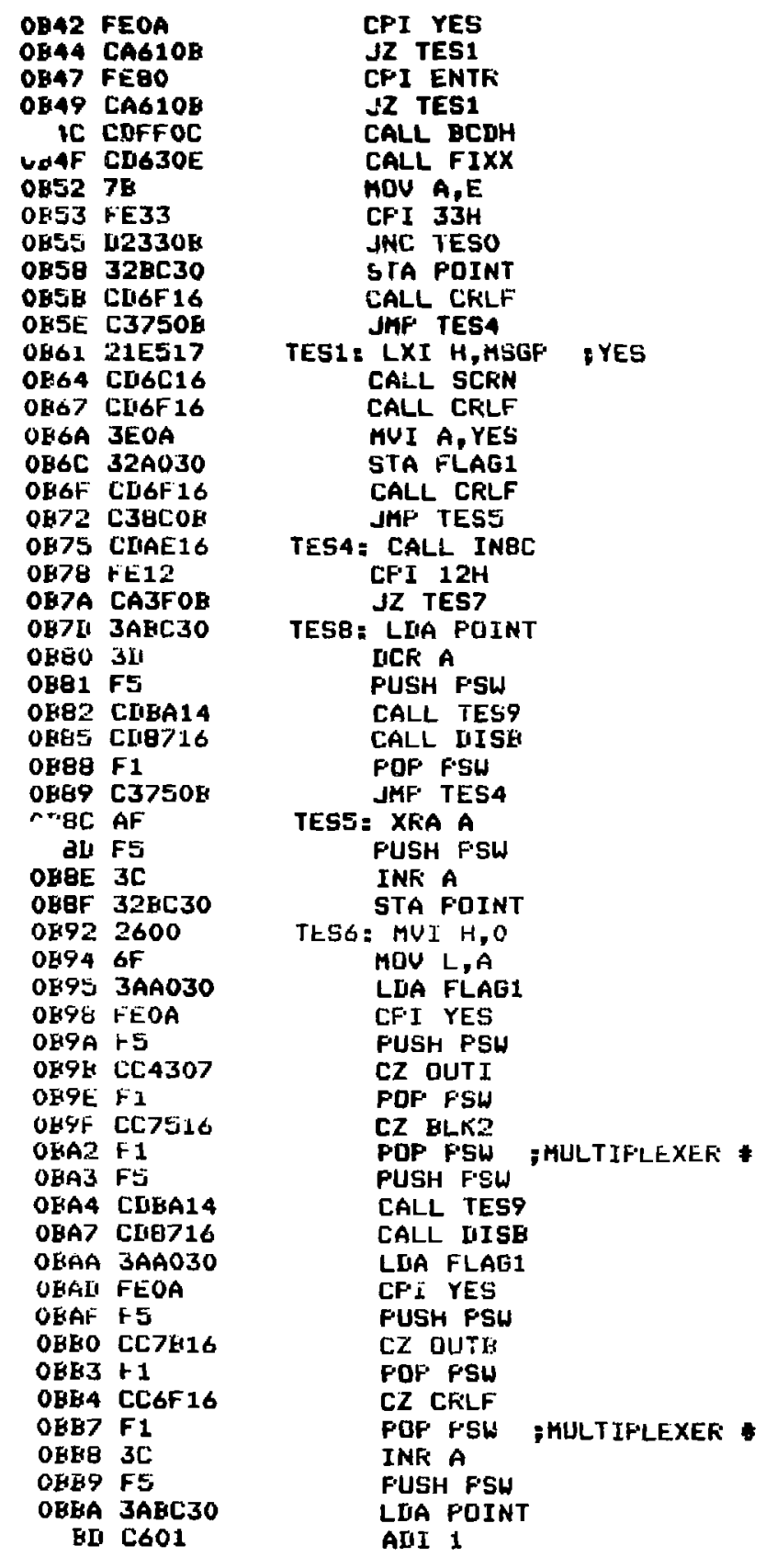




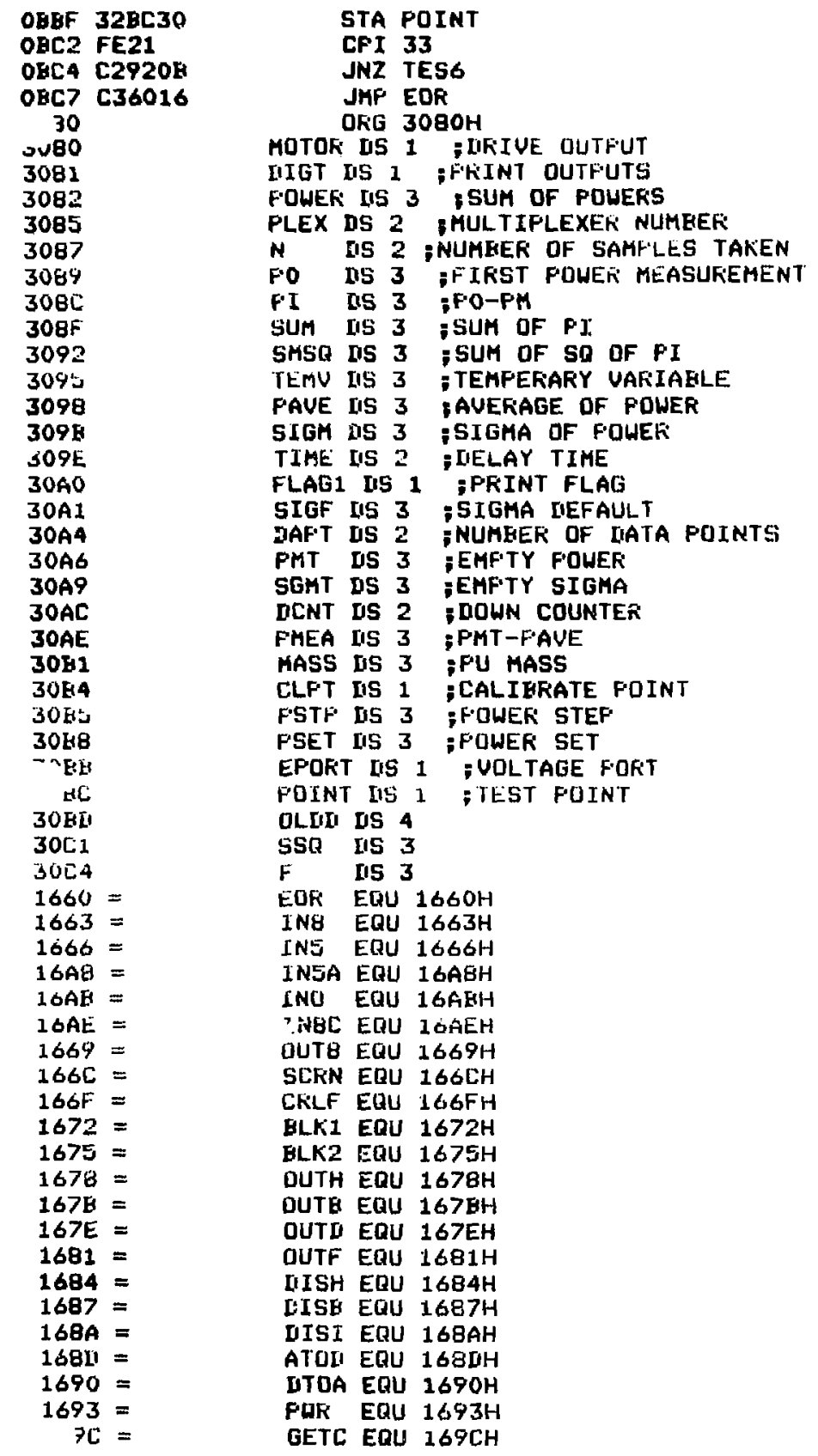




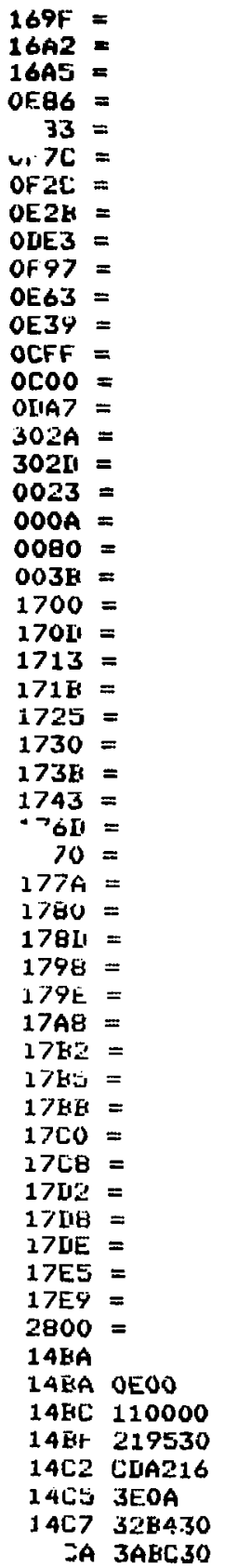

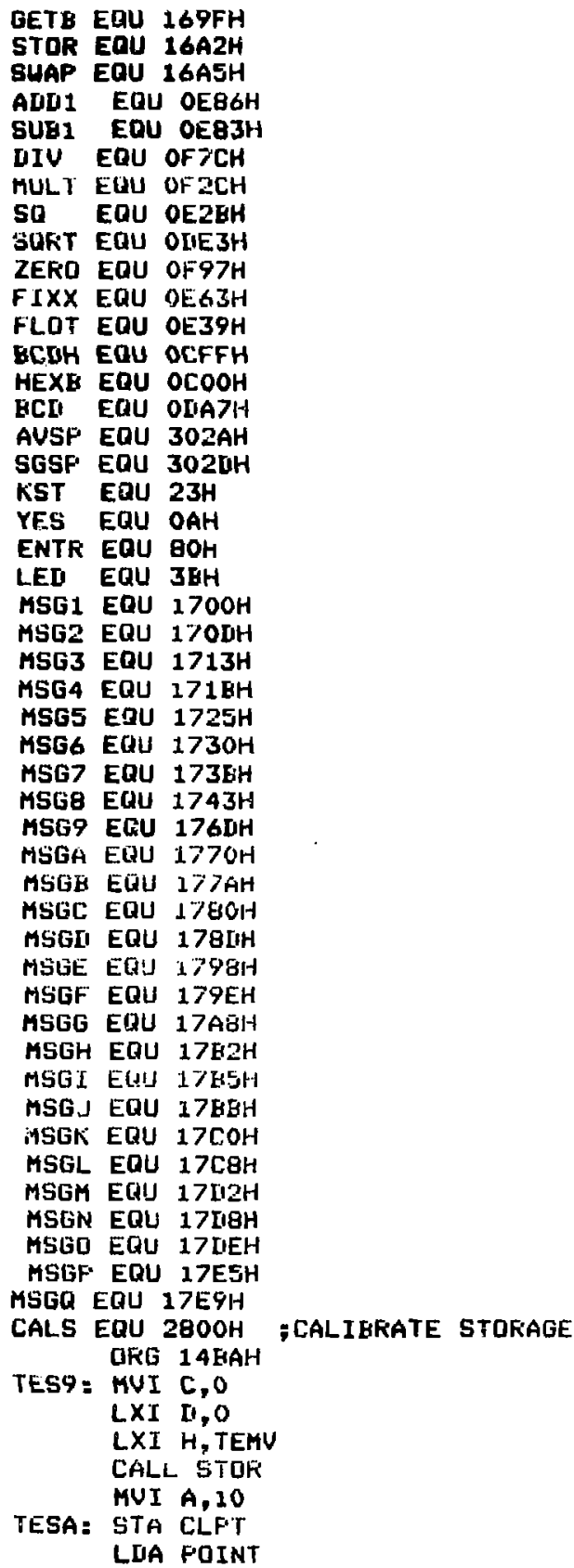




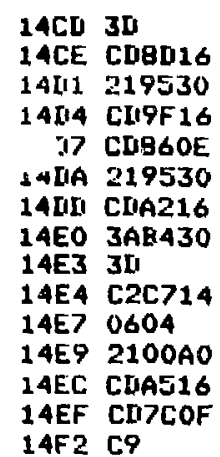

$14 C 035$

14CE CDQD16

219530

17 CUB6OE

$14 E 4$ C2C714

$14 E 7 \quad 0604$

14EF CD7COF

14F2 C9
DCF A

CALL ATOI

LXI H,TENU

CALL GETB

CALL AIIDI

LXI H,TENU

CALL STDF

LDA CLFT

DCE A

JNZ TESA

HUI $B, O 4 H$

LXI $\mathrm{H}, \mathrm{OAOOOH}$

CALL SWAP

CALL DIV

RET 
TYFE DXR

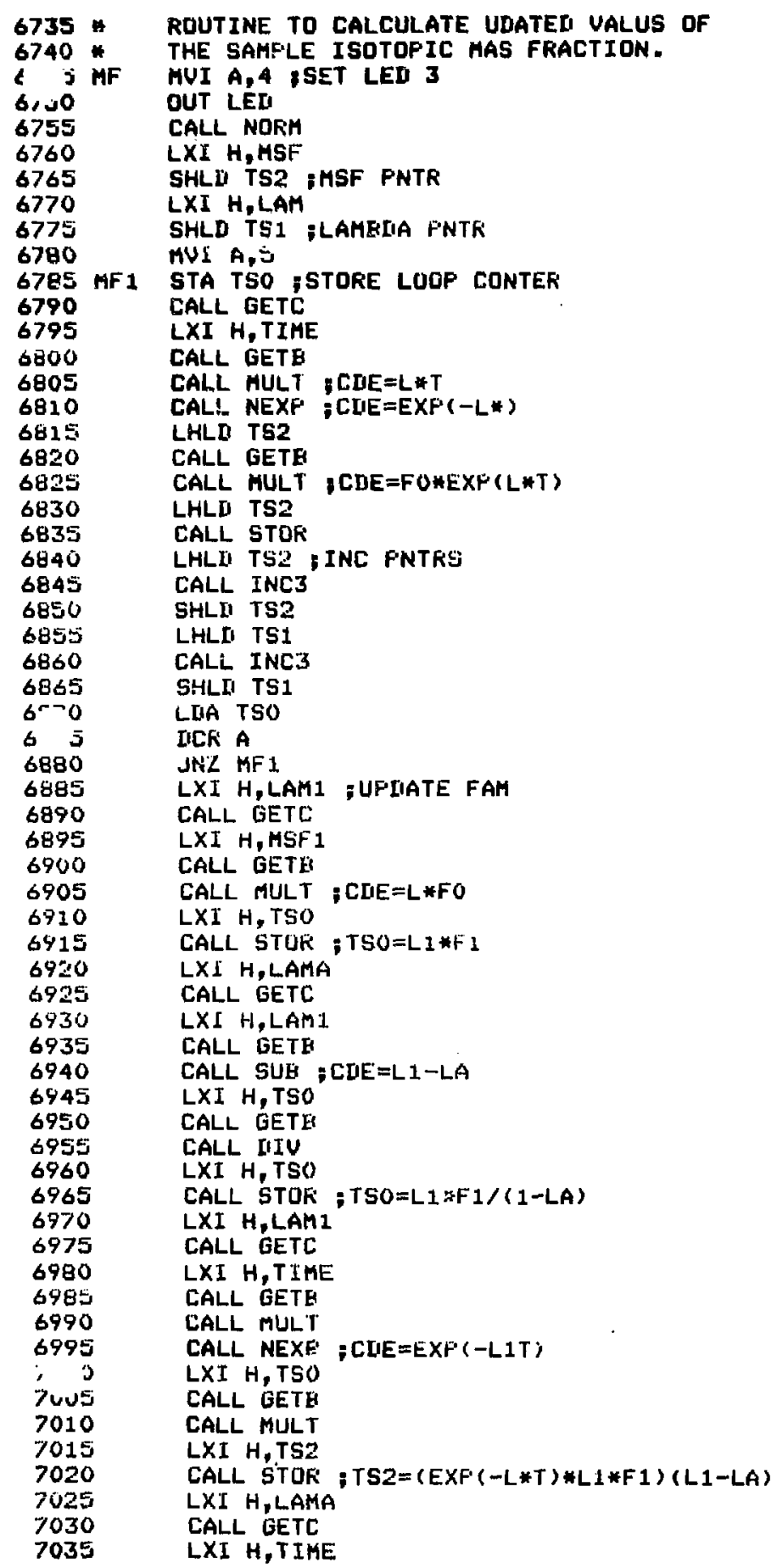




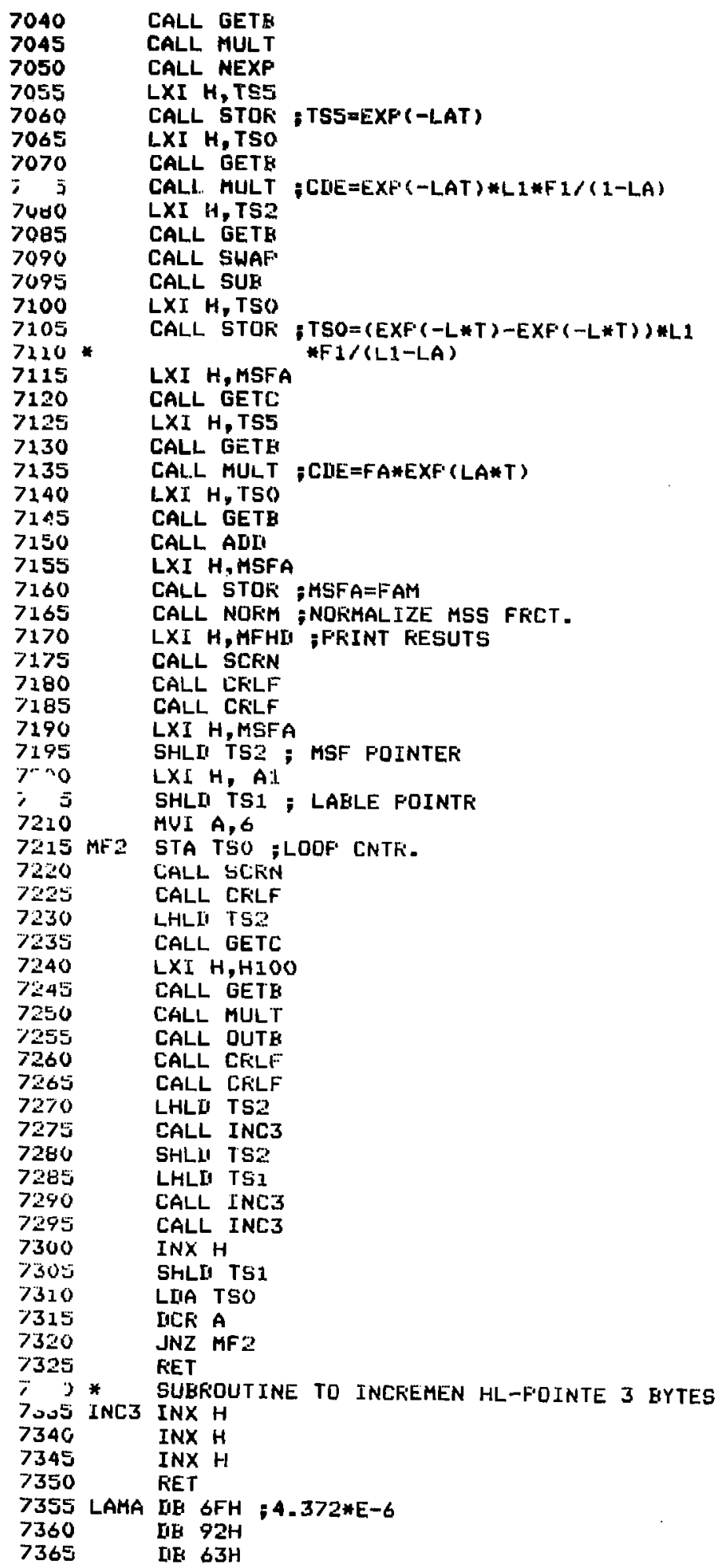




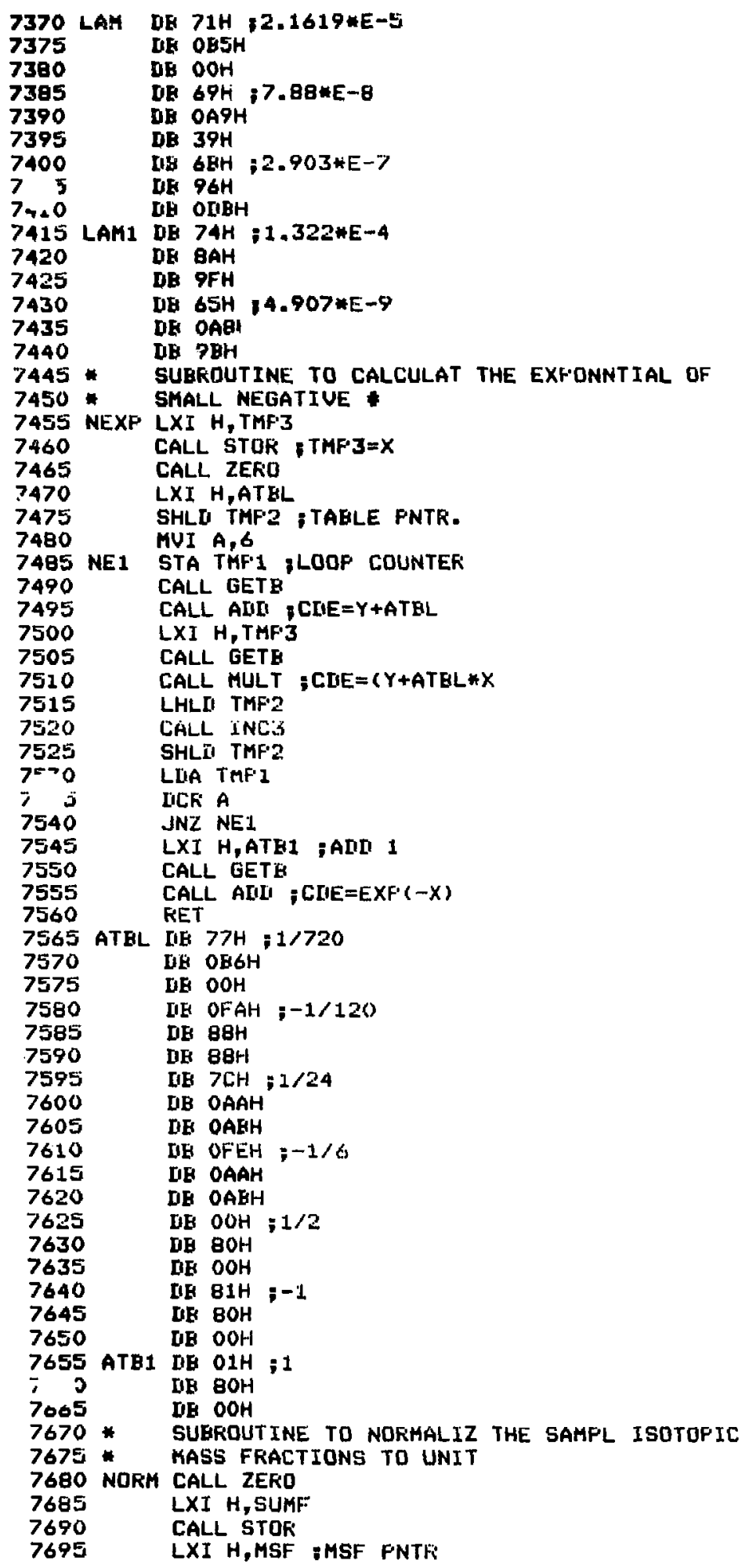




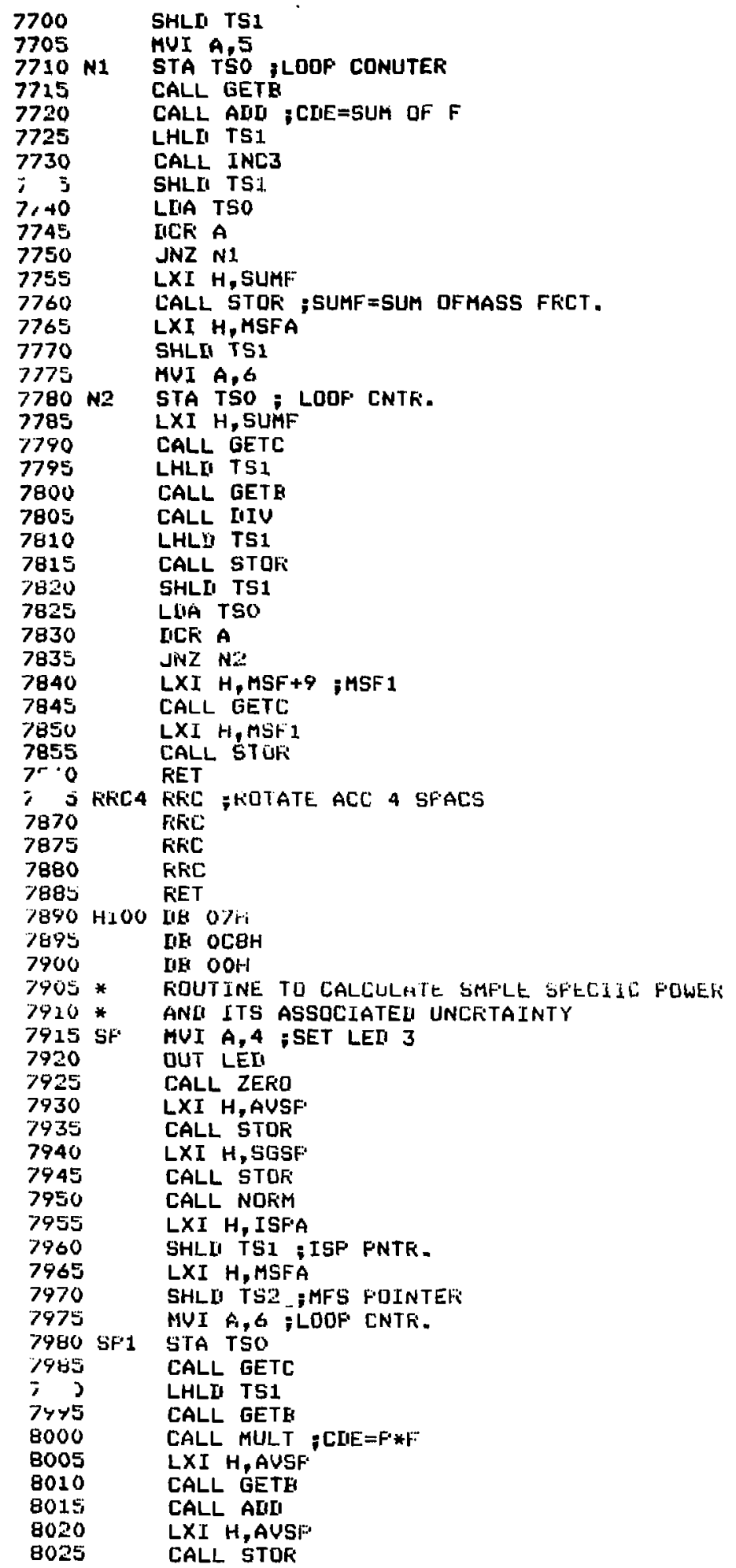




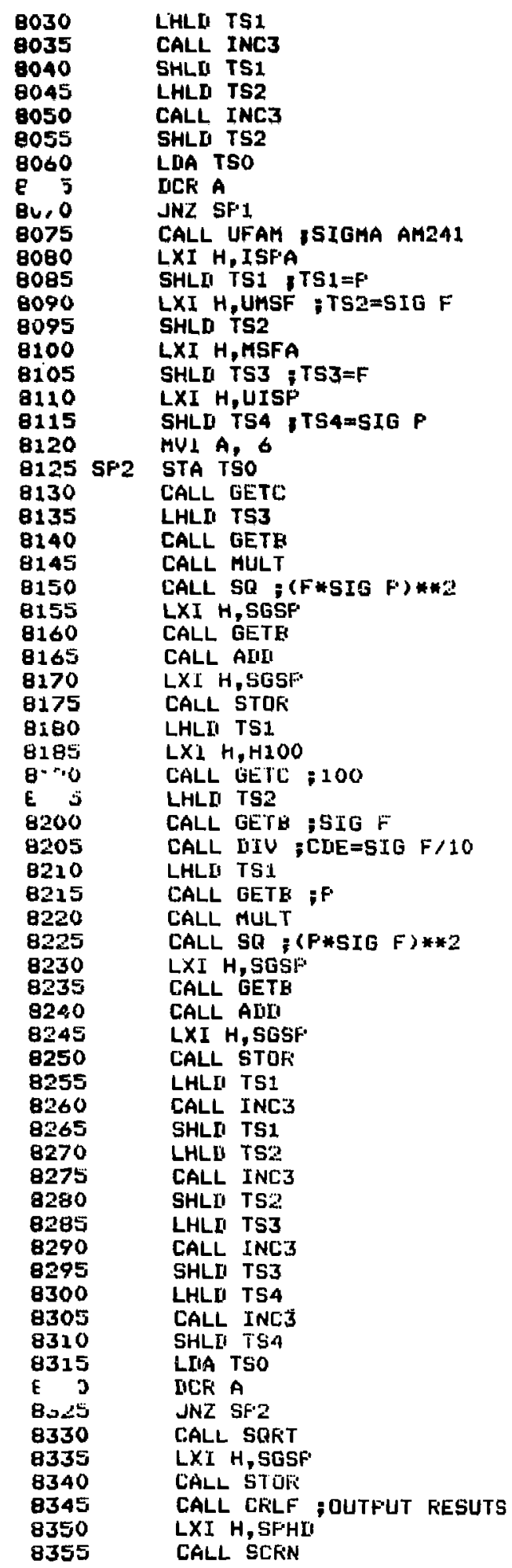




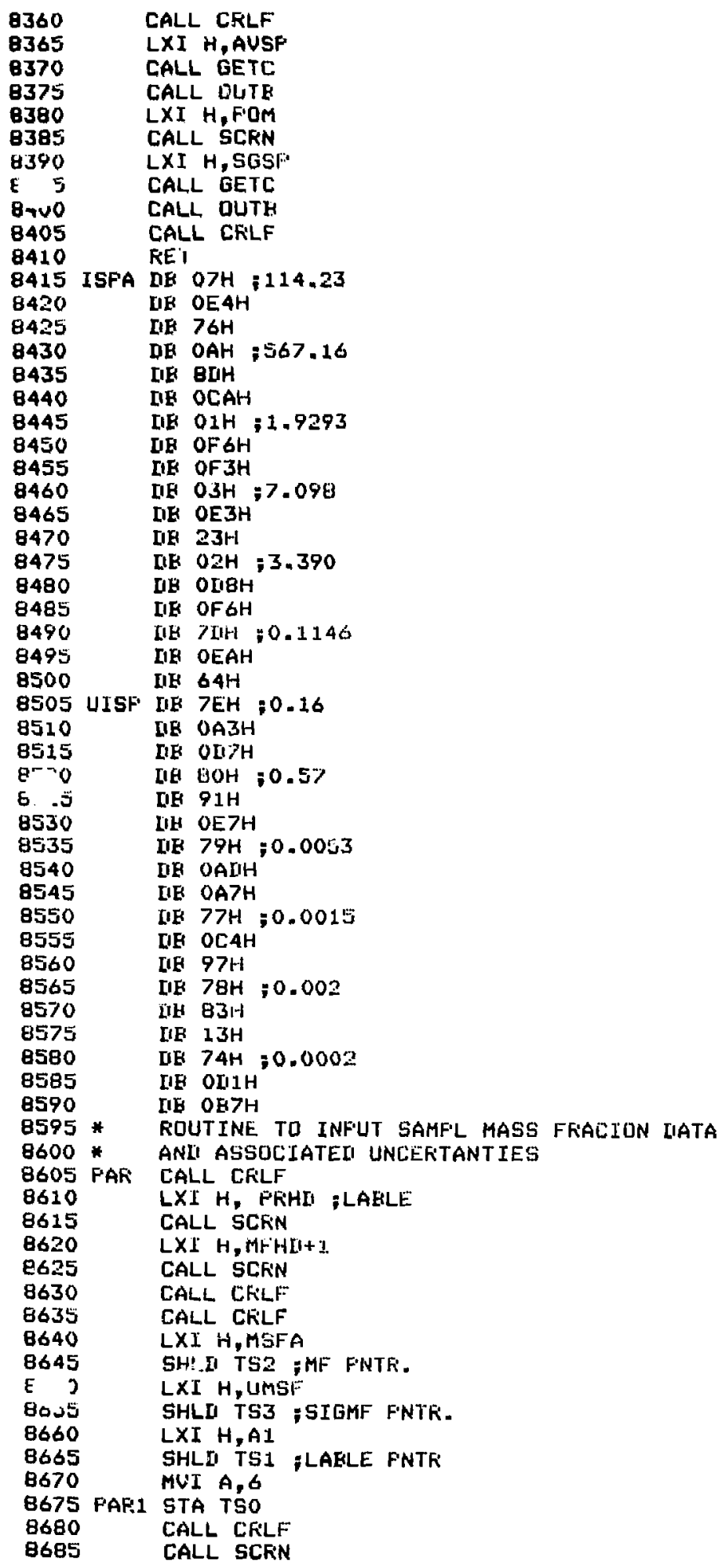




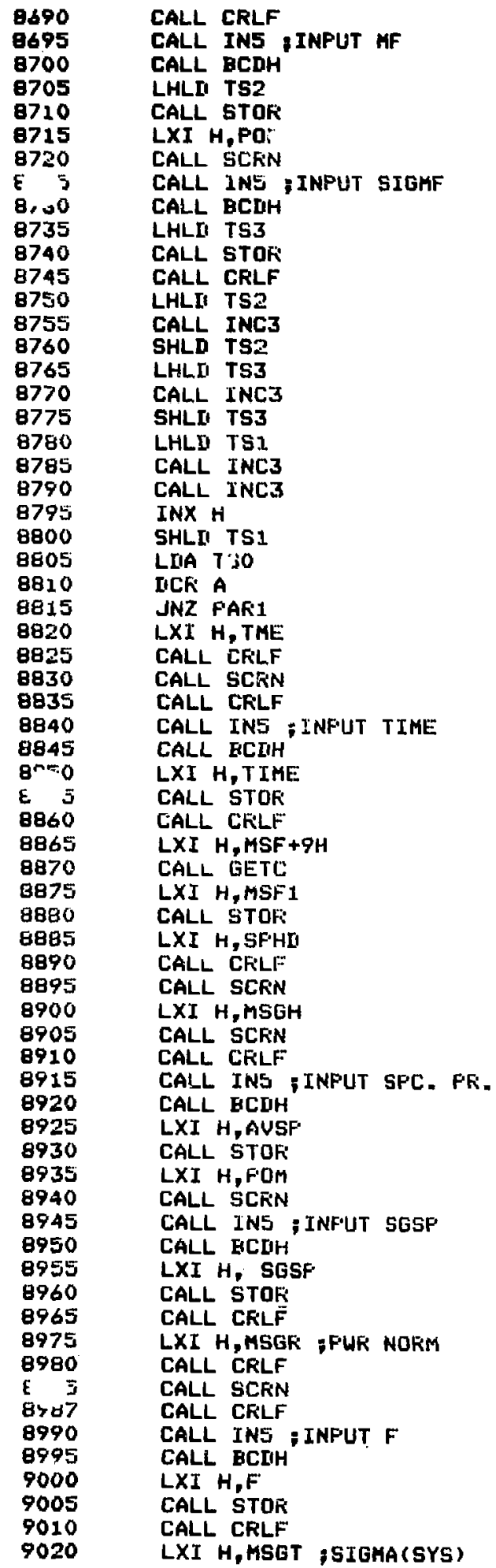




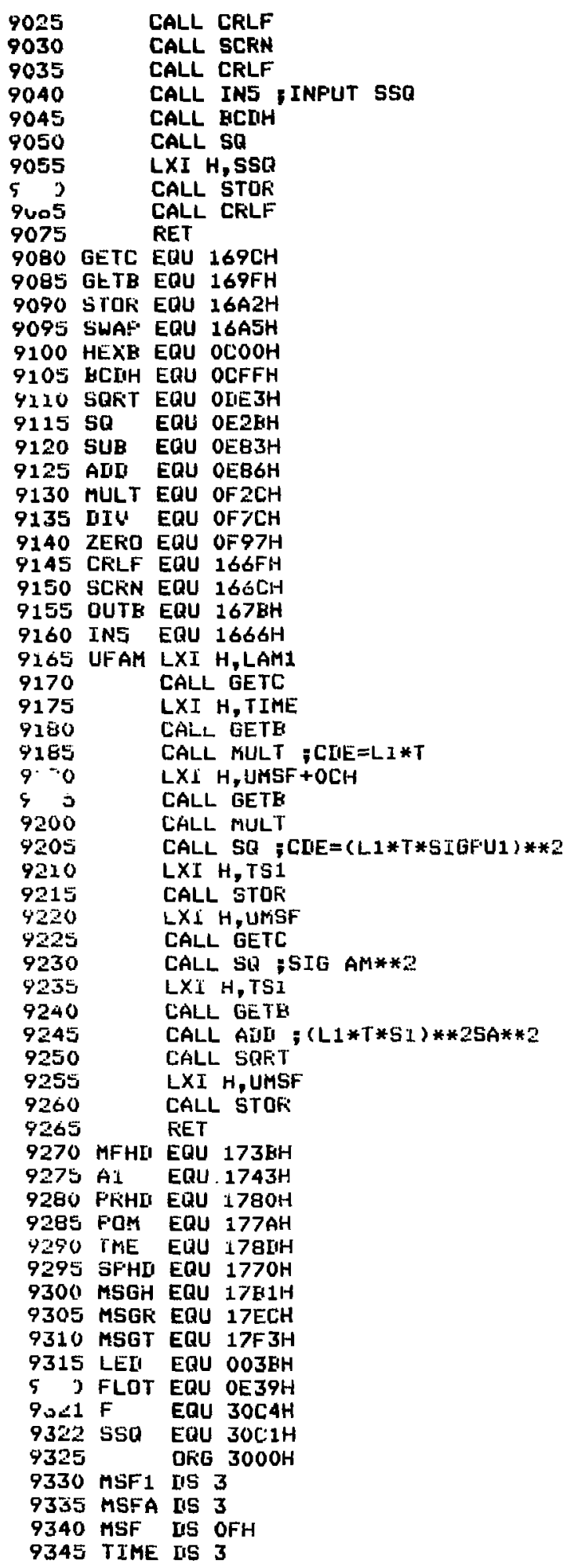




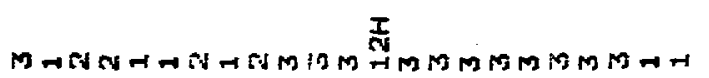

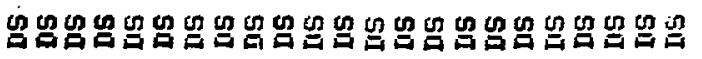

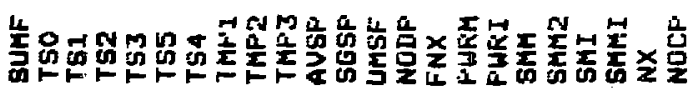

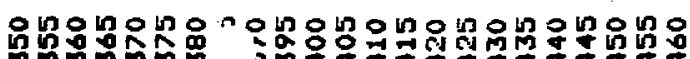

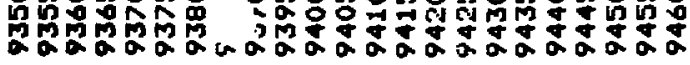




\section{APPENIDIX 0}

\section{SIMPLIFIED OPFRATING INSTRUCTIONS}

A. Start Up

NOTE:

This synopsis is intended to be a check list for system operation DO NOT OPERATE this device wi thout first reading the more detailed instructions.

1. Connect calorimeter chamber to control unit.

2. Connect calorimefer control unit to data-acquisition system.

3. Connect system poirer cord to building power and turn on power switch.

4. Reset microprocessor $(\mu)$. FAILURE TO RESET THE MICROPROCESSOR MAY RESULT IN DAMAGE TO THE PRINT HEAD.

5. Wait about 3-4 hours for the system to reach thermal equilibrium. The first fuel rod to be measured can be inserted at start up to reduce the time for the first measurement. (Temperature error meters should read approximately zero.)

B. Sample Measurement

1. Insert rod and center in calorimeter.

2.. Start sample measurements by pressing RUN.

$\begin{array}{ll}\text { Parameters } & \text { PRINT ALL? } \\ \text { DELAY-MIN } & -60 \\ \text { Sigma } \% & -0 \text { (Statistical uncertainty } \\ & \text { \#DP/RUN }\end{array}$

The program will continue to measure and print out until stopped by pressing the RST key. When the power measurements become steady, indicating that thermal equilibrium has been reached, press RST.

3. Start final sample measurement.

$\begin{array}{lllc}\text { Parameters } & \text { PRINT ALL? } & - & \text { ENTR (NO) } \\ & \text { DELAY-MIN } & - & 0 \\ \text { Sigma } \% & - & 0.02 \\ \text { \#DP/RUN } & -125\end{array}$

After print out, program will halt. Measured value will be retained by the microprocessor for future calculation. Additional measurements can be srade by pressing YES.

4. Press INIT

Enter isotopic data. If the uncertainties in the entries are not known, skip by pressing ENTR. If the specific power is knokm, then the isotopic inputs may be skipped and the specific power can be entered at this point. The PNORM entry allows a bias correction to be eistered. 
SIG(SY) allows inclusion of a systematic error in the error propagation calculation. Skip entry if unknown. PNORM and SIG(SY) have default values of 1.0 and 0.0 and are reset to these values each time the RST key is used.

5. Remove the fuel rod being measured and press $\mathrm{P}_{0}$.

$\begin{array}{lll}\text { Paraneters } & \text { PRINT ALL? } & - \text { ENTR (NO) } \\ & \text { DELAY-NIN } & -10 \\ & \text { SIGMA \% } & -0.02 \\ \text { \#DP/RUN } & -125\end{array}$

The baseline power will be measured and the sample power and sample plutonium content will be calculated. Repeat measurement several times by pressing YaS key to ensure that the calorimeter has reached thermal equilibrium.

C. Electrical Calibration

1. Insert the electric fuel rod and connect the cable to the output connector on the front panei of the calibration module.

2. Wait for the calorimeter to reach thermal equilibrium.

3. Press the RUN key.

$\begin{array}{lllc}\text { Parameters } & \text { PRINT ALL? } & - & \text { ENTR (NO) } \\ \text { DELAY-MIN } & - & 0 \\ \text { SigMa \% } & - & 0 \\ \text { \#DP/RUN } & - & 125\end{array}$

Calorimeter will continue to measure the power until stopped. When the power repeats within the measurement precision, press reset. The last run will be stored and used by the calibration program.

4. Press the CAL key.

$\begin{array}{lllc}\text { Parameters } & \text { CAL PNTS } & - & 5 \\ \text { PRINT ALL? } & - & \text { ENTR (NO) } \\ \text { DELAY-MIN } & - & 20 \\ \text { Sigma } \not & - & 0.02 \\ \text { \#DP/RUN } & - & 125\end{array}$

The calibration routine checks out the perfonnance of the entire calorimeter sjstem.

The output for each calibration point is a pair of power measurements. The first is the power to the electric fuel rod. The second is the power to the sample chamber heater. Test points have been provided on the calibration module for messuring the power to the electric fuel rod with an external digital voltmeter. At the end of the calibration sequence, a leas squares fit of tho pairs of points should give a slope of approximately one and an intercept of approximately zero. For $x=$ calibrate power and $\mathrm{y}=$ measured power, example: 


$\begin{array}{lll}a_{0} & = & -0.00290 \\ a_{1} & = & 1.01486 \\ r^{2} & = & 0.99999598 \\ s_{x y} & = & 0.00102 \\ s_{0} & = & 0.00075 \\ s_{1} & = & 0.00077\end{array}$

The "calibrate" routine checks the accuracy of the $A$ to $D$ and the linearity of the calorimeter measurement system. The cable connected to the electric fuel rod may introduce a small bias so that absolute calibration of the measurement chamber power with the electric fuel rod is not recommended. A small bias is also associated with the fuelcolumn length.

For the most accurate calibration of the measurement-chamber power, a standard fuel rod with the same fuel-column length as the rods to be measured should be used.

II. EXPLANATION OF TYPICAL OUTPUT TAPE

\section{USER ACTION/RESPONSE}

Press RST

Press $\underline{\text { RUN }}$

Press ENTR (NO)

Input system equilibration time

Limit of acceptable measurement uncertainty

Input system assay time 25 pnts/min Power supplied by calorimeter to maintain constant $\mathrm{T}_{3}$

Assay will automatically be repeated if

$$
\frac{(\overline{\mathrm{P}})}{\overline{\mathrm{P}}} \quad \text { SIGMA } \% \text { Otherwise, }
$$

repetition is a user option

\section{Press CAL}

Input reequilibration time
SYSTEM OUTPUT

CALORIMETER READY

MEAS

PRINT ALL? NO

DELAY-MIN $\quad 60$

SIGMA-\% $\quad 0.02$

\#DP/RUN $\quad 125$

POWER W

$1.9405+/-6.9365$

E -5
AGAIN? YES

POWER W

$1.9409+/-7.0728$

E -5

AGAIN? NO

CALIBRATE

CAL PNTS 5

PRINT ALL? NO

DEIAY-MIN 20

SIGMA \% 0.02 
\#DP/RUN 125

Reference input power

CALIBRATE W

$0.34288+/-1.9639$

E -5

Calorimeter-supplied power

EMPTY POWER W

$1.5943+/-1.2532$

E - 4

CALIBRATE W

$0.67216+/-2.4625$

F -5

EHPTY POWER W

$1.2588+/-1.1581$

E -4

CALIBRATE W

$1.0137+/-3.2839$

E - 5

EMPTY POWER W

$0.91113+/-1.3736$

$\mathrm{E}-4$

CALIBRATE W

$1.3446+/-3.6233$

E -5

EMPTY POWER W

$0.57366+/-1.3263$

E -4

CALIBRATE W

$1.6810+/-4.2598$

E -5

EMPPTY POWER W

$0.22760+/-1.4167$

E - 4

Press $\underline{\text { RST }}$

CALORIMETER READY

Press INIT

DATA INPUT MASS $\%$

Enter numberic, followed by ENTR

(NOTE: 0.72112 , not .72112)

AM241

$0.72112+/-$ (Measurement uncertainty)

If measurement error is not known, press ENTR

NOTE: ${ }^{241}$ Am content should be

PU238

entered relative to $\mathrm{Pu}$ value.

$0.04312+1-$

PU 239

$87.1389+1-$

Pu240

$11.5464+1-$ 
Systematic measurement uncertainty

Press FRAC

Microprocessor calculated values for the sample isotopic composition

Press SP

Microprocessor-calculated sample specific power $P$ (mW/g)

with fuel rod in measurement chamber

Press RUN

System reequilibration time

following sample input

(User must determine delay time for fuel rods being measured)

5-min assay

Calorimeter-supplied power $\left(\overline{\mathrm{P}}_{\mathrm{c}}\right)$
Pu241

$1.0831+/-$

Pu242

$0.18848+/-$

TIME-DAYS

20

POWER W/G

$+1-$

$P$ NORM

1.0

SIG(SY)

0

MASS \%

AM241

0.72396

Pu238

0.04310

Pu239

87.140

Pu240

11.546

Pu241

1.0802

Pu242

0.18847

POWER W

$3.6090+/-0.00477$

MEAS

PRINT ALL? ENTR（NO)

$\begin{array}{lr}\text { DELAY-MIN } & 60 \\ \text { SIGMA- } & 0.05\end{array}$

\#DP/RUN $\quad 125$

POWER W

$0.77826+/-8.0381$

$E-5$ 
After fuel rod is removed:

Press $\underline{\mathrm{P}_{0}}$

$\begin{array}{lc}\text { EMPTY MEAS } & \\ \text { PRINT ALL? } & \text { ENTR (NO) } \\ \text { DELAY-MIN } & 10 \\ \text { SIGMA-\& } & 0.05 \\ \text { \#DP/RUN } & 125 \\ \text { EMPTY POWER W } \\ 1.9376+/-1.1192 \\ \text { E- } 4\end{array}$

Sample-supplied power $\overline{\mathrm{P}}_{\mathrm{S}}=\overline{\mathrm{P}}_{0}-\overline{\mathrm{P}}_{\mathrm{c}}$

POWER W

1.1594

Sample mass, $\bar{M}_{P u}=\bar{P}_{S} / P_{\text {eff }}$

PU KG

$0.32126+/-4.2924$

E -4

AGAIN?

YES

EMPTY POWER W

$1.9372+/-1.4131$

$E-4$

POWER W

1.1589

PU KG

$0.32113+/-4.3089$

$\mathrm{E}-4$

AGAIN?

No 